\title{
Economic evaluation of the diagnosis of renal artery stenosis in hypertensive patients
}

Citation for published version (APA):

van Helvoort-Postulart, D. (2006). Economic evaluation of the diagnosis of renal artery stenosis in hypertensive patients. [Doctoral Thesis, Maastricht University]. Universiteit Maastricht. https://doi.org/10.26481/dis.20060518dh

Document status and date:

Published: 01/01/2006

DOI:

10.26481/dis.20060518dh

Document Version:

Publisher's PDF, also known as Version of record

\section{Please check the document version of this publication:}

- A submitted manuscript is the version of the article upon submission and before peer-review. There can be important differences between the submitted version and the official published version of record. People interested in the research are advised to contact the author for the final version of the publication, or visit the DOI to the publisher's website.

- The final author version and the galley proof are versions of the publication after peer review.

- The final published version features the final layout of the paper including the volume, issue and page numbers.

Link to publication

\footnotetext{
General rights rights.

- You may freely distribute the URL identifying the publication in the public portal. please follow below link for the End User Agreement:

www.umlib.nl/taverne-license

Take down policy

If you believe that this document breaches copyright please contact us at:

repository@maastrichtuniversity.nl

providing details and we will investigate your claim.
}

Copyright and moral rights for the publications made accessible in the public portal are retained by the authors and/or other copyright owners and it is a condition of accessing publications that users recognise and abide by the legal requirements associated with these

- Users may download and print one copy of any publication from the public portal for the purpose of private study or research.

- You may not further distribute the material or use it for any profit-making activity or commercial gain

If the publication is distributed under the terms of Article $25 \mathrm{fa}$ of the Dutch Copyright Act, indicated by the "Taverne" license above, 
Economic evaluation of the diagnosis of renal artery stenosis in hypertensive patients 
(0) D. van Helvoort-Postulart, 2006

ISBN-10:9052784841

ISBN-13:9789052784847

Printed by: Datawyse/Universitaire Pers Maastricht

Cover design: M.J.A.M. van Helvoort 


\section{Economic evaluation of the diagnosis of renal artery stenosis in hypertensive patients}

\section{PROEFSCHRIFT}

ter verkrijging van de graad van doctor aan de Universiteit Maastricht,

op gezag van de Rector Magnificus,

Prof. Mr. G.P.M.F. Mols

volgens het besluit van het College van Decanen, in het openbaar te verdedigen

op donderdag 18 mei 2006 om 12.00 uur

$$
\text { door }
$$

Debby van Helvoort-Postulart

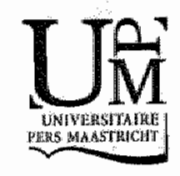




\section{Promotoren}

Prof. Dr. J.M.A. van Engelshoven

Prof. Dr. M.G.M. Hunink (Erasmus Universiteit Rotterdam)

\section{Copromotor}

Dr. C.D. Dirksen

\section{Beoordelingscommissie}

Prof. Dr. J.L. Severens (voorzitter)

Prof. Dr. Ir. B.G.C. Dellaert

Prof. Dr. W.N.J. Groot

Prof. Dr. P.J.E.H.M. Kitslaar

The studies described in this thesis were financially supported by the Dutch Health Care Insurance Board ( $\mathrm{CvZ}$ ), grant number OG 97-003, and the Netherlands Organization for Health Research and Development (ZonMw), grant number 945-10-067.

Financial support by the Netherlands Heart Foundation for the publication of this thesis is gratefully acknowledged. 
aan Mark 



\section{Contents}

Chapter 1 Introduction

Chapter 2 Cost analysis of procedures related to the management of renal artery stenosis from various perspectives

Chapter 3 A comparison between willingness-to-pay and willingness to give up time

Chapter 4 Between best and worst: trading levels in conjoint analysis

Chapter 5 A comparison between conjoint analysis and direct willingness-topay

Chapter 6 Cost-effectiveness of the diagnosis and treatment of renal artery stenosis

Chapter 7 General discussion

Summary

Samenvatting

Dankwoord 



\section{Chapter 1}

Introduction 


\section{Introduction}

Renal artery stenosis is a narrowing or occlusion of the luminal diameter of the renal artery, and may occur alone, in association with hypertension, renal insufficiency, or both. Renovascular hypertension refers to hypertension that is caused by renal artery stenosis.

The prevalence of renal artery stenosis depends on the clinical setting. Among patients with hypertension, prevalence ranges from less than $1 \%$ in unselected hypertensive patients, about $5 \%$ in hospital-based populations, and up to $40 \%$ in patients referred to hypertension clinics $[1,2]$. The most common cause of renal artery stenosis is atherosclerosis, which usually involves the ostium and proximal third of the main renal artery and the perirenal aorta [3]. Atherosclerotic renal artery stenosis typically affects older male smokers with coexistent vascular disease elsewhere [4]. Fibromuscular dysplasia accounts for $16 \%-40 \%$ of cases $[5,6]$ and is predominantly found in younger women [4].

As compared to essential hypertension, renovascular hypertension seems less responsive to treatment with antiliypertensive medications, has a higher risk of progression to accelerated or malignant hypertension and may result in irreversible renal failure. Therefore, it is important to diagnose renal artery stenosis, so that adequate treatment can be initiated. Currently, percutaneous transluminal renal angioplasty (PTRA) and stent placement are accepted treatment options for renal artery stenosis. The major objectives of anatomical correction of renal artery stenosis are to normalize blood pressure with the aim to prevent cardiovascular complications, such as myocardial infarction or stroke, and to prevent or delay the loss of renal function.

\section{Diagnostic imaging modalities for renal artery stenosis}

Traditionally, intra-arterial digital subtraction angiography (DSA) is considered to be the reference standard for the detection of renal artery stenosis. DSA, however, has a risk of mortality [7,8] and morbidity such as arterial dissection [8,9] and renal failure $[10,11]$. Furthemore, DSA is a relatively expensive imaging technique and requires a period of bed rest and observation after the procedure because of the intra-arterial catheterization. For these reasons, and because the prevalence of renal artery stenosis among unselected hypertensive patients is low, DSA cannot be used routinely. Therefore, selection of hypertensive patients with an increased risk of renal artery stenosis, on the basis of clinical characteristics, is recommended [12,13] Furthermore, there is a need for minimally invasive diagnostic imaging modalities that can be used as 
screening tests to select patients for DSA. Currently, computed tomography angiography (CTA) and magnetic resonance angiography (MRA) are widely used techniques for the diagnostic work-up for hypertensive patients suspected of having renal artery stenosis. CTA and MRA are minimally invasive procedures that can be performed on an outpatient basis. However, CTA requires the administration of iodinated contrast media and exposes the patient to radiation. The MRA technique uses non-nephrotoxic gadolinium as contrast agent and magnetic fields instead of X-rays. Disadvantages of MRA are the associated high costs and contra-indications such as claustrophobia, metallic implants and pacemakers.

\section{Economic evaluation in health care}

Rising health care expenditures have led to an increased number of published economic evaluation studies since the early 1990 s $[14,15]$. The goal of economic evaluation is to inform decision-making. For example, on the macro level the national government decides on the health care services and interventions that are covered by the National Health Service, whereas on the micro level research findings are translated into clinical practice. Economic evaluation is defined as the comparative analysis of alternative courses of action in terms of both their costs and consequences. The basics of economic evaluation involve identifying, measuring, valuing, and comparing the costs and benefits of alternatives being considered [16].

Health care resources are scarce and choices have to be made regarding their use. The concept of opportunity cost is fundamental to health economics. It is based upon the idea that scarcity of resources means that expending resources on one health care activity inevitably means sacrificing activity somewhere else. The opportunity cost of undertaking an activity is defined as the value of the foregone benefits of the next best alternative. Each decision that involves a choice between two or more options has an opportunity cost. The aim of economic evaluation of health care programs is to ensure that the benefits of the programs implemented are greater than the opportunity cost of such programs.

There are four methods of economic evaluation: cost-minimization analysis, costeffectiveness analysis, cost-utility analysis and cost-benefit analysis. The methods difeer with respect to the way that the consequences of applying health technologies are measured and valued. The measurement of costs is similar regardless of the type of analysis being undertaken. The perspective of the analysis refers to the viewpoint from which an economic evaluation is conducted. Examples are the societal viewpoint that 
incorporates all costs and health effects regardless of who incurs the costs and who obtains the effects, and the viewpoint of the health care provider that incorporates only costs and health effects that accrue to the provider, and distegards others.

A cost-minimization analysis is conducted when the consequences of the alternative strategies are assumed equal, resulting in an assessment based on comparing costs. In cost-effectiveness analysis the consequences are one dimensional and measured in naturally occurring units, such as changes in blood pressure or mortality. When the more beneficial program is also more costly, the incremental cost-effectiveness ratio depicts the extra cost per extra unit of benefit obtained. A high incremental cost-effectiveness ratio implies that a large expenditure will be required to achieve the extra benefit and is less economically attractive than a low incremental cost-effectiveness ratio. An external value judgment will be required to assess whether the extra unit of outcome is worthwhile. In cost-utility analysis the outcome measure is a quality adjusted life-year, which combines quality and quantity of life. Health state preferences are used as quality weights in the calculation of quality adjusted life years. Cost-utility analysis is quite similar to cost-effectiveness analysis, and may be thought of as a special form of the latter. From a theoretical point of view, the preferred type of econonnic evaluation is the cost-benefit approach in which costs as well as benefits are measured in monetary units. Cost-benefit analysis provides a broader comparison between alternative claims on limited resources, enabling comparisons to be made between programs within health care and with options in other public sectors. As assigning monetary values to health outcomes is controversial, however, cost-benefit analysis is very rarely used in health care $[17]^{\circ}$

Within the cost-benefit framework there are three approaches to the monetary valuation of health outcomes. The human capital approach considers an individual as investing in future health by using health care resources and at least part of the return on that investment in future healthy time is the increased productive capacity of the individual measured by the value of future earnings. The human capital approach is production-based and not consistent with the principles of welfare economics because the method does not measure the value placed on morbidity or mortality avoided, and is restricted to impacts on labour productivity. The revealed preference approach to measuring subjects" willingness to pay for health consequences is to observe decisions that individuals actually make concerning health risks, and to infer the willingness to trade money for health consequences. The revealed preference method has been studied in the labour market where wage premiums are offered to induce workers to accept 
more risky jobs. For health care programs, however, it is difficult to apply the revealed preference approach since health and health services are usually not purchased in the market place. The third approach, whicll will be elaborated on in this thesis, involves the elicitation of stated preferences.

\section{Stated preferences}

The most commonly used stated preference method in health care is contingent valuation [18]. The contingent valuation method involves asking individuals directly in a survey with hypothetical scenarios the maximum amount of money the respondents are willing to pay to have the commodity in question, or the minimum amount the respondents would be willing to accept in compensation to be deprived of the commodity. The contingent valuation method to estimate willingness-to-pay will be denoted as direct willingness-to-pay. The method is based on the assumption that when individuals are considering their maximum willingness to pay, they will take into account all attributes of the service of importance to them, not just health gains. Despite of the growing interest in conducting contingent valuation studies in health care since the mid-1980s [19], the contingent valuation method has been shown to be subject to a number of problems. The following brief owerview does not pretend to be complete, but highlights some of the major issues. A key problem is the occurrence of framing effects, which suggests that how something is presented influences the choices people make [20]. An example of a framing effect is starting point bias, which tends to occur in bidding games, although studies are not conclusive [21-24]. Also, the existence of range bias is frequently suggested in connection with the payment card technique [e.g. 25], although empirical evidence from health care studies is lacking. In addition, contingent valuation seems sensitive to question order effects. Two studies have investigated this form of framing [26,27], and one of these studies provided evidence for the presence of question order effects [27]. Other problems associated with contingent valuation include the occurrence of preference reversals, which means that within a subject inconsistency exists between ordinal rankings of the programs and the ranking implied by the willingness-to-pay values [28-30], a high proportion of protest answers, and inability to discriminate between alternatives being valued. [31,32]. Furthermore, various techniques exist to elicit respondents' willingness to pay, such as open-ended questions, bidding games, payment cards, and dichotomous choice questions [33]. Applying these techniques leads to differences in willingness-to-pay responses. For example, research indicates that the payment scale (or payment card) technique and dichotomous choice 
method both yield higher willingness-to-pay values than does the open-ended format $[34,35]$.

An alternative to contingent valuation is conjoint analysis. It was originally developed in mathematical psychology, and has been widely used in market research, transport economics and environmental economics: It is an upcoming technique in the area of health economics during the 1990s [36]. Conjoint analysis is based on the assumption that complex decistons, including purchase decisions, are based not on a single factor or criterion, but on several factors "considered jointly". Any good or service can be described by its characteristics or attributes. The extent to which an individual values a good or service depends upon the nature and levels of these attributes [37]. In a conjoint analysis study, preferences are elicited using ranking, rating or discrete choice exercises. A discrete choice experiment is based on random utility theory and closely resembles actual decision-making, and is therefore the preferred elicitation method. Including cost as an attribute allows willingness-to-pay to be indirectly estimated. Therefore, the conjoint analysis method to estimate willingness-topay will be referred to as the indirect willingness-to-pay method.

According to a review by Ryan et al. [38], conjoint analysis seems a promising technique. Few difficulties have been reported when answering choice-based conjoint analysis questions $[39-44]$. Two studies report that the technique was well received by policy-makers [36,45]. Many studies have assessed the internal consistency with satisfactory results $[36,40,42-44,46-49]$. Also high levels of internal validity have been demonstrated $[40-43,45-47,49-51]$. Because of these favourable results, it seems worthwhile conducting further research to investigate the value of the conjoint analysis technique within the framework of cost-benefit analysis in health care.

In order to obtain willingness-to-pay estimates from conjoint analysis studies, a costattribute needs to be included and levels should be assigned to it. Currently, no rigorous method is available to determine the appropriate levels for the cost-attribute to be implemented in a conjoint analysis study. Therefore, it has been argued that efforts should be made to define techniques that can be used to establish these levels [47,52]. This is particularly important since evidence suggests that a wider range for the costattribute leads to a higher importance of that attribute [53]. Also, the number of levels included in the research design may artificially impact the relative attribute importance [53-55]. Up till now, only one published paper has reported on the sensitivity of willingness-to-pay estimates to the levels of attributes [56]. The authors found that 
overall willingness-to-pay estimates for a hypothetical policy change did not differ substantially.

Another question concems the convergence between willingness-to-pay results obtained with conjoint analysis and direct willingness-to-pay. One of the major problems in assessing the feasibility of the willingness-fo-pay concept in health care is that there is no reference standard, i.e. what consumers would actually pay. Accordingly, in the absence of a reference standard, criterion validity cannot easily be established. So, convergent validity, serving as some second-best type of validity, measures the extent to which the results are consistent with other measures that are held to measure the same construct [38]. Since both contingent valuation and conjoint analysis intend to measure willingness-to-pay it is to be expected that the results of both measures converge. Up till now contingent valuation and conjoint analysis were only compared in the field of environmental economics [57-60]. All these studies yielded willingness-to-pay estimates that would lead to the same decision with respect to the most preferred alternative. It is a challenge to extend this research to the health care sector.

Apart from the problems associated with the contingent valuation method, the willingness-to-pay concept in itself is criticized, among other things, for attempting to assign a monetary valuation to health. Alternatively, the willingness to give up time method might be used. This method was proposed in the framework of cost-benefit analysis by Johannesson and Jönsson [61]. The potential advantage of using time instead of money is that it may be less value-laden. Since both willingness-to-pay and willingness to give up time intend to measure preferences it is expected that the results of both methods converge and would lead to the same policy decision.

\section{The RADISH study and the WTP-CA study}

The studies described in this thesis are based on the data of two investigations. The Renal Artery Diagnostic Imaging Study in Hypertension, the RADISH study, was performed from 1998 to 2001. Patients with a diastolic blood pressure equal to or exceeding $95 \mathrm{mmH}$ g, aged 18-75 years and one or more clinical features suggestive of renovascular hypertension [12], were submitted to the diagnostic work-up for detecting renal artery stenosis. Patients were prospectively recruited from the departments of internal medicine of three non-academic teaching hospitals and three academic hospitals in the Netherlands. All participants were subjected to three diagnostic imaging tests. The study aimed to assess the validity of CTA and MRA as compared to the reference 
statidard DSA for the detection of renal artery stenosis in patients suspected of having renovascular hypertension. A total of 402 patients were included in the study. For 356 patients, the results of CTA, MRA, and the reference standard DSA, were available. DSA showed clinically relevant renal artery stenosis in 72 patients, resulting in an overall prevalence of $20 \%$. Twenty-seven patients $(38 \%)$ had fibromuscular dysplasia. The sensitivity and specificity were $64 \%(95 \% \mathrm{Cl}, 55 \%$ to $73 \%)$ and $92 \%(95 \% \mathrm{CI}$, $90 \%$ to $95 \%)$ for CTA and $62 \%(95 \% \mathrm{CI}, 54 \%$ to $71 \%$ ) and $84 \%(95 \% \mathrm{CI}, 81 \%$ to $87 \%)$ for MRA [62]. A second goal of the RADISH study was to investigate whether CTA or MRA can replace DSA for detecting renal artery stenosis, which could lead to cost savings and fewer complications during the diagnostic work-up. These advantages, however, need to be weighed against the health effects in the long-term as a result of missed diagnoses of renal artery stenosis. Therefore a cost-effectiveness analysis was performed. As part of the RADISH study, a willingness-to-pay study was conducted using the ex-post user-based approach. The aim was to assess preferences for DSA, MRA and CTA. Furthermore, willingness-to-pay was compared with willingness to give up time. The results are presented in this thesis.

The second investigation, the WTP-CA study, was conducted from 2001 to 2003. This study aimed to investigate the convergence between direct willingness-to-pay and the conjoint analysis technique to estimate willingness-to-pay indirectly. Both methods were applied to the field of diagnostic imaging techniques to detect renal artery stenosis, in order to obtain preferences for DSA, MRA and CTA. Respondents were randomly selected members of the general population, who were randomized to either a direct willingness-to-pay or conjoint analysis questionnaire. The study used the ex-ante insurance-based approach. As part of the WTP-CA study, a method was explored to determine the range and levels for the cost-attribute in conjoint analysis. The results are presented in this thesis.

\section{Objective and thesis outline}

The general objective of this thesis is twofold. The first aim is to estimate the costs, benefits and incremental. cost-effectiveness of the diagnostic imaging work-up for hypertensive patients suspected of having renal artery stenosis. The results of the studies presented in this thesis could provide relevant information to inform decision-making by clinicians and policy-makers. The second aim is to address some methodological issues with respect to the use of willingness-to-pay. 
To control for rising health care expenditures, policy-makers are forced to make decisions regarding resource allocation. An informed decision requires knowledge of both the costs and benefits of alternative courses of action. Costs can be assessed from different perspectives, dependent on the purpose of the analysis. To demonstrate the differences in costs when assessed from various perspectives, a cost analysis is presented to show the costs associated with procedures related to the diagnosis and treatment of renall artery stenosis from the perspective of the radiology department, hospital, health care sector patient and society (Chapter 2).

A cost-effectiveness analysis from the societal perspective, which includes all costs and effects relevant to society, should theoretically include preferences for diagnostic imaging techniques. Traditionally, preferences for health states are measured using the visual analogue scale, time trade-off method, and standard gamble technique. Alternatively, the willingness-to-pay method and the willingness to give up time method might be used to assess short-term disutility associated with undergoing health care interventions. A study is presented that determines the convergence of the contingent valuation method to assess willingness-to-pay with the willingness to give up time, as well as the agreement between the responses to both methods (Chapter 3).

Conjoint analysis is a technique to determine willingness-to-pay indirectly. In order to estimate willingness-to-pay, a cost-attribute should be included and levels should be assigned to the cost-attribute. The levels should be chosen in such a way that they be subject to trading decisions. The published literature shows a wide variety with respect to how the levels are determined. To date, there is no well-established tectinique to set the appropriate levels for the cost-attribute. Therefore, a study is described that explores a method to determine the levels for the cost-attribute in conjoint analysis (Chapter 4).

Ideally, one would like to compare the results from willingness-to-pay studies with actual purchase of health care services. However, for most health care programs actual market does not exist so criterion validity cannot easily be established. A study is presented, in which direct willingness-to-pay is compared with indirect willingness-topay, the latter obtained with conjoint analysis (Chapter 5).

Treatment for renal artery stenosis may result in improvement or cure of hypertension and, consequently lead to a reduction of cardiovascular morbidity and. mortality. Furthermore, relief of the stenosis may stop the deterioration of renal function. So, timely detection of renal artery stenosis, followed by treatment, is important. The optimal diagnostic imaging strategy, however, has not yet been defined. An economic evaluation study is described that analyzes the costs, effectiveness, and 
Chapter 1

cost-effectiveness of the dilagnostic work-up for hypertensive patients suspected of having renovascular hypertension (Chapter 6).

Finally, the main findings of the studies presented in this thesis are summarized and discussed, with special attention to the methodological issues with respect to the concept of willingness-to-pay in health care (Chapter 7). 


\section{References}

1. Derkx FH, Schalekamp MA. Renal artery stenosis and hypertension. Lancet 1994, 344:237239.

2. Eardley KS, Lipkin GW. Atherosclerotic renal artery stenosis: is it worth diagnosing? J Hum. Hypertens 1999; 13:217-220.

3. Safian RD, Textor SC. Renal-Artery Stenosis. N Engl I Med 2001; 344: $431-442$.

4. McLaughlin $\mathrm{K}$, Jardine $\mathrm{AG}$, Moss, JG. ABC of arterial and venous disease: Renal artery stenosis. BMJ 2000; 320: 1124-1127.

5. Pohl MA, Novick AC. Natural history of atherosclerotic and fibrous renal artery disease: Clinical implications. Am J Kidney Dis 1985; 5: A 120-A130.

6. Textor SC. Epidemiology and clinical presentation. Semin Nephrol 2000; 20;426-431.

7. Hessel S.I, Adlams DF, Abrams HL. Complications of angiography. Radiology 1981; 138: $273-281$.

8. Waugh JR, Sacharias N. Arteriographic complications in the DSA era. Radiology 1992; 182 : $243-246$.

9. Young $\mathrm{N}$, Chi KK, Ajaka $J_{*}$ McKay L, O"Neill D, Wong KP. Complications with outpatient angiography and interventional procedures. Cardiovase Intervent Radiol 2002; 25: 123-126.

10. Rudnick MR, Berns IS, Cohen RM, Goldfarb S. Nephrotoxic risks of renal angiography: contrast media-associated nephrotoxicity and atheroembolism - a critical review. Am 1 Kidney Dis 1994; $24: 713-727$.

11. Cochran ST, Bomyea K, Sayre IW. Trends in adverse events after IV administration of contrast media. AJR Am J Roentgenol 2001; 176: 1385-1388.

12. Working Group on Renovascular Hypertension. Detection, evaluation, and treatment of renovascular hypertension. Final report. Arch Intern Med 1987; 147: 820-829.

13. Krijnen $P$, Van Jaarsveld BC, Steyerberg EW, Man in "t Veld AJ, Schalekmp MA, Habbema ID. A clinical prediction rule for renal artery stenosis. Ann Inten Med $1998 ; 129:$ 705-711.

14. Elixhauser A, Luce BR, Taylor WR, Reblando J. Health care CBA/CEA: an update on the growth and composition of the literature. Med Care 1993; 31 (Suppl): ISI-1.1, JSI 8-149.

15. Elixhenuser A, Halpern M, Schmier J, Luce BR. Health care CBA and CEA from 1991 to 1996: an updated bibliography. Med Care 1998; 36 (Suppl): MS1-9, MS18-147.

16. Drummond $M F$, $\mathrm{O}^{3}$ Brien $B$, Stoddart GL, Torrance GW. Methods for the economic evaluation of health cane programmes. Second edition. Oxford, Oxford University Press, 1997. 
17. Anell A, Norinder A. Health outcome measures used in cost-effectiveness studies: a review of original articles published between 1986 and 1996 . Health Policy $2000 ; 51: 87-99$.

18. Diener $A, 0, B$ inen $B$, Gafin $A$. Health care contingent valuation studies: a review and dassification of the litterature. Health Econ $1998 ; 7: 313-326$.

19. Smith RD. Construction of the contingent valuation market in health care: a critical assessment. Health Econ $2003 ; 12: 609-628$.

20. Tversky $\mathrm{A}$, Kahmeman $\mathrm{D}$. The framing of decisions and the psychology of choice. Science 1981; $211: 453-458$.

21. O'Brien $B$, Viramontes $J L$. Willingness to Pay: a valid and reliable measure of health state preference? Med Decis Making 1994; 14: 289-297.

22. Kartman $B$, Andersson $F$, Johannesson M. Willingness to pay for reductions in angina pectoris attacks. Med Decis Making 1996; 16: 248-253.

23. Stalhammar NO. An empirical note on willingness to pay and starting-point bias. Med Decis Making 1996; 16:242-247.

24. O'Brien B.l, Goeree $\mathbb{R}$, Gafni $A$, et al. Assessing the value of a new pharmacentical. A feasibility study of contingent valuation in managed care. Med Care 1998; 36:370-384.

25. Klose T. The contingent valuation method in health care. Health Policy 1999; 47: 97-123.

26. Kartman B, Stalhammar NO, Johannesson $M$. Valuation of health changes with the contingent valuation method: a test of scope and question order effects. Health Econ 1996; 5 : $531-541$.

27. Stewart JM, O'Shea E, Donaldson C, Shackley P. Do ordering effects matter in willingnessto-pay studies of health care? J Health Econ 2002; $21: 585-599$.

28. Donaldson $C$, Shackley $P$, Abdalla M. Using willingness to pay to value close substitutes: carrier screening for cystic fibrosis revisited. Health Econ 1997; 6: 145-159.

29. Olsen $I A$. Aiding priority setting in health care: is there a role for the contingent valuation method? Health Econ 1997; 6: 603-612.

30. Gyldmark M, Morrison GC. Demand for health care in Denmark: results of a national sample survey using contingent valuation. Soc Sci Med 2001; 53: $\Downarrow 023-1036$.

31. Donaldson $\mathrm{C}$, Shackley P, Abdalla M, Miedzybrodzka Z. Willingness to pay for antenatal carrier screening for cystic fibrosis. Health Econ 1995; 4: 439-452.

32. Ryan $M$, Rateliffe $J$, Tucker $J$. Using willingness to pay to value alternative models of antenatal care. Soc Soi Med 1997; 44:371-380.

33. Blumenschein $\mathrm{K}$, Johannesson M. Use of contingent valuation to place a monetary value on pharmacy services: an overview and review of the literature. Clin Ther 1999:21: 1402-1417. 
34. Frew $E_{3}$, Wolstenholme JL, Whynes $D K$. Willingness-to-pay for collorectal cancer screening. Eur J Cancer 2001; 37: 1746-1751.

35. Johannesson $\mathrm{M}$, Jönsson $\mathrm{B}$, Borgquist $\mathrm{L}$. Willingness to pay for antihypertersive therapy results of a Swedish pilot study. J Health Econ 1991; 10:461-473.

36. Ryan M, Farrar S. Using conjoint analysis to elicit preferences for health care. BMJ 2000; 320: $1530-1533$.

37. Ryan M, Bate A, Eastmond CI, Ludbrook A. Use of discrete choice experiments to elicit preferences. Qual Health Care 2001; 10 (Suppl): 155-160.

38. Ryan M, Scott DA, Reeves C, et al. Eliciting public preferences for health care: a systematic review of techniques. Health Technol Assess 2001; 5 (5).

39. Ferguson RP, Wetle $T$, Dubitzky $D$, Winsemius $D$. Relative importance to elderly patients of effectiveness, adverse effects, convenience and cost of antihypertensive medications. $A$ pilot study. Drugs Aging 1994; 4: 56-62.

40. Ryan M, Hughes J. Using conjoint analysis to assess women's preferences for miscarriage management. Healli Econ 1997; 6:261-273.

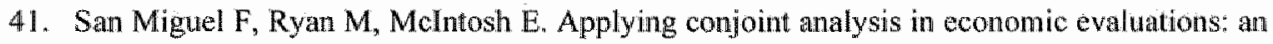
application to menomhagia. Appl Econ 2000; 32: 823-833.

42. Scott A, Vick S. Patients, doctors and contracts: an application of primcipal-agent theory to the doctor-patient relationship. Scott J Polit Econ 1999; 46: 111-134.

43. Vick $S, S c o t t A$. Agency in health care. Examining patients" preferences for attributes of the doctor-patient relationship. II Health Econ 1998; 17: 587-605.

44. Shackley P, Ryan M. Involving consumers in health care decision making. Health Care Anal 1995; 3: 196-204.

45. Ryan M. A rolle for conjoint analysis in technology assessment in health care? Int J Technol Assess Health Care 1999; 15: 443-457.

46. Ratcliffe J, Buxton M. Patients' preferences regarding the process and outcomes of lifesaving technology. An application of conjoint analysis to liver transplantation. Int J Technol Assess Health Care 1999;15:340-351.

47. Ryan M. Using conjoint analysis to take account of patient preferences and go beyond health outcomes: an application to in vitro fertilisation. Soc Sci Med 1999; 48: 535-546.

48. Spoth R, Redmond C. Identifying program preferences through conjoint analysis:; illustrative results from a parent sample. An J Health Promot 1993; 8: 124-133.

49. Pol van der M, Cairns ل. Establishing patient preferences for blood transfusion support: an application of conjoint analysis. J Health Serv Res Policy 1998; 3; 70-76. 
50. Bryan S, Buxton M, Sheidon R., Grant A. Magnetic resonance imaging for the investigation of knee injuries: an investigation of preferences. Health Econ 1998; 7:595-603.

51. Propper C. Contingent valuation of time spent on NHS waiting Iists. Econ J1990; 100: 193199.

52. Ratclife J. The use of conjoint analysis to ellicit willingness-to-pay values. Proceed with caution? Int I Technol Assess Health Care 2000; 16:270-275.

53. Verlegh PW, schifferstein HNJ, Wittink. DR. Range and number-of-levels effects in derived and stated measures of attribute importance. Market Lett 2002; 13:41-52.

54. American Marketing Association. Conjoint analysis: a guide for designing and interpreting conjoint studies. Market Research Division, Marketing Research Techrique Series, 1992.

55. Ratcliffe J, Longworth $L$. Investigating the structural reliability of a discrete choice experiment within health technology assessment. Int J Technol Assess Health Care 2002; 18: 139-144.

56. Ryan M, Wordsworth $S$. Sensitivity of willingness to pay estimates to the level of attributes in discrete choice experiments. Scot I Polit Econ 2000; 47: 504-524.

57. Adamowicz W, Boxall P, Williarns M, Louviere J. Stated preference approaches for measuring passive use values: Choice experiments and contingent waluation. Amer I Agr Econ $1998 ; 80: 64-75$.

58. Hanley $N$, MacMillan $D$, Wright $R E$, et al. Contingent valuation versus choice experiments: Estimating the benefits of environmentally sensitive areas in Scotland. J Agr Econ 1998; 49: $1-15$.

59. Hanley N, Wright RE, Adamowicz V. Using choice experiments to value the environment. Environ Resource Econ 1998; 11:413-428.

60. Boxall PC. Adamowicz WL, Swait J, Williams M, Louviere J. A comparison of stated preference methods for envirommental valuation. Ecolog Econ 1996; 18:243-253.

61. Johannesson $M$, Jonsson $B$. Economic evaluation in health care: Is there a role for costbenefit analysis? Health Policy 1991; 17: 1-23.

62. Vasbinder GBC, Nelemans PJ, Kessels AGH, et al., for the Renal Artery Diagnostic Imaging Study in Hypertension (RADISH) study Group. Accuracy of computed tomographic anglograply and magnetic resonance angiography for diagnosing renal artery stenosis. Ann Intern Med 2004: 141: 674-682. 


\section{Chapter 2}

\section{Cost analysis of procedures related to the management of renal artery stenosis from various perspectives}

D. van Helvoort-Postulart, C.D. Dirksen, A.A. Kroon, P.J. Nelemans, P.W. de Leeuw, A.G.H. Kessels, J.M.A. van Engelshoven, M.G.M. Hunink 
Chapter 2

\begin{abstract}
Aim was to determine the costs associated with the diagnostic work-up and percutaneous revascularization of renal artery stenosis from various perspectives. A prospeetive multi-centre comparative study was conducted between 1998 and 2001 . A total of 402 hypertensive patients with suspected renal artery stenosis were included. Costs were assessed of computed tomography angiography (CTA), magnetic resonance angiography (MRA), digital subtraction angiography (DSA), and percutaneous revascularization. From the societal perspective, DSA was the most costly (E1721) and CTA the least costly diagnostic technique ( 6424$)$. CTA was the least costly imaging procedure irrespective of the perspective used. The societal costs associated with percutaneous renal artery revascularization ranged from $€ 2680$ to $€ 6172$. Overall the radiology department incurred the largest proportion of the costs. For the management of renal artery stenosis, performing the analysis from different perspectives leads to the same conclusion concerning the least costly diagnostic imaging and revascularization procedure.
\end{abstract}




\section{Introduction}

Among hypertensive patients in the general population the proportion of nonessential (secondary) hypertension is 4\% [1]. Renovascular hypertension is the most common form of secondary hypertension. Timely diagnosis is important because renovascular hypertension has a worse prognosis than essential hypertension, seems less amenable to treatment with antihypertensive drugs, carries a higher risk of progression to accelerated or malignant hypertension, and may result in irreversible renal failure. Anatomical correction of renal artery stenosis aims at preventing premature death, major cardiovascular complications such as myocardial infarction and stroke, and loss of renal function.

Digital subtraction angiography (DSA) is considered the reference standard for detecting renal artery stenosis. DSA, however, has a risk of mortality $[2,3]$ and morbidity such as arterial dissection [3,4] and renal failure [5-7]. Furthermore, it is a relatively expensive imaging technique. Less invasive diagnostic tests such as computed tomography angiography (CTA) and magnetic resonance angiography (MRA) are currently available for the diagnostic work-up of renal artery stenosis. Percutaneous transluminal renal angioplasty (PTRA) with or without selective stent placement and primary stent placement are accepted and widely used treatment options for renal artery stenosis. The Renal Artery Diagnostic Imaging Study in Hypertension (RADISH) was performed to compare the diagnostic accuracy of CTA and MRA to that of DSA. The results of this part of the study are presented elsewhere [8].

The purpose of this paper was to determine the costs associated with the diagnostic work-up and percutaneous revascularization of renal artery stenosis from the perspective of the radiology department, hospital, health care sector, patient, and society.

\section{Materials and methods}

\section{Design}

The multi-centre RADISH study included patients with a diastolic blood pressure equal to or exceeding $95 \mathrm{mmHg}$, aged 18-75 years, and one or more clinical features suggestive of renovascular hypertension [9]. Over a 3-year period (between October $28^{\text {th }}, 1998$, and October $\left.30^{\text {th }}, 2001\right), 402$ patients were prospectively recruited from the departments of internal medicine of three non-academic teaching hospitals and three academic hospitals in the Netherlands and underwent the diagnostic work-up for detecting renal artery stenosis. Of these, 46 patients were excluded from the analyses 


\section{Chapter 2}

because they did not undergo one or more of the three diagnostic tests [8]. Thus the results of CTA, MRA, and DSA were available for 356 subjects. Renal artery stenosis was found in 72 patients $(20 \%)$ and fibromuscular dysplasia in $27(38 \%)$. Clinical and socioeconomic characteristics are presented in Table 1 . The ethical review board of each hospital approved the study, and written informed consent was obtained from all subjects. DSA was considered the reference standard for detecting renal artery stenosis. Patients underwent CTA and MRA to establish the validity of these non-invasive techniques. Luminal narrowing of at least $50 \%$ and cases of fibromuscular dysplasia were consiclered clinically relevant. Patients with a diagnosis of renal artery stenosis and atherosclerotic ostial stenoses were treated with stent placement whereas fibromuscular dysplasia was managed with PTRA. Atherosclerotic non-ostial stenoses were treated with PTRA or PTRA followed by selective stent placement immediately after unsuccessful PTRA.

\section{Cost analysis}

The cost calculations were performed according to the Dutch guidelines for cost calculations in health care [10]. The cost analysis was performed from the perspective of the radiology department, hospital, health care sector, patient and society.

Time costs included time spent by family and friends in providing informal care and patient time costs due to the inability to do their usual activities which was approximated with absence from work and/or inability to do the housekeeping. Informal care and inability to do the housekeeping were valued using a shadow price of $€ 8$ per hour, being the wage rate of a cleaning person [10]. Productivity losses were estimated with the friction cost method. According to this method production losses will be confined to the period needed to replace a sick worker. The length of this period and the resulting costs depend on the situation on the labour market [11-13].

Costs were calculated by multiplying unit costs by resource quantities. Data on the resource quantities were collected in all participating hospitals. Unit costs for diagnostic imaging and therapeutic procedures and laboratory tests, including personnel, materials, and equipment were available from the coordinating centre (Maastricht University Hospital). Unit costs were not available from the other participating hospitals. For housing and overhead the unit costs were increased by 35\% [10]. For hospitalization, outpatient visits, home care utilization, general practitioner visits, and travel costs, prices quoted in the Dutch guidelines were used [10]. Since there was no guideline price available for a one-day admission, the costs were assumed to be two-thirds of an 
Table 1 Clinical and socio-economic characteristics

\begin{tabular}{|c|c|}
\hline Age & $52 \pm 12$ \\
\hline Males & $52 \%$ \\
\hline Diastolic blood pressure & $107 \pm 15$ \\
\hline Systolic blood pressure & $183 \pm 25$ \\
\hline \multicolumn{2}{|l|}{ Number of antihypertensive drugs } \\
\hline 0 & $6 \%$ \\
\hline 1 & $19 \%$ \\
\hline 2 & $29 \%$ \\
\hline 3 or more & $46 \%$ \\
\hline Creatinine $(\mu \mathrm{mol} / 1)$ & $105 \pm 44$ \\
\hline Creatinine $\geq 125 \mu \mathrm{mol} / / 1$ & $20 \%$ \\
\hline Cholesterol (mmol/l) & $5.7 \pm 1.1$ \\
\hline Body mass index & $28 \pm 5$ \\
\hline Presence of left ventricular hypertrophy & $55 \%$ \\
\hline \multicolumn{2}{|l|}{ Marital status } \\
\hline Married & $72 \%$ \\
\hline Not married & $12 \%$ \\
\hline Divorced & $6 \%$ \\
\hline Widower & $4 \%$ \\
\hline Living together & $6 \%$ \\
\hline Paid work ${ }^{*}$ & $57 \%$ \\
\hline Hours a week (range) & $34 \pm 17(4-104)$ \\
\hline Volunteer work" & $7 \%$ \\
\hline Hours a week (range) & $5 \pm 6(1-25)$ \\
\hline Unable to work, fully or partially disabled & $18 \%$ \\
\hline Retired" & $11 \%$ \\
\hline Unemployed $^{*}$ & $1 \%$ \\
\hline School going or studying" & $4 \%$ \\
\hline Do the housekeeping & $31 \%$ \\
\hline
\end{tabular}

- These items were not nutually exclusive; patients were allowed to chouse more than one option.

overnight admission. The costs of major complications as a result of CTA and MRA were estimated on average to equal the costs of a one-day admission. For major complications from invasive procedures (DSA, PTRA, stent placement) it was assumed that hospital stay was prolonged on average with two days. Costs of dying from procedures were estimated to equal the costs of two days of stay in an intensive care unit. The costs of procedure-related major complications and mortality were acljusted for the major complication and mortality rates. Major cormplications were defined as complications that required therapy and/or prolonged the patient's hospital stay. The major complication rates for DSA $(1.3 \%)$, CTA $(1.1 \%)$, and MRA $(0.3 \%)$ were derived 
by the author (D.V.H.P.) from the database of the RADISH study [8]. Revascularization was associated with a major complication rate of $8.8 \%$ [14]. Mortality from CTA and DSA was $0.0011 \%$ and $0.033 \%$, respectively $[2,15]$. Mortality from MRA was assumed to be zero. Revascularization was associated with a mortality of $1 \%$ [16].

Data conceming costs outside the health care sector and information about general practitioner visits and home care utilization were gathered by cost diaries. Patients were asked to provide information about fees paid to a housekeeper. For general practitioner visits the reported number of visits during the first four weeks after revascularization was compared with the average number of visits in the Dutch population. The difference was attributed to renovascular hypertension, of which half was ascribed to the revascularization of renal artery stenosis. For home care utilization and informal care the quantities at the time of inclusion in the RADISH study and during the first four weeks after revascularization were compared, and the difference was attributed to the revascularization procedure. Both productivity losses and time costs due to inability to do the housekeeping occurring during the first four weeks after revascularization were attributed to the revascularization procedure. Costs are presented in 2000 euros $(\epsilon 1=$ $\$ 0.8$, October 2000, Central European Bank).

\section{Results}

\section{Cost analysis}

The costs associated with the diagnostic work-up and revascularization for renal artery stenosis are presented in Table 2 . In the coordinating centre patients were admitted for two nights for DSA. Since CTA and MRA were performed on an outpatient basis, hospitalization costs were not attributed to these procedures. The costs of dying from CTA were negligible (E0.03) and therefore not included in the total costs. For a revascularization procedure patients were admitted for two nights. Before and after revascularization both creatinine and haemoglobin levels were tested ( $e 1.73$ and $\in 1.43$, respectively).

Figure 1 presents the costs of procedures related to the management of renal artery stenosis from the societal perspective, including costs incurred by the radiology department, additional hospital costs, additional health care costs, patient costs, and additional societal costs. Productivity losses and time spent by family and friends in providing informal care were considered additional societal costs. Time costs due to the inability to do the housekeeping were considered patient costs. From the societal 
Table 2 Costs of the diagnostic work-up and revascularization for renal artery stenosis

\begin{tabular}{|c|c|c|c|c|c|}
\hline & $\mathrm{CTA}$ & MRA & DSA & PTRA & STENT \\
\hline \multicolumn{6}{|l|}{ Health care } \\
\hline Procedures & 385 & 925 & 912 & $1603(2246)$ & $3311(5095)$ \\
\hline Personnel & 118 & 152 & 217 & $294(371)$ & $371(448)$ \\
\hline Materials & 58 & 68 & 146 & $489(783)$ & $1848(3283)$ \\
\hline Equipment & 209 & 705 & 549 & $820(1092)$ & $1092(1364)$ \\
\hline Hospitalization & $\mathrm{N} / \mathrm{a}$ & $\mathrm{N} / \mathrm{a}$ & 704 & 704 & 704 \\
\hline Laboratory tests & $\mathrm{N} / \mathrm{a}$ & $N / a$ & $\mathrm{~N} / \mathrm{at}$ & 6 & 6 \\
\hline Major complications & 3 & $\mathbb{1}$ & 9 & 62 & 62 \\
\hline Mortality $^{\dagger}$ & Negligible & 0 & 1 & 24 & 24 \\
\hline General practitioner & $\mathrm{N} / \mathrm{a}$ & $\mathrm{N} / \mathrm{a}$ & N/a & 5 & 5 \\
\hline Home care & $\mathrm{N} / \mathrm{a}$ & $\mathrm{N} / \mathrm{a}$ & $\mathbb{N} / a$ & 33 & 33 \\
\hline \multicolumn{6}{|l|}{ Non-health care } \\
\hline Travel costs & 3 & 3 & 3 & 3 & 3 \\
\hline Paid housekeeper & $\mathrm{N} / \mathrm{a}$ & $\mathrm{N} / \mathrm{a}$ & N/a & 0 & 0 \\
\hline Informal care & $\mathrm{N} / \mathrm{a}$ & $\mathrm{N} / \mathrm{a}$ & $\mathrm{N} / \mathrm{a}$ & 34 & 34 \\
\hline \multicolumn{6}{|l|}{ Inability to do the } \\
\hline housekeeping & 4 & 4 & 14 & 94 & 94 \\
\hline Productivity losses & 29 & 33 & 78 & 112 & 112 \\
\hline Total costs & 424 & 966 & 1721 & $2680(3323)$ & $4388(6172)$ \\
\hline
\end{tabular}

CTA: computed tomography anglography; MRA: magnetic resonance angiography; DSA: digital subtraction angiography; PTRA: percutaneous transluminal renal angioplasty" N/at: not applicable: Parentheses: costs of a bilateral procedure.

"Costs of major complications were incurred ir 1.1\% (CTA), $0.3 \%$ (MRA), 1.3\% (DSA), and $8.8 \%$ (PTRA; stent placement) of cases but were averaged out across all patients.

"Costs of mortality were incurred in $0.0011 \%$ (CTA), 0.033\% (DSA), and 1\% (PTRA; stent placement) of cases but were averaged out across all patients. Mortality from MRA was assumed to be zero.

perspective DSA was the most costly (€1721) and CTA the least costly diagnostic technique (6424). The costs associated with the MRA technique were 6966.

The duration of hospitalization due to DSA varies across countries and hospitals. If patients were admitted for one night or could return home after a couple of hours of bed rest and observation, the hospitalization costs were 6352 and 6235 , respectively. The societal costs associated with a DSA procedure thus decreased to $€ 1369$ and $€ 1252$, respectively. The costs of major complications may vary considerably. If the costs were assumed to be $€ 18$, being the fee for a general practitioner visit [10], the societal costs would be 6421 (CTA), 6965 (MRA), e1712 (DSA), E2620 (PTRA), and 64328 (stent placement). If the costs of major complications were assumed to equal 62464 , being the costs of a hospital stay for seven days [10], the societal costs would be 6448 (CTA), E972 (MRA), E1744 (DSA), E2835 (PTRA), and E4543 (stent placement). The costs incurred by the radiology department were 6385,6925 , and 6912 for CTA, MRA, and 


\section{Chapter 2}

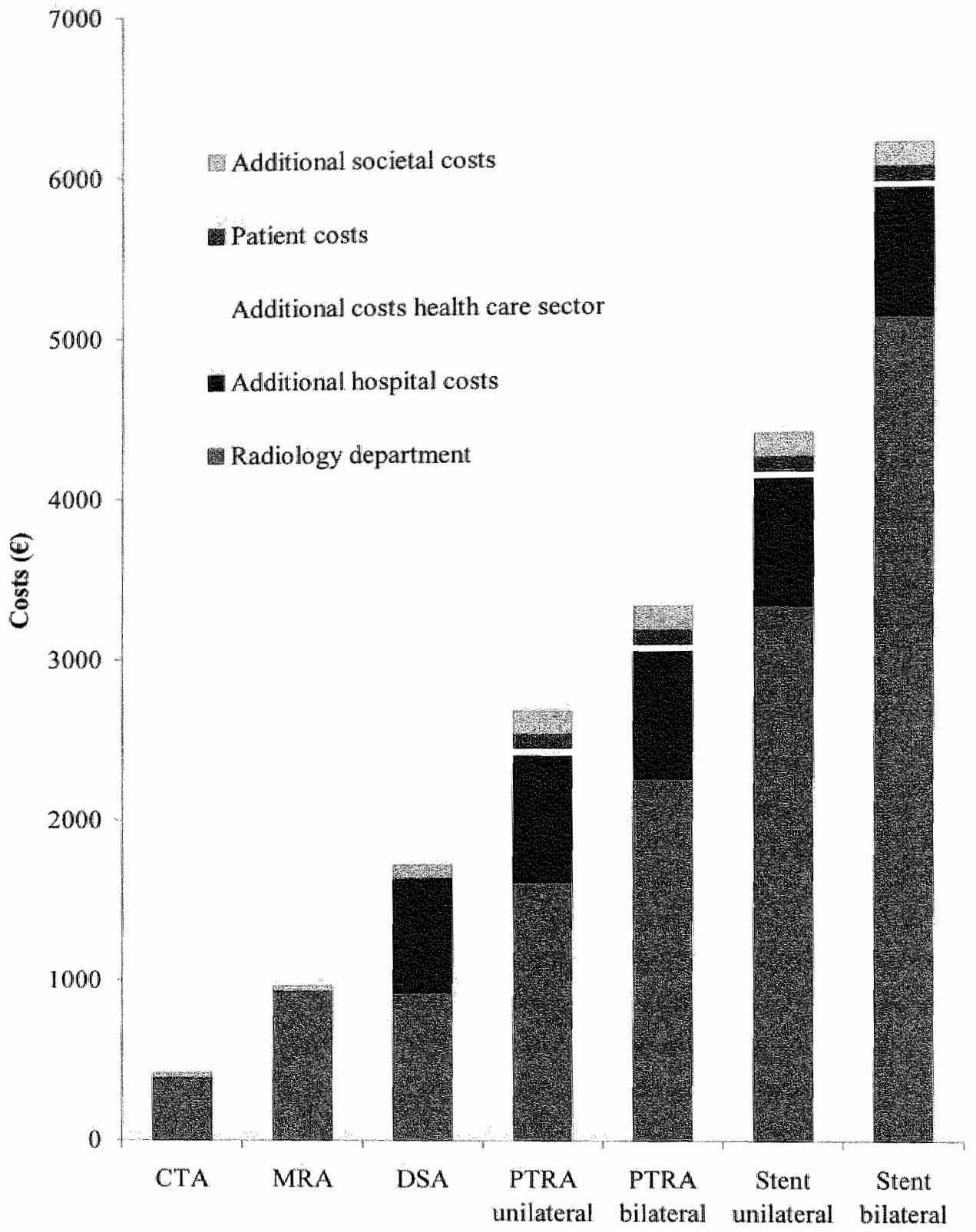

Figure 1 Costs of procedures related to the management of renal artery stenosis from the societal perspective, including costs incurred by the radiology department, additional hospital costs, additional health care costs, patient costs, and additional societal costs. A cost component that is too small relative to the societal costs may not be visible in the figure. 
DSA, respectively. For DSA hospitalization ( 6704$)$ accounted for the majority of the additional hospital costs. Patient costs accounted for $2 \%$ (CTA), 1\% (MRA), and $1 \%$ (DSA) of the total societal costs.

The total societal costs associated with renal artery revascularization ranged from e2680 to 66172 . A bilateral stent placement procedure was the most expensive therapeutic scenario. The hospital costs, including costs incurred by the radiology department, accounted for 90\% (PTRA unilateral), 92\% (PTRA bilateral), 94\% (stent unilateral), and $95 \%$ (stent bilateral) of the total societal costs. The additional health care costs, including general practitioner and home care utilization, were $€ 38$ for a PTRA or stent procedure.

\section{Discussion}

The decision which imaging modality or combination of imaging procedures to use in practice usually depends on the clinical parameters of the test, such as the diagnostic performance and complications. However, because resources, such as persons, time, and equipment are scarce, costs should also be considered.

In this study we assessed the costs of CTA, MRA, DSA, PTRA, and PTRA followed by stent placement for the diagnostic work-up and treatment for renal artery stenosis. From the societal perspective DSA was the most costly ( 61721 ) and CTA the least costly diagnostic technique ( $€ 424)$. The costs associated with the MRA technique were $€ 966$. The total societal costs associated with renal artery revascularization ranged from $€ 2680$ to 66172 . Overall the radiology department incurred the largest proportion of the societal costs of the procedures. C.TA was the least costly diagnostic imaging procedure irrespective of the perspective used. However, DSA, in contrast to CTA, has the advantage of providing therapeutic options at the time of the diagnostic evaluation, thus leading to cost savings in patients with demonstrated renal artery stenosis.

It was difficult to compare our results with other studies reporting costs related to the management of renal artery stenosis. It is not uncommon in the literature to report hospital charges, or, alternatively insurance reimbursements, used as surrogates for the actual costs [17-19]. However, charges are generally higher than costs and do not reflect the actual opportunity costs of the health care resources used. Furthermore, different perspectives are used. Some cost analyses include patient expenses, time costs, and productivity losses whereas other analyses ignore these costs. Finally, policy and routines may vary across hospitals and as a result, lead to differences in costs. To our knowledge two studies have used the actual costs of diagnostic and revascularization 
procedures for the management of renal artery stenosis. A study by Nelemans et al. [20] assessing the cost-effectiveness of the diagnosis of renal artery stenosis based the costs of the diagnostic tests, PTRA, and stent placement on a cost calculation study, including personnel, materials, and capacity. The analysis took the perspective of the health care system, and therefore costs outside the health care sector, such as travel expenses; patient time, and productivity losses were not taken into account. Xue et al. [21] analyzed the initial treatment costs, including post-procedural care, of PTRA and stent placement in patients with renovascular hypertension. The procedural costs were $\$ 1402$ and $\$ 2573$ for PTRA and stent placement, respectively. Post-procedural hospitalization was required for $17 \%$ of the patients who underwent PTRA and $15 \%$ of the patients who underwent stent placement. The average costs for post-procedural care were $\$ 540$ and $\$ 1779$ for PTRA and stent placement, respectively. The difference in postprocedural hospitalization costs between PTRA and stent placement was rellated to the prolonged hospitalization of a single patient (35 days) in the latter group. Although not explicitly stated by the authors, the analysis was performed from the hospital perspective.

A first limitation of the present study was that assumptions had to be made about the costs of major complications and deaths from diagnostic imaging and percutaneous revascularization procedures. This was done since relatively few patients experienced a major complication. Moreover there were no deaths related to the procedures. Consequently, using actual costs would probably lead to biased cost estimates. The costs of major complications, however, constituted a small proportion of the hospital costs and total societal costs and thus had only a minor impact on the overal» results, which was confirmed by the sensitivity analysis. Also, secondary data from the literature were used for the major complication rate associated with a revascularization procedure [14] and mortality rates for CTA, DSA, and percutaneous revascularization $[2,15,16]$ since these figures could not be determined empirically.

A second limitation was that future costs were excluded from the analysis because our aim was to analyze the costs of the initial procedures and to make comparisons between perspectives. It seems reasonable to assume, however, that the downstream costs differed between the diagnostic tests depending on the sensitivity and specificity of CTA and MRA. All patients participating in the RADISH study underwent three diagnostic imaging modalities. DSA was considered the reference standard for detecting renal artery stenosis. In addition, patients underwent CTA and MRA to establish the validity of these non-invasive imaging techniques. Both CTA and MRA had a poor 
sensitivity $(69 \%$ and $57 \%$, respectively) but an adequate specificify $(91 \%$ and $90 \%$, respectively) for detecting renal artery stenoses [8]. The cost consequences of hasenegative test results from CTA and MRA, for example the costs related to the inereased risk of cardiovascular diseases and chronic renal fallure, and the costs of antihypertensive drugs were not considered since the consequences of a missed diagnosis of renal artery stenosis generally reveal in the long-term. In clinical practice a PTRA or stent placement procedure would be planned if CTA or MRA demonstrated stenosis. False-positive test results could lead to inappropriate treatment of patients. The diagnostic DSA performed as part of a PTRA or stent placement procedure would detect stenoses incorrectly referred for PTRA or stent placement. However, the costs of a revascularization procedure that is stopped equal the costs of a diagnostic DSA plus an additional amount of money for inefficient use of personnel, equipment, and room time.

A third limitation was that health benefits were not included in the analysis, and therefore it was not possible to weigh the potential cost savings against the health effects associated with different diagnostic tests. The unique feature of diagnostic tests is that the results are intermediate outcomes. Thus gains in effectiveness and potential cost savings are largely determined by the therapeutic strategy adopted on the basis of the test results. Downstream costs are strongly dependent on the patency and clinical results, follow-up schedule, and the need for repeated diagnostic work-up and revascularization. In a cost-effectiveness analysis comparing various diagnostic strategies for detecting renal artery stenosis, initial and long-term costs and health effects will be included.

Given current budget constraints, policy-makers are forced to make resource allocation decisions to control health care expenditures. The perspectiwe of the analysis determines which costs are included, and the decision from which perspective to perform a cost analysis is related to the purpose of the analysis. For example, an analysis performed from the perspective of the radiology department may be valuable for the department in negotiations with the hospital board and health insurance organizations, whereas a cost analysis from the societal perspective is required to inform public policy-makers on the macroeconomic level. The current analysis showed that cost calculations related to the management of renal artery stenosis lead to different results depending on the perspective. For example, the costs associated with a unilateral PTRA procedure ranged from $€ 1603$ (radiology department perspective) to $€ 2680$ (societal perspective). However, the ordering of the procedures according to costs was the same, irrespective of the perspective of the analysis. Furthermore, the non-health 
Chapter 2

care costs were almost negligible, whereas the hospital perspective, and in particular the radiology department perspective, included the largest part of the costs.

In conclusion, for the management of renal artery stenosis performing the analysis from different perspectives leads to the same conclusion conceming the least costly diagnostic imaging and revascularization procedure. 


\section{References}

1. Kidney $\mathrm{DD}$, Deutsch L. The indications and results of percutaneous transhuminal angioplasty and stenting in renal artery stenosis. Semin Vasc Surg 1996; 9, 188-197.

2. Hessel SJ, Adams DF, Abrams HL. Complications of angiography. Radiology 1981; 138: $273-281$

3. Waugh JR, Sacharias $\mathbb{N}$. Arteriographic complications in the DSA era. Radiology 1992; 182 : $243-246$.

4. Young N, Chi KK, Ajaka J, McKay L, O'Neill D, Wong KP. Complications witli outpatient: angiography and interventional procedures. Cardiovasc Intervent Radiol 2002; 25: 123-126.

5. Rudnick MR, Berns JS, Cohen RM, Goldfarb S. Nephrotoxic risks of renal angiography: contrast media-associated nephrotoxicity and atheroembolism ... a critical review. Am J Kidney Dis 1994; 24: 713-727.

6. Cochran ST, Bomyea K, Sayre JW. Trends in adverse events after IV administration of contrast media. AJR Am J Roentgenol 2001; 176: 1385-1388.

7. Thomsen HS, Morcos SK; Members of Contrast Media Safety Committee of European Society of Urogenital Radiology (ESUR). In which patients should serum creatinine be measured before iodinated contrast medium administration? Eur Radiol 2005; 15: 749-754.

8. Vasbinder GBC, Neletnans PJ, Kessels AGH, et all., for the Renal Artery Diagnostic Imaging Study in Hypertension (RADISH) Study Group. Accuracy of computed tomographic angiography and magnetic resonance angiography for diagnosing renal artery stenosis. Ann Intern Med 2004; 141:674-682.

9. Working Group on Renovascular Hypertension. Detection, evaluation, and treatment of renovascular hypertension. Final report. Arch Intern Med 1987; 147: 820-829.

10. Oostenbrink JB, Koopmanschap MA, Rutten FFH. Handleiding voor kostenonderzoek: Methoden en richtlijnprijzen voor economische evaluaties in de gezondheidszorg. Amstelveen, College voor zorgverzekeringen, 2000.

11. Koopmanschap MA, Ineveld van BM. Towards a new approach for estimating indirect costs of disease. Soc Sci Med 1992; 34: 1005-1010.

12. Koopmanschap MA, Rutten FF, Ineveld van BM, Roijen van $\mathrm{L}$. The friction cost method for measuring indirect costs of disease. J Health Econ 1995; 14:171-189.

13. Koopmanschap MA, Rutten FF. A practical guide for calculating indirect costs of disease. Pharmacoeconomics $1996 ; 10: 460-466$.

14. Martin LG, Rees CR, O'Bryant $T$. Percutaneous angioplasty of the renal arteries. In: Strandness DE, Breda van A, eds. Vascular diseases: surgical and interventional therapy, $3^{\text {rd }}$ edition. New York, Churchill Livingstone, 1994; 721-741. 
15. Lawrence $\mathrm{V}$, Matthai $\mathrm{W}$, Hartmaier S. Comparative safety of high-osmolality and lowosmolality radiographic contrast agents. Invest Radiol 1992;27: 2-28.

16. Leertouwer TC, Gussenhoven Ej, Bosch JL, et al Stent placement for renal arterial stenosis: where do we stand? A meta- analysis. Radiology $2000 ; 216: 78-85$.

17. Rademacher $\mathrm{J}$, Brunkhorst $\mathrm{R}$. Diagmosis and treatment of renovascular stenosis - a costibenefit analysis. Nephrol Dial Transplant 1998; 13:2761-2767.

18. Lawrence WF, Grist TM, Brazy PC, Fryback DG. Magnetic resonance angiography in progressive renal fallure: A technology assessment. Am J Kidney Dis 1995; 25: $701-709$.

19. Blaufox MD, Middleton ML, Bongiovani $J_{\text {" Davis }} \mathrm{BR}$. Cost efficacy of the diagnosis and therapy of renovascular hypertension. I Nucl Med 1996; 37: 171-177.

20. Nelemans PJ, Kessels AGH, Leetw de P, Haan de M, Engelshoven van J. The costeffectiveness of the diagnosis of renal artery stenosis. Eur J Radiol 1998; 27: 95-107.

21. Xue F, Bettmann MA, Langdon DR, Wivell WA. Outcome and cost comparison of percutaneous transluminal renal angioplasty, renal arterial stent placement, and renal arterial bypass grafting. Radiology 1999;212:378-384. 


\section{Chapter 3}

\section{A comparison between willingness-to-pay and willingness to give up time}

D. van Helvoort-Postulart, C.D. Dirksen, A.G.H. Kessels, J.M.A. van Engelshoven, M.G.M. Hunink 


\section{Chapter 3}

\section{Summary}

Aim was to compare the results of the willingness-to-pay method with the willingness to give up time method to assess preferences for digital subtraction angiography (DSA), computed tomography angiography (CTA) and magnetic resonance angiography (MRA). Respondents were patients participating in the Renal Artery Diagnostic Imaging Study in Hypertension. Data were gathered using telephone interviews. Comparability of willingness-to-pay and willingness to give up time was assessed using Wilcoxon signed-rank tests. Agreement was determined within respondents using the Kappa statistic. Both the willingness-to-pay method and the willingness to give up time method revealed that patients preferred CTA to MRA in order to avoid DSA. The agreement between willingness-to-pay and willingness to give up time responses was high (Kappa 0.65-0.85). The willingness-to-pay technique yielded relatively more protest answers (12\%) as compared to the willingness to give up time technique ( $2 \%$, which raises questions with respect to the application of the willingness-to-pay method in a broad decision-making context. On the other hand, the strength of willingness-topay is that the method directly arrives at a monetary measure well founded in economic theory, whereas the willingness to give up time method requires conversion to monetary units. 


\section{Introduction}

The decision as to which imaging modality or combination of imaging procedures to use in clinical practice asually depends on the diagnostic performance, complications, and the costs of the diagnostic procedures. In a cost-effectiveness analysis conducted from the societal perspective, which includes all costs and effects to society, preferences for diagnostic modalities should also be included in the analysis. To incorporate preferences for imaging tests in a cost-effectiveness study, these preferences should be measured as a utility or a cost. Commonly used utility instruments are the visual analogue scale, time trade-off, and standard gamble [1]. These utility elicitation methods are to a large degree applied to the measurement of chronic health states. However, diagnostic imaging procedures typically cause temporary morbidity, and traditional methods fail to measure these short-term changes in health status since these techniques assume that health states remain constant over some length of time.

Another way to measure preferences is to place a monetary value on gains and losses in utilities, the willingness-to-pay method [2]. Patients are asked how much they would be willing to pay either to avoid or to undergo a certain procedure. Willingnessto-pay is a potentially useful tool for assessing short-term disutility associated with undergoing health care interventions. However, up till now, the willingness-10-pay method has not been used in the context of health care decision-making. One of the major problems in assessing the feasibility of the willingness-to-pay concept in health care is that there is no reference standard, i.e. what consumers would actually pay. Accordingly, in the absence of the reference standard, criterion validity cannot easily be established. Instead, the construct or theoretical validity can be determined, i.e. the extent to which results are consistent with theoretical constructs, for example by means of so-called scope tests. The proposition underlying scope tests is that willingness-topay should vary with the scope of the benefit arising from the program [3]. Furthermore, the convergence of the willingness-to-pay method with other measures can be analyzed $[4,5,6]$. The willingness-to-pay technique is criticized for attempting to assign a monetary value to things, which are considered to be incommensurate with monetary valuation, i.e. the relief of suffering or the saving of a thuman life. Another criticism of willingness-to-pay is that it is inevitably a function of ability to pay, which could have implications for equity. Finally, it is argued that willingness-to-pay may not discriminate between the alternatives being valued [7,8,9].

Alternatively, to obtain a time value for preferences for diagnostic imaging modalities, we might use a method that assesses the willingness to give up time for a 
procedure. The possibility to use time to value health care was first mentioned by Johamesson and Jonsson [10]. The potential advantage of using time instead of money is that it may be less value-laden. Although both elicitation methods intend to measure preferences, so far, only three studies have been carried out that determined both willingness-to-pay and willingness to give up time [11,12,13].

The purpose of this paper was to compare the results of the willingness-to-pay method with the willingness to give up time method to assess preferences for digital subtraction angiography, computed tomography angiography and magnetic resonance angiography for the diagnostic work-up of renall artery stenosis. Specifically, the focus was on examining $(1)$ the comparability of willingness-to-pay and willingness to give up time (convergence validity), and (2) the agreement between the answers to willingness-to-pay and willingness to give up time questions.

\section{Clinical setting}

The percentage of secondary hypertension is $4 \%$ in the general hypertensive population [14] with renovascular hypertension being the most common form of secondary hypertension. As compared to essential hypertension, renovascular hypertension seems less responsive to treatment with antihypertensive medications, has a higher risk of progiession to accelerated or malignant hypertension and may result in irreversible renal failure. Hence, timely detection and treatment of renal artery stenosis is important.

Intra-arterial digital subtraction angiography (DSA) is considered the reference standard for detecting renal artery stenosis. A disadvantage of DSA is that the procedure has a risk of mortality and morbidity. In addition, DSA is expensive compared with other imaging modalities. At present, minimally invasive imaging techniques, such as computed tomography angiography (CTA) and magnetic resonance angiography (MRA) are available for the diagnostic work-up of renal artery stenosis.

The multi-centre Renal Artery Diagnostic Imaging Study in Hypertension (RADISH) was performed to detemine the diagnostic accuracy of CTA and MRA as compered to DSA. Patients with a diastolic blood pressure equal to or exceeding 95 minltg, aged $18-75$ years, and one or more clinica】 features suggestive of renovascular hypertension [15], were submitted to the diagnostic work-up for detecting renal artery stenosis. Over a three-year period, patients were prospectively recruited from the departments of internal medicine of three non-academic teaching hospitals and three academic hospitals in the Netherlands. The University Hospital Maastricht was the coordinating centre. The ethical review board of each hospital approved the study, and 
written informed consent was obtained from all subjects. All participants were subjected to three diagnostic imaging tests. DSA was used as the reference standard for detecting renal artery stenosis. Patients underwent CFA and MRA in order to establish the validity of these non-invasive techniques. Atherosclerotic stenoses $\geq 50 \%$ as well as cases of fibromuscular dysplasia were considered clinically relevant. Patients with a diagnosis of renal artery stenosis were treated in accordance with current opinion. The results of this part of the study are presented elsewhere [16].

\section{Methods}

\section{Questionnaire}

A questionnaire (available in Dutch) was developed that consisted of four parts. In part 1, a description of each imaging modality (DSA, CTA and MRA) was given, to serve as a reminder. In part 2, respondents' willingness to pay was first estimated for CTA in comparison to the reference standard DSA, and then for MRA compared to DSA. Patients after having undergone these three diagnostic tests were asked to imagine the hypothetical scenario in which the patient had to return to the hospital with the same complaints two years later. Furthermore, they were asked to imagine that the health insurance company did not cover CTA, whereas, on the other hand, DSA was covered. So, if the patient chose CTA instead of DSA, the patient would have to pay an out of pocket price for the imaging test. Then, they were asked how much they would be willing to pay for CTA in order to avoid DSA. The elicitation process started with the take-it-or-leave-it question whether the patient would be willing to pay E23 for CTA. Subsequently, a payment card was presented including a range of lower or higher values for the respondent to choose from, dependent on the answer to the take-it-or-leave-it question [17]. The payment card included the following willingness-to-pay amounts: 60 , $\epsilon 11, € 23, \epsilon 45, € 90, \epsilon 182, € 363, \in 726$ and $€ 1452$. The original amounts were presented in Dutch guilders (in rounded numbers) and converted to Euros $(€ 1=2.20371$ Dutch guilders). Patients who were not willing to pay (C0) were asked to state the reason for their refusal, including the options (a) not willing to pay on principle, (b) no preference for either of the tests, (c) preference for DSA, and (d) do not know. The same procedure was followed for MRA in comparison to DSA.

In part 3, willingness to give up time questions were asked. First, patients were asked which imaging modality (CTA or DSA) they would prefer in the hypothetical situation in which the patient had to return to the hospital for repeat diagnostic work-up. If patients expressed a preference for CTA, they were told that they could have CTA or 
DSA free of charge. However, the tests would be performed during leisure time. Leisure time was defined as time not used for paid work, such as reading a book, making phone calls, doing volunteer work, visiting someone, sleeping, doing sports, cleaning the house or going to a movie. Then, patients were asked to imagine that CTA would take a particular time for recovery. This meant that after CTA the patient would spend some time in a bed in a hospital ward. Just like the time for the CTA itself, the time needed for recovery would be in the leisure time of the patient. Finally, they were asked if, and how much leisure time (i.e. time for recovery in a bed) they were willing to give up for CrA to avoid DSA. The questions were asked in a closed format. For instance, patients were presented with the scenario in which the recovery time in a hospital bed after CTA was 30 minutes, and were asked to choose between CTA and DSA. Then, the recovery time was increased to 4 hours, 12 hours, 24 hours, one week, one month, and one year. In each case, patients were asked to choose between CTA and DSA. Similar questions were asked for MRA compared to DSA.

In part 4, patients were asked to provide some demographic and socio-economic information (age, gender, marital status, education, and income). Patients were also asked to indicate the experienced burden associated with each of the diagnostic imaging tests on visual analogue scale ranging from 0 (not bothersome at all) to 10 (extremely bothersome).

Data were gathered using telephone interviews. Willingness-to-pay and willingness to give up time questions were asked during a single telephone interview. At the time of the inclusion in the RADISH study, patients received the questionnaire and an appointment was made for the telephone interview. The patients were instrueted to read the questionnaire before the interview took place. The interviews were performed after the patients had undergone the DSA, CTA, and MRA procedures. Patients returned the questionnaire to the researcher who determined the scores on the visual analogue scales.

\section{Analyses}

To assess the comparability (convergence validity), willingness-to-pay and willingness to give up time was estimated for three groups of patients: (1) all patients, (2) excluding patients who gave a protest answer, and (3) patients with a positive willingness-topay/willingness to give up time response. Patients answering that they were not willing to pay for reasons of principle were considered to give protest answers. Similarly, a willingness to give up time response was defined as a protest answer if the patient expressed a preference for CTA (or MRA) as opposed to DSA but nevertheless did not 
want to give up time for CTA (or MRA). For the willingness to give up time method, patients who had no preference, patients who stated a preference for DSA, and patients who gave a protest answer were assigned a zero time value. The willingness to give up time response was calculated as the arithmetic mean of two categories. For instance, if the patient chose CTA when the recovery time was 4 hours and DSA when the recovery time was 12 hours, it was assumed that the patient was indifferent between CTA and DSA when the recovery time was 8 hours, being the maximum willinginess to give up time value.

Agreement was determined by comparing the results of willingness-to-pay and willingness to give up time within patients. The strength of the agreement was. investigated in three ways. First, it was examined to what extent patients who were willing to pay for a particular test also reported a positive time value for that test. Second, it was examined to what extent patients who were not willing to pay for CTA or MRA since they preferred DSA or had no preference for either one of the diagnostic imaging tests, expressed the same choice on the willingness to give up time questions. Third, the strength of the agreement between willingness-to-pay and willingness to give up time was investigated with respect to the difference between CTA and MRA. For that purpose the responses to the willingness-to-pay and willingness to give up time questions were classified into three groups: (1) willingness-to-pay (willingness to give up time) for CTA is higher than willingness-to-pay (willingness to give up time) for MRA, (2) willingness-to-pay (willingness to give up time) for CTA equals willingnessto-pay (willingness to give up time) for MRA, and (3) willingness-to-pay (willingness to give up time) for CTA is lower than willingness-to-pay (willingness to give up time) for MRA. It was investigated to what extent patients who were willing to pay a higher (lower, equal) amount of money for CTA than for MRA also reported a higher (lower, equal) time value for CTA as opposed to MRA. The following patients were exchuded from the analyses of agreement between willingness-to-pay and willingness to give up time: patients who gave a protest answer, patients who were not willing to pay for unknown reasons, patients with a missing willingness-to-pay or willingness to give up time response, and patients who had no preference or a preference for DSA and nevertheless reported a positive willingness to give up time value for CTA or MRA. The latter were considered inconsistent responses within the willingness to give up time method. 
Table 1 Patient characteristics $(\mathrm{N}=217)$

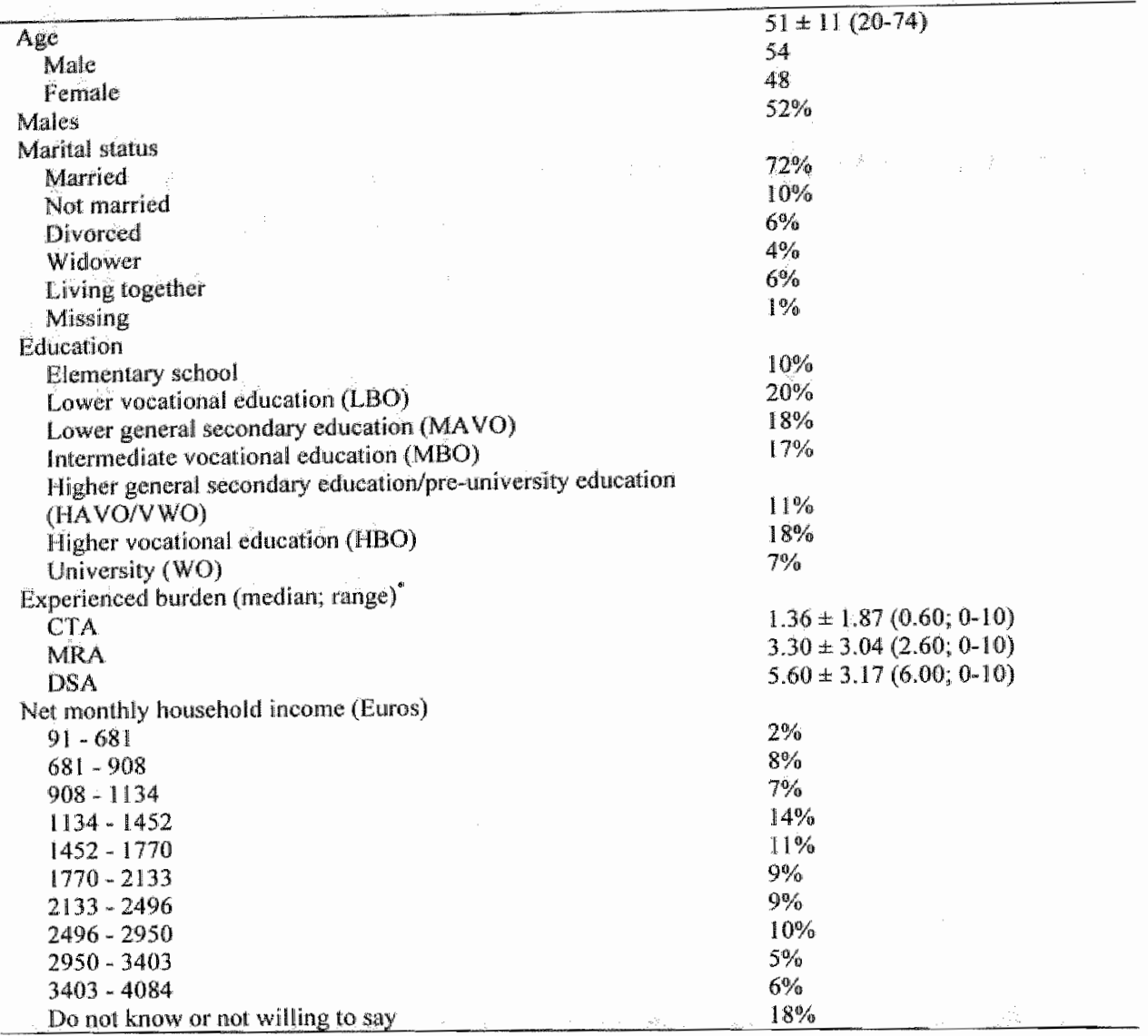

Due to rounding the percentages do not add up to $100 \%$.

Experienced burden was nicusured on a visual analogue scale ranging from 0 (not bothersome at all) to 10 (extromely bothersome)

\section{Statistical analysis}

Responses were tested for normality with a Kolmogorov-Sminnov (K-S) test. Scores that were not normally distributed were tested using non-parametric statistical tests. For the willingness-to-pay and willingness to give up time responses, descriptive statistics were calculated. Both median and mean values were presented. The linear weighted Kappa statistic was used to determine the agreement between willingness-to-pay and willingness to give up time responses beyond that of chance. Data were analyzed using SPSS for Windows, version 11.5. All amounts are presented in Euros. 
Willingness-to-pay wersus willingness to give up time

\section{Results}

\section{Response}

Of the 402 patients who participated in de RADISH study, 342 patients were eligible to fill in the patient preference questionnaire. Of these, 30 patients were excluded for several reasons (unwilling to fill in questionnaires; organizational problems; inability to speak, read or write in Dutch; inability to fill in questionnaires due to physical or cognitive limitations). Data from the pilot study $(\mathrm{N}=32)$ were excluded from the analyses. Of the remaining 280 patients, 217 patients completed the preference questionnaire $(78 \%)$. Patient characteristics are presented in Table 1.

\section{Willingness-to-pay}

A total of 213 patients $(98 \%)$ completed the willingness-to-pay part of the preference questionnaire for CTA and 215 patients (99\%) for MRA. Patients were willing to pay a median of $€ 91$ (mean 180; SD 260) and $€ 91$ (mean 163; SD 264) for CTA and MRA, respectively, in order to avoid DSA. Willingness-to-pay responses were not normally distributed $(\mathbb{K}-S ; p<0.001)$. Therefore, CTA and MRA values were compared using a non-parametric pair-wise Wilcoxon signed-rank test. Patients were willing to pay a significantly higher amount for CTA than for MRA $(p=0.005)$.

Table 2 shows that $66 \%$ of the patients who were unwilling to pay for CTA and $45 \%$ of the patients who were unwilling to pay for MRA, were unwilling to pay for reasons of principle. After excluding these protest answers from the analysis, median willingness-to-pay was $€ 91$ (mean 204; SD 268) for CTA and $€ 91$ (mean 185; SD 274) for MRA. The difference was statistically significant (Wilcoxon signed-rank test; $p=$ 0.009 ).

In the subgroup of patients who stated a positive willingness-to-pay value (CTA: $82 \%$; MRA: 74\%), median willingness-to-pay was $€ 182$ (mean 219; SD 272) for CTA and E182 (mean 220; SD 286) for MRA. The difference was not significant (Wilcoxon signed-rank test; $\mathrm{p}=0.535$ ).

\section{Willingness to give up time}

A total of 209 patients $(96 \%)$ completed the willingness to give up time part of the preference questionnaire for CTA and 210 patients (97\%) for MRA. Patients were asked to consider the choice between CTA and DSA, and the choice between MRA and DSA, in the hypothetical situation in which the patient had to return to the hospital for a repeat diagnostic work-up. The results are presented in Table 3. 
Table 2 Patients unwilling to pay for CTA and MRA

\begin{tabular}{lll}
\hline & CTA $(\mathrm{N}=213)$ & MRA $(\mathrm{N}=215)$ \\
Patients unwilling to pay & $18 \%$ & $26 \%$ \\
Reason & & \\
On principle & $66 \%$ & $45 \%$ \\
No preference & $13 \%$ & $11 \%$ \\
Preference for DSA & $13 \%$ & $33 \%$ \\
Do not know & $8 \%$ & $11 \%$ \\
\hline
\end{tabular}

CTA: comptuted tomograplly angiography; MRA: magnetic resonance angiography; DS A: digita subtraction angiography.

Table 3 Patient preferences for CTA and MRA

\begin{tabular}{lll}
\hline & CTA $(\mathrm{N}=209)$ & MRA $(\mathrm{N}=210)$ \\
Preference for CTA or MRA & $92 \%$ & $81 \%$ \\
No preference & $5 \%$ & $7 \%$ \\
Preference for DSA & $3 \%$ & $12 \%$ \\
\hline
\end{tabular}

CTA: computed tomography angiography; MRA: magnetic resonance angiography; DSA: digital subtraction angiography.

The willingness to give up time was median 96 hours (mean 550; SD 1785) for CTA, and median 96 hours (mean 388; SD 1448) for MRA. Patients were willing to give up significantly more time for CTA as compared to MRA (Wilcoxon signed-rank test; $\mathrm{p}<0.001)$

Four patients expressed a preference for CTA as opposed to DSA but did not want to give up time for CTA. Five patients had a preference for MRA but did not want to give up time for MRA. Excluding these protest answers from the analysis, the willingness to give up time was median 96 hours (mean 561, SD 1801) for CTA and median 96 hours (mean 397; SD 1465) for MRA. The difference between CTA and MRA was statistically significant (Wilcoxon signed-rank test; $p<0.001$ ).

In the subgroup of patients who stated a positive willingness to give up time value (CTA: 89\%; MRA: 78\%), median willingness to give up time was 96 hours (mean 609; SD 1870) for CTA and 96 hours (mean 488; SD 1610) for MRA. The difference was not significant (Wilcoxon signed-rank test; $\mathrm{p}=0.069$ ). 


\section{Analyses of agreement between willingness-to-pay and willingness to give up time}

A subgroup of 175 patients $(81 \%)$ was analyzed for the agreement between the two measures for CTA and 172 patients (79\%) for MRA. The results are presented in Table 4 for CTA and Table 5 for MRA. For CTA, 169 of 175 patients $(97 \%)$ expressed the same preferences on the willingness-to-pay and willingness to give up time instrument. For MRA, 164 of 172 patients $(95 \%)$ reported the same preferences on both instruments. The resulting weighted Kappa values were 0.74 (SD $0.11 ; 95 \%$ CI, 0.52 to 0.96 ) for CTA and 0.85 (SD $0.06 ; 95 \% \mathrm{CI}, 0.74$ to 0.96 ) for MRA.

The agreement between willingness-to-pay and willingness to give up time with respect to the difference between CTA and MRA could be determined in a subgroup of 165 patients (76\%). The results are presented in Table 6 . Hundred and forty-three of 1.65 patients $(87 \%)$ stated the same preferences on the willingness-to-pay and willingness to give up time instrument. For example, 27 patients were willing to pay a higher amount of money for CTA than for MRA. Of them, 20 patients also reported a higher time value for CTA. The resulting weighted Kappa value was 0.65 (SD $0.07 ; 95 \% \mathrm{CI}, 0.51$ to 0.78 ).

\section{Discussion}

In the current study we assessed patient preferences for diagnostic imaging modalities using the willingness-to-pay method and the willingness to give up time method. We analyzed the comparability of willingness-to-pay and willingness to give up time and the agreement between the answers to willingness-to-pay and willingness to give up time questions.

First, our results provided evidence for the comparability of willingness-to-pay and willingness to give up time. Overall, patients were willing to pay a higher amount of money for CTA than for MRA. However, in the subgroup of patients who stated a positive willingness-to-pay value, patients were indifferent between CTA and MRA. Likewise, patients were willing to give up more time for CTA as compared to MRA, although in the subgroup of patients who reported a positive willingness to give up time value, patients were indifferent between CTA and MRA. So, both methods revealed that patients preferred CTA to MRA in order to avoid DSA. Our results were in concordance with the scores on the visual analogue scales that reflected the experienced burden associated with each of the diagnostic imaging tests. We found that patients experienced CTA as the least bothersome and DSA as the most bothersome test (Table 1). Furthermore, our results were in accordance with an earlier study that determined 
Chapter 3

Table 4 Agreement between willingness-to-pay and willingness to give up time for CTA

\begin{tabular}{lllll}
\hline & Positive WTP & No preference & Preference DSA & Total \\
Positive WTGT & 161 & 1 & 1 & 163 \\
No preference & 3 & 4 & 0 & 7 \\
Preference DSA & 1 & 0 & 4 & 5 \\
Total & 165 & 5 & 5 & 175 \\
\hline
\end{tabular}

WTP: willingness-to-pay, WTGT: willingness to give up time; CTA: computed tomography angiography; DSA : digital subtraction angiography.

Table 5 Agreement between willingness-to-pay and willingness to give up time for MRA

\begin{tabular}{lllll} 
& Positive WTP & No preference & Preference DSA & Total \\
Positive WTGT & 1.42 & 0 & 1 & 143 \\
No preference & 3 & 5 & 0 & 8 \\
Preference DSA & 3 & 1 & 17 & 21 \\
Total & 148 & 6 & 18 & 172 \\
\hline
\end{tabular}

WTP: willingness-to-pay; WTGT: willingness to give up time; MRA: magnetic resonance angiography; DSA: digital subtraction angiography.

Table 6 Agreement between willingness-to-pay and willingness to give up time for the difference between CTA and MRA.

\begin{tabular}{|c|c|c|c|c|}
\hline & $\begin{array}{l}\text { WTGT CTA > } \\
\text { WTGT MRA }\end{array}$ & $\begin{array}{l}\text { WTGT CTA = } \\
\text { WTGT MRA }\end{array}$ & $\begin{array}{l}\text { WTGT CTA< } \\
\text { WTGT MRA }\end{array}$ & Total \\
\hline $\begin{array}{l}\text { WTP CTA > } \\
\text { WTP MRA }\end{array}$ & 20 & 7 & 0 & 27 \\
\hline $\begin{array}{l}\text { WTP CTA }= \\
\text { WTP MRA }\end{array}$ & 6 & 118 & 2 & 126 \\
\hline $\begin{array}{l}\text { WTP CTA < } \\
\text { WTP MRA }\end{array}$ & 0 & 7 & 5 & 12 \\
\hline Total & 26 & 132 & 7 & 165 \\
\hline
\end{tabular}
WTP: willingness-tompay; WTGT: willingness to give up time; CTA: computed tomography angiography;
MRA: magnetic resonance angiography. 
preferences for CTA, MRA and DSA in patients with symptomatic tight carotid stenosis [18]. The authors found that patients most preferred CTA, with DSA and MRA being equally less popular. Three studies comparing DSA with MRA reported a preference for MRA, in patients with peripheral vascular disease [19,20] and carotid artery disease [21].

A second finding of our study was that a vast majority of the answers to the willingness-to-pay questions was consistent with the willingness to give up time responses. The Kappa values ranged from 0.65 to 0.85 . Theoretically, the agreement between the responses to the willingness-to-pay questions and the willingness to give up time questions cannot be higher than the test-retest reliability of willingness-to-pay. In the published literature, test-retest reliability coefficients are reported ranging from 0.33 to $0.80[22,23,24,25]$. The time period between the test and the retest was two weeks in the study by Flowers et al. [23] with a reliabillity coefficient of 0.80 , and about one month in the remaining studies assessing the test-retest reliability of willingness-to-pay $[22,24,25]$ with coefficients ranging from 0.33 to 0.70 . In our study the time period between the willingness-to-pay and willingness to give up time questions was wery short since the patients answered to the willingness-to-pay and willingness to give up time questions during a single telephone interview that took approximately 20 minutes. Therefore, comparing our Kappa values with reliability coefficients from the literature seems somewhat unfair. Nevertheless, we conclude that the agreement between willingness-to-pay and willingness to give up time responses was high.

Johannesson [11] performed a study in which the feasibility of willingness-to-pay and willingness to give up time was tested in the area of lipid lowering Respondents with high lipid levels were asked to state their willingness-to-pay and willingness to give up time for a reduction of their lipid levels to normal. The correlation coefficient between willingness-to-pay and willingness to give up time was 0.64 and significant. In addition, the author found that willingness-to-pay and willingness to give up time questions seemed to be about equally acceptable to the respondents. Also, Barner et al. [12] reported a significant correlation $(\mathrm{p}<0.05)$ of 0.33 between willingness-to-pay and willingness to give up time.

Third, we found that, both for CTA and MRA, $12 \%$ of the patients were not willing to pay for reasons of principle, being protest answers. Visser [13] reported that about $20 \%$ of the patients were not willing to pay for any test no matter how small the amount. Patients giving a protest answer are characteristically not willing to pay any amount for any test. However, they may have a preference for a particular diagnostic imaging 


\section{Chapter 3}

modality but are not willing to pay for it, indicating that the willingness-to-pay instrument may not be a suitable preference measure for these patients. With respect to the willingness to give up time questions, only $2 \%$ of the patients gave a protest answer, which suggests that the willingness to give up time is an acceptable instrument. The high percentage of protest answers on the willingness-to-pay questions is probably related to the Dutch health care system with about $99 \%$ of the population being insured (StatLine Dutch Bureau of Statistics, 1995-2004). Furthermore, compared with other countries, the out of pocket expenses ( $6 \%$ of the total health care expenses) are low [26]. As a result, in the Netherlands, patients are not used to paying for health care interventions at the point of consumption. A second possible explanation is that money may be more value-laden than time, and consequently, patients may be resistant to paying for health care interventions out of their own pocket. Third, it can be speculated that patients may overlook the imaginary nature of the questions. In everyday life, health insurances actually reimburse the concerning diagnostic modalities. Therefore, patients may not understand the necessity to pay an out of pocket price. Indeed, the questions required a high degree of imagination and cognitive capabilities on the part of the patients. However, this was anticipated which is why we performed structured telephone interviews to guide patients through the questionnaire.

Fourth, we found that $77 \%$ of the patients stated the same willingness-to-pay for CTA as for MRA and 78\% stated the same time value for CTA as for MRA. This was a disappointing result, although not uncommon in the willingness-to-pay literature. To our knowledge, there is no literature available that discusses the discriminative ability of willingness to give up time questions. Of course, patients may have actually been indifferent between the imaging modalities. Also, patients may have preferred one of the diagnostic tests, however, their preference may not have been strong enough to pay more or give up more time for the preferred option. In addition, the nature of the health care intervention may have contributed to the results. The focus of the current study was on the intermediate outcomes of diagnostic imaging techniques. The effects of diagnostic testing on health status, in terms of survival and quality of life, were not made explicit in the questionnaire. It is expected that the willingness-to-pay method and willingness to give up time method will discriminate better when health care services with more pronounced effects on health status are valued. As a result, patients may have valued narrow policy options [7,8]. Donaldson et al. [9] referred to this phenomenon as valuing "close substitutes". 
A limitation of the present study was that patients who were not willing to pay since they preferred the modality that was covered by the health insurance (DSA) to the test that they had to pay for (CTA or MRA) could only choose a zero willingness-to-pay value. In fact, these patients might have stated a negative willingness-to-pay, i.e. willingness-to-accept. Therefore we may have overestimated willingness-to-pay for CTA and MRA as opposed to DSA. Similarly, patients who preferred DSA to CTA or MRA were assigned a zero time value, which nay have resulted in an overestimation of the willingness to give up time for CTA and MRA. Although this is not of major importance for the comparison between willingness-to-pay and willingness to give up time, for use in economic evaluation studies, the analysis may be biased towards CTA and MRA.

In practice, using the willingness-to-pay approach, the short-term procedure-related morbidity is thought of as a cost of that procedure, and it is assumed that the amount of money the patient is willing to pay to avoid the imaging modality represents the monetary cost corresponding to the discomfort the patient experienced. With respect to the willingness to give up time method, the amount of time the patient is willing to give up to avoid the imaging test represents the experienced disconfort. To carry out costeffectiveness analysis the time has to be converted to monetary units by using the opportunity costs of leisure time. Preferences determined with the willingness to give up time method, after conversion to monetary units; should be added to the cost of the imaging modality.

In conclusion, both the willingness-to-pay method and the willingness to give up time method revealed that patients preferred CTA to MRA in order to avoid DSA. AIso, the agreement between willingness-to-pay and willingness to give up time responses was high. The willingness-to-pay technique yielded relatively more protest answers as compared to the willingness to give up time technique, which raises questions with respect to the application of the willingness-to-pay method in a broad decision-making context. On the other hand, the strength of willingness-to-pay is that the method directly yields a monetary measure well founded in economic theory, whereas for use in an economic evaluation study, the willingness to give up time method requires conversion to monetary units. 


\section{References}

1. Torrance $\mathrm{GW}$. Measurement of health state utilities for economic appraisal. I Health Econ $1986 ; 5: 1.30$.

2. O'Brien B, Gafni A. When do the "dollars" make sense? Toward a conceptual framework for contingent valuation studies in health care. Med Decis Making 1996; 16. 288-299.

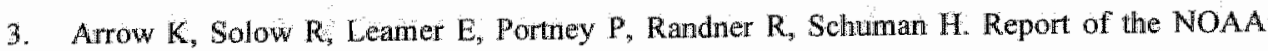
panel on contingent valuation. Fed Reg 1993; 58: 4602-46 14 .

4. O Brien $B$, Viranontes $\mathrm{J}$. Willingness to pay: a walid and reliable measure of health state preference. Med Decis Making 1994; 14: 289-297.

5. Blumenschein $K$, Johannesson $M$. Relationship between quality of life instruments, health state utilities, and willingness to pay in patients with asthma. Ann Allergy Asthma Immunol $1998 ; 80: 189-194$.

6. Zillich $\mathrm{AJ}$, Blumenschein $\mathrm{K}$, Johannesson $\mathrm{M}$, Freeman $\mathrm{P}$. Assessment of the relationship between measures of disease severity, quality of life, and willingness to pay in asthma. Pharmacoeconomics $2002 ; 20 ; 257-265$.

7. Donaldson $C$, shackley $P, A b d a l l a ~ M$, Miedzybrodzka $Z$. Willingness to pay for antenatal. carrier screening for cystic fibrosis. Health Econ 1995; 4: 439-452.

8. Ryan M, Ratcliffe J, Tucker J. Using willingness to pay to value altemative models of antenatal care. Soc Sci Med 1997; 44: 371-380.

9. Donaldson $C$, Shackley $P$, Abdalla M. Using willingness to pay to value close substitutes: carrier screening for cystic fibrosis revisited. Health Econ 1997; 6: 145-159.

10. Johannesson $\mathrm{M}$, Jonsson B. Economic evaluation in health care: Is there a role for costbenefit analysis? Health Policy 1991; 17; 1-23.

11. Johamesson M. Economic evatuation of lipid lowering - A feasibility test of the contingent valuation approwch. Health Policy 1992; 20:309-320.

12. Barner ${ }^{\mathrm{C}} \mathrm{C}, \mathrm{Mason} \mathrm{HL}$, Murray MD. Assessment of asthma patients' willingness to pay for" and give time to an asthma self-management progtam. Clin Ther 1999; $21: 878-894$.

13. Visser K. Patient preferences for MR angiography, Duplex US, and DSA in the work-up of peripheral arterial disease. Dissertation. Rotterdam, The Netherlands, 2001.

14. Kitney DD, Deutsch $\mathrm{L}$. The indications and results of percutaneous transhuminal angioplasty and stenting in renal artery stenosis. Semin Vase Surg 1996; 9: 188-197.

15. Working Group on Renovascular Hypertension. Detection, evaluation, and treatment of renovascular hypertension. Final report. Arch Intern Med 1987; 147: 820-829.

16. Vasbinder $G B C$, Nelemans PI, Kessels $A G H$, et al., for the Renal Artery Diagnostic Imaging Study in Hypertension (RADISH) Study Group. Accuracy of computed tomographic 
angiography and magnetic resonance angiography for diagnosing renal artery stenosis. Ann Intern Med 2004; 141: 674-682.

17. Blumenschein $\mathrm{K}$, Johannesson $\mathrm{M}$. Use of contingent valuation to place a monetary value on pharmacy services: An overview and review of the hiterature. Clin Ther 1999;21:14021417.

18. Patel SG, Collie DA, Wardlax JM, et al. Outcome, observer teliability, and patient preferences if CTA, MRA, or Doppler ultrasound were used, individually or together, instead of digital subtraction angiography before carotid endarterectomy. J Neurol Neurosurg Psychiatry $2002 ; 73: 21-28$.

19. Swan IS, Fryback DG, Lawrence WF, et al. MR and conventional angiography: work in progress toward assessing utility in radiology. Acad Radiol 1997; 4: 475-482.

20. Swan IS, Fryback DG, Lawrence WF, Sainfort $F_{3}$ Hagenauer ME, Heisey DM. A timetradeoff method for cost-effectiveness models applied to radiology. Med Decis Making $2000 ; 20: 79-88$.

21. U-King-Im JM, Trivedi R, Cross J, et al. Conventional digital subtraction x-ray angiography versus magnetic resonance angiography in the evaluation of carotid disease: patient satisfaction and preferences. Clin Radiol 2004; 59:358-363.

22. O'Brien $B$, Viramontes $\mathrm{J}$. Willingness to pay: a valid and reliable measure of health state preference? Med Decis Making 1994; 14: 289-297.

23. Flowers CR Garber AM, Bergen MR, Lenert LA. Willingness-to-pay utility assessment: feasibility of use in normative patient decision support systems. Proc AMIA Amn Fall Symp 1997: 223-227.

24. Dong $H$, Kouyate $B$, Cairns $J$, Sauerborn $\mathbb{R}$. A comparison of the reliability of the take-it-orleave-it and the bidding game approaches to estimating willingness-to-pay in an rural population in West Africa. Soc Sci Med 2003; 56:2181-2189.

25. Onwujekwe $\mathrm{O}$, Fox-Rushby $\mathbb{I}$, Hanson $\mathrm{K}$. Inter-rater and test-retest reliability of three contingent valuation question formats in south-east Nigeria. Health Econ 2005; 14:529-536.

26. Raad woor de Volksgezondheid en Zorg (Council for Public Health and Health Care). Exploderende zorguitgaven: signalement over uitgavenmanagement. Sig 03/01. Zoetermeer, the Netherlands, 2003. 



\section{Chapter 4}

\section{Between best and worst: trading levels in conjoint analysis}

C.D. Dirksen, D. van Helvoort-Postulart, J. Ouwersloot, J.M.A. van Engelshoven, J.D.P. Kasper 
Chapter 4

\section{Abstract \\ Objectives}

Discrete choice experiments are increasingly being used in health care to estimate willingness-to-pay. This means that a cost-attribute should be included. An important criterion is that levels are subject to trading decisions. A systematic approach is proposed for deciding on the levels for the cost-attribute.

\section{Methods}

The proposed method was applied to diagnostic imaging tests. A random sample of members of the general population was asked to compose the most and least attractive diagnostic test and to report maximum willingness-to-pay for the most and least attractive alternative. This revealed the respondents" consideration sets and maximum individual intervals. Using this information, three rules (MAX, MEAN and MIN) were applied to determine the range and to determine the interval for the cost-attribute. Based on the resulting range and interval, the levels subsequently derived. The rules were assessed against the criterion of levels being subject to trading decisions.

\section{Results}

The MEAN-rule was the preferred rule, both to determine the range and to determine the interval. Thus, combining the MEAN-rule for the range with the MEAN-rule for the interval yielded the optimal solution with respect to levels being subject to trading decisions. Nevertheless, even this optimal solution would provoke only a small proportion of respondents to make trade-offs.

\section{Conclusions}

The proposed method contributes to the discussion of optimal experimental design. Further research should indicate whether the method is valid and practically applicable. 


\section{Introduction}

Conjoint analysis is a technique to measure preferences for products and services and is increasingly being used in the health care sector [1-7]. Conjoint analysis is based on the assumption that complex decisions, including purchase decisions, are not based on a single criterion, but on several factors considered jointly [8]. It is a technique in which respondents' utilities or valuations of product attributes are inferred from the preference they express for various combinations of these product attributes [9]. In a typical conjoint analysis study individuals are presented with hypothetical scenarios involving different levels of attributes that have been defined as important in the provision of a product or service. Preferences for these hypothetical scenarios are obtained using rating, ranking or choice exercises.

The discrete choice method of conjoint analysis most closely resembles actual decision-making, is based on random utility theory [10] and is therefore the preferred elicitation method. In discrete choice experiments respondents are presented with a series of pairs of scenarios and, for each pair, are asked to choose which they prefer: With results from a discrete choice experiment information is provided with respect to the (relative) importance of a given attribute, the rate at which individuals are willing to trade between attributes and overall benefit scores for alternative scenarios. In a typical stated preference survey, five stages can be identified: (1) determination of the attributes, (2) assigning levels to the attributes, (3) construction of the choice sets by combining the attribute levels in each of the alternatives, (4) collection of responses, and (5) analysis of data [3]. In this paper we focus on the second stage.

Discrete choice experiments are increasingly being used in health care to estimate willingness-to-pay. In that case a cost-attribute should be included and levels should be assigned to it. There is a considerable variety with respect to how the levels for the costattribute are determined. In some papers, the levels for the cost-attribute are not explained $[2,11,12]$. Others have set the levels for the cost-attribute in a pilot stuidy $[1,6,13,14]$. Some researchers have determined the levels for the cost-attribute on the basis of actual costs $[7,15]$. It has been argued that efforts should be made in defining techniques for establishing the most appropriate levels for the cost-attribute [5,16]. To obtain valid willingness-to-pay estimates from discrete choice experiments, i.e. providing correct estimates of changes in utility, an important criterion is that levels are assigned so that individuals are willing to trade between the cost-attribute and other attributes of interest. In this paper, a method is explored to determine the levels of the cost-attribute for use in a discrete choice experiment. This method aims to avoid non- 
trading behaviour in a discrete choice experiment related to the chosen range and interval for the cost-attribute.

\section{Theoretical background}

\section{Compensatory and non-compensatory decision-making}

An important assumption in random utility theory is that individuals are willing and able to trade-off characteristics when making their discrete choices. This assumption is based on the axiom of continuity. The decision-making process involving different attribuites to be traded against each other is referred to as compensatory decisionmaking.

Empirical studies have shown that it is not uncommon that subjects violate the continuity axiom and adopt non-compensatory decision-making strategies, including lexicographic preferences, target setting and dominance [11,15,17-19]. Scott [17] has given a summary of non-compensatory decision-making. At the one extreme of noncompensatory decision-making are strict Jexicographic preferences, indicating that an absolute order of preferences exists, which precludes any degree of substitution. Dominance is described as a special case of lexicographic preferences. Only one attribute is examined, and when the level of the dominant attribute is the same in both alternatives, the others may still be traded off. Somewhere in between a perfect compensatory model and a strict lexicographic ordering lies target setting behaviour based on using thresholds. Target setting behaviour allows for some substitution and operates by an individual setting a target for the most important attribute and this target must be reached before the second most important attribute is considered.

In addition, it is argued that another type of non-compensating behaviour can be distinguished, namely inferiority. In that case an attribute is (partly) ignored, and any deterioration (or to a particular threshold level) of that attribute is accepted because not yielding any or enough disutility to enforce trading. Hence, the attribute is considered (partly) inferior.

Choices that are consistent with the compensatory decision-making model imply that individuals will accept more of one attribute (e.g. higher survival rate) in compensation for a reduction in income. So, in order to obtain correct willingness-topay estimates, an attempt should be made to reduce violation of the continuity axiom. 


\section{Reasons for non-compensatory decision-making}

With respect to the reasons of non-compensatory decision-making, a distinetion can be made between internal and external factors [20]. Internal contexts can motivate individuals' values based on strength of their beliefs, attitudes or dispositions toward the object of valuation, of which the most common is the rights-based view of choice and an ethical belief that individuals should be provided with a specific characteristic [21]. Also the concept of bounded rationality may be internally driven, meaning that individuals do not have the cognitive capacity to process multi-attribute information and make use of heuristics or rules of thumb [22].

External factors are related to the (complexity of a) decision task. This is also referred to as a framing effect, which suggests that how something is presented (the "frame") influences the choices people make [23]. For example, non-trading behaviour may emerge because individuals have preferences that are outside the range offered in an experiment [19]. Also, the interval between levels may be too large or too small. Too large an interval may result in a dominant preference for the cost-attribute, where individuals are not prepared to trade-off money, and always choose the scenario with the lowest level for the cost-attribute [17,24]. Too small an interval may have the consequence that individuals do not consider the difference between the levels to be important [1.7].

The method proposed in this paper focuses on avoiding non-trading behaviour due to framing effects, related to the chosen range and interval for the cost-attribute.

\section{Clinical setting}

Renal artery stenosis may cause hypertension and renal disease. The prevalence of renal artery stenosis varies from $3 \%-10 \%$ in a general hypertensive population to $20 \%-40 \%$ in patients with clinical characteristics suggestive of renal artery stenosis. To prevent patients from developing cardiovascular complications and deterioration of renal function, it is important to detect and subsequently treat renal artery stenosis. Digital subtraction angiography (DSA) is considered the reference standard for detecting renal artery stenosis, but has a risk of morbidity and mortality. Currently, magnetic resonance angiography (MRA) and computed tomography angiography (CTA) are available for the diagnostic work-up of patients suspected of having renal artery stenosis. Both MRA and CTA are relatively non-invasive procedures. 


\section{Description of the method}

\section{Considerations and assumptions}

In a discrete choice experment with $n$ attributes and $l$ levels, $t$ combinations can be made. From an individual perspective, these will vary from the least attractive combination to the most attractive combination. In most conjoint analysis studies the number of possible scenarios is too high to present them all in a full factorial design, given the individuals" cognitive limitations and time constraints. Therefore, mostly fractional factorial designs are used in which the number of scenarios is reduced to a manageable level while still being able to estimate the model:

Two assumptions were made. First, from an individual perspective, the levels for the cost-attribute in a discrete choice experiment should be equal to or in between the individual's willingness to pay for the least attractive alternative and the willingness to pay for the most attractive alternative in order for the cost-attribute to become subject to trading decisions. Consequently, it was assumed that the individual's maximum absolute willingness to pay for any other scenario should be equal to or in between both stated extremes, in this paper referred to as the individual's "consideration set". Second, it was assumed that the difference between the lowest and highest willingness-to-pay value of the indiwidual's consideration set represents the maximum marginal willingness-to-pay in moving from the worst scenario to the best scenario, in this paper referred to as the "individual interval". Consequently, an individual should be willing to trade between alternatives provided that the interval between levels for the cost-attribute does not exceed the individual interval.

From an individual perspective, a discrete choice experiment would be optimal with respect to the cost-attribute if the range for the cost-attribute coincides with or lies within that individual"s consideration set. In this special case the interval between the levels is always equal to or smaller than the "individual interval". Theoretically this situation is possible if all respondents express equal willingness-to-pay values for the worst and best option. However, in real world this will probably never be the case. Therefore, we propose a method to determine the levels for the cost-attribute in such a way that they match the consideration sets of as many as possible respondents.

\section{Procedure}

The method consists of six steps: (1) obtaining individual willingness-to-pay values for the worst and best alternative, (2) determination of the range for the cost-attribute, i.e. the lowest and highest level, (3) determination of the interval between the levels, (4) 
calculation of the levels, (5) comparison with consideration sets and individual intervals, and (6) choice of the ultimate levels for the cost-attribute. Three rules are applied to determine the range and interval, referred to as the MAX-rule, MEAN-rule and MTN-rule:

(1) Obtaining individual willingness-to-pay values

Individual willingness-to-pay values for the least attractive and most attractive diagnostic test are obtained by a questionnaire, which is described in the section "Data collection and analysis".

(2) Determination of range

MAX-rule: the range for the cost-attribute is based on the lowest observed willingness-to-pay for the least attractive test and the highest observed willingnessto-pay for the most attractive test. ${ }^{2}$ This rule leads to the widest possible range, referred to as $\mathrm{MAX}_{\mathrm{R}}$.

MEAN-rule: the range is based on the mean willingness-to-pay of the least attractive test and the mean willingness-to-pay of the most attractive test, referred to as $M \mathrm{MEN}_{\mathrm{R}}$.

MIN-rule: the range is based on the highest observed willingness-to-pay for the least attractive test and the lowest observed willingness-to-pay for the most attractive test, referred to as $\mathrm{MDN}_{\mathrm{R}}$. This rule leads to the smallest possible range and can only be used provided that the lowest observed willingness-to-pay for the most attractive test is higher than the highest observed willingness-to-pay for the least attractive test.

(3) Determination of the interval

MAX-rule: the interval between the levels is equal to the largest individual interval, referred to as $\mathrm{MAX}_{1}$.

MEAN-rule: the interval is equal to the mean of the individual intervals, referred to as MEAN.

MIN-rule: the interval between the levels is equal to the smallest individual interval, referred to as $\mathrm{MIN}_{\mathrm{I}}$, which can only be determined provided that the smallest individual interval is greater than zero.

(4) Calculation of the levels

Based on the ranges and intervals, the levels are derived. At most six solutions for calculation of the levels are possible $\mathrm{MAX}_{\mathbb{R}^{-}}-\mathrm{MAX}_{1}, \mathrm{MAX}_{\mathrm{R}^{-}}-\mathrm{MEAN}_{1}, \mathrm{MAX}_{\mathrm{R}^{-}}$

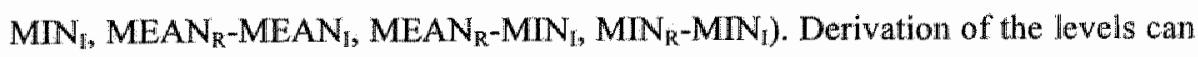


best be ilfustrated with wo examples. First, suppose a range of $e 5$ to $e 55$ and an interval of $€ 25$. This would result in the following levels: $€ 5, € 30$ and $€ 55$, which is calculated by using the following formula: (range / interval) $-1=50 / 25-1=1$. The outcome of the calculation is the number of intermediate levels that is required to arrive at an appropriate interval between the levels. The specific levels are determined by adding the interval to the lowest level of the range, and so on, to the highest level of the range. Second; suppose a range from $€ 10$ to $€ 45$ and an interval of 225 . The number of intermediate levels is 0.4 , which should be rounded up in order not to exceed the interval, thus resulting in one intermediate level. This would result in the following levels: $€ 10, € 35$ and $€ 60$, hence exceeding the highest level of the range. In order to prevent this, the interval should be recalculated. One intermediate level means two equal definite intervals of $(45-10) / 2=17.5$. Thus the levels are: $€ 10, \epsilon 27.50$ and $€ 45$.

(5) Comparison with consideration sets and individual intervals Table I provides a classification of possible trading and non-trading behaviour due to range and interval effects. The proportion of respondents within each category is determined as follows. First, for each rule the range is compared with the individual consideration sets. Second, for each rule the definite interval is compared with the individual intervals.

(6) Choice of ultimate levels for the cost-attribute

The optimal solution with respect to the levels for the cost-attribute is defined as the combination of the optimal rule for the range and the optimal rule for the interval.

\section{Practical application}

The proposed method is designed to serve as a pre-study for a discrete choice experiment. This pre-study is performed in a representative sample of a specified target population, for example patients, students or members of the general population. The ultimate levels resulting from the pre-study are to be used in a non-adaptive discrete choice experiment. In the discrete choice experiment another representative sample from the same target population as used in the pre-study should be taken.

\section{Data collection and analysis}

A questionnaire was developed which consisted of four parts (available in Dutch). In the first part information was provided with respect to hypertension and renal artery 
Table 1 Effects of range and interval on (non-) trading

\begin{tabular}{|c|c|}
\hline Range & Effect \\
\hline $\mathrm{R}<\mathrm{CS}$ & All $(22)$ levels inferior (attribute fully inferior) \\
\hline $\mathrm{R} \leq \mathrm{CS}$ & $\geq 1$ lewel inferior (target setting) \\
\hline $\mathrm{R}=\mathrm{CS}$ & Optimal trading \\
\hline $\mathrm{CS}<\mathbb{R}<\mathrm{CS}$ & $\geq 1$ lewel inferior (target setting) $A N D \geq 1$ level dominant (target setting) \\
\hline $\mathbb{R} \geq \operatorname{CS}$ & $\geq 1$ level dominant (target setting) \\
\hline $\mathrm{R}>\mathrm{CS}$ & All $(22)$ levels dominant (attribute fully dominant) \\
\hline Interval & Effect \\
\hline $\begin{array}{l}\text { Interval > individual interval } \\
\text { Interval } \leq \text { individual interval }\end{array}$ & $\begin{array}{l}\text { Attribute fully cominant } \\
\text { Optimal trading }\end{array}$ \\
\hline
\end{tabular}

$\mathbb{R}<C S$ : range fully below lower bound of consideration set; $R \leq C S$ : range partly" below lower bound of consideration set $\mathrm{R}=\mathrm{CS}$ : range coincides with or is within consideration set; $\mathrm{CS}<\mathrm{R}<\mathrm{CS}$; range betow lower AND beyond upper bound of consideration set; $R \geq C S$ : range partly beyond upper bound of consideration set; $\mathrm{R}>\mathrm{CS}$ : range fully beyond upper bound of considemtion set.

"This study does not provide incomation about the snallest interval that should be used in the experiment in order to prevent that the interval becomes too small (and thus potentially inferior).

"Partly is defined as at least one level of the range.

stenosis. In part 2 the selected attributes and levels of the diagnostic tests were presented and explained. The relevant attributes and levels, which are presented in Table 2 , were determined by means of expert opinion and results of a prospective clinicall trial [25]. In part 3 respondents were asked to compose the most attractive diagnostic test by determining the most preferred level for each of the attributes (question 1). Then respondents were asked if they would take a supplementary private insurance for the most attractive test (question 2). The alternative option was that the respondent had to pay the full price of the diagnostic test at the point of consumption. In order to avoid strategic behaviour; no information was provided with respect to the "real world" costs of diagnostic imaging techniques. If respondents were willing to take a supplementary private insurance they were asked to state their maximum willingiess to pay, expressed as a monthly insurance prenium (question 3). Questions 1-3 were repeated with respect to the least attractive diagnostic test. The open-ended willingnesisto-pay technique was used. In accordance with the Dutch health care financing system, the "ex-ante insurance-based" perspective was chosen as the payment vehicle. In this approach persons at risk for a disease, and therefore at risk of consuming the health care program, are asked to state their willingness to pay as an insurance premium to have the program available $[26,27]$. In part 4 of the questionnaire respondents were asked to provide some demographic and socio-economic information.

Data were gathered using telephone interviews. A random sample from residents of the Heuvelland region (adherence of university hospital Mastricht) received an 
Chapter 4

Table 2 Atributes and levels of the diagnostic imaging techriques

\begin{tabular}{|c|c|c|c|}
\hline Atuibutes & Levels & Leasil preferred & Most preferred \\
\hline \multirow[t]{3}{*}{ Sensitivity } & $50 \%$ & 48 & 0 \\
\hline & $85 \%$ & 4 & 0 \\
\hline & $100 \%$ & 0 & 52 \\
\hline \multirow[t]{2}{*}{ Hospital stay } & One overnght stay & 39 & 13 \\
\hline & Return home same day & 13 & 39 \\
\hline \multirow{2}{*}{ Access to blood vessel } & Artery in groin area & 51 & 1 \\
\hline & Blood vessel in arm & 1 & 51 \\
\hline \multirow{2}{*}{ Radiation } & $X$-ray & 48 & 4 \\
\hline & Magnetic & 4 & 48 \\
\hline \multirow{2}{*}{ Risk of death } & $0.1 \%$ & 52 & 0 \\
\hline & No risk & 0 & 52 \\
\hline \multirow[t]{2}{*}{ Risk of complications } & $1 \%$ & 52 & 0 \\
\hline & Norisk & 0 & 52 \\
\hline \multirow[t]{2}{*}{ Space surrounding the patient } & Tunnel & 50 & 2 \\
\hline & Open space & 2 & 50 \\
\hline
\end{tabular}

"Respondents $(\mathrm{N}=52)$ indicating each of the levels as leasi preferred or most preferred.

information letter to explain the aim of the study. Following the letter residents were called to give informed consent. After setting a date and time for the telephone interview, the questionnaire was sent to the respondents (i.e. those who gave informed consent). Respondents were instructed to read the questionnaire before the interview took place. Mean willingness-to-pay, standard deviations and ranges were calculated using SPSS statistical software package, version 10.0. Willingness-to-pay results are presented in Euros.

\section{Results}

\section{Response}

Hundred and ten informative letters were sent to a random sample of residents from the Heuvelland region. Ninety-three residents $(84.5 \%)$ could be contacted by telephone. Three residents were not eligible for the study due to language problems. Sixty-eight residents $(61.8 \%)$ agreed to participate in the study, of which 12 withdrew at the time of the telephone interview. The interview was held with 56 respondents $(50.9 \%)$, of which $22(39.3 \%$ ) were men. Mean age was 53.5 (SD 16.4) for men and 50.7 (SD 16.4) for women.

\section{Application of the method}

(1) Obtaining individual willingness-to-pay values

Four respondents were not able to compose their most and least attractive test. These respondents were excluded from further analysis. Fifty-two respondents 
Table 3 Individual willingness-to-pay results

\begin{tabular}{lll}
\hline Respondent & Least attractive test & Most atractive test \\
\hline 1 & 0.7 & 0.7 \\
2 & 0.9 & 4.5 \\
3 & 1.1 & 2.3 \\
4,5 & 2.3 & 2.3 \\
6 & 2.3 & 4.5 \\
7 & 2.3 & 5.7 \\
$8,9,10$ & 4.5 & 4.5 \\
11 & 4.5 & 9.1 \\
12 & 6.8 & 6.8 \\
13 & 6.8 & 11.3 \\
14 & 6.8 & 18.2 \\
$15,16,17,18,19$ & 11.3 & 11.3 \\
20 & 13.6 & 22.7 \\
21 & 20.4 & 20.4 \\
$22,23,24,25$ & 22.7 & 22.7 \\
\hline
\end{tabular}

Results are arranged from low to high according to the values for the least attractive test.

were able to indicate the least and most preferred level for each attribute (Table 2). Forty-one $(78.8 \%)$ respondents were willing to take a supplementary private insurance for their most attractive test, 29 of them (55.7\%) also took a supplementary private insurance for their least attractive test. Of 41 respondents who were willing to take a supplementary private insurance for the most attractive test, 37 respondents $(90.2 \%)$ stated a willingness-to-pay value. Of 29 respondents who were willing to take a supplementary private insurance for the least attractive test, 26 respondents $(89.6 \%)$ stated a willingness-to-pay value. Two respondents stated extremely high willingness-to-pay values; one respondent stated a willingness-to-pay of 990.76 for both the most and least attractive test, and another respondent stated a willingness-to-pay of $€ 136.13$ for the most attractive test. These willingness-to-pay values were more than three standard deviations from the mean willingness-to-pay, and therefore the two respondents were excluded from further analysis (outliers), resulting in respectively 35 and 25 respondents in the analysis. Twenty-five respondents were willing to pay for both their most and least attractive test. Since this study was performed in the context of a supplementary private insurance, only these 25 respondents were included for further analysis. For each respondent, willingness-to-pay results are presented in Table 3. For the most attractive test, willingness-to-pay ranged from 60.7 to $€ 22.7$, with a mean willingness-to-pay of $€ 10.9$ (SD 7.7). For the least attractive test, willingness-topay also ranged from 60.7 tot $€ 22.7$, with a mean willingness-to-pay of 69.3 (SD 7.6). Seventeen $(68 \%)$ respondents stated the same willingness-to-pay for the most 
and least attractive diagnostic test (mean $E 11.3 ; \mathrm{SD} 8.0$ ). In these cases the individual interwal was zero. The other $8(32 \%)$ respondents stated a mean willingness-to-pay of 69.8 (SD 7.2) for the most attractive test and a mean willingness-to-pay of 64.8 (SD 4.8) for the least attractive test.

(2) Determination of the range

$\mathrm{MAX}_{\mathrm{R}}$ ranged from $e 0.7$ to 622.7 and $\mathrm{MEAN}$ ranged from 69.3 to $610.9 . \mathrm{MN}_{\mathrm{R}}$ could not be detemined, because the lowest observed willingness-to-pay for the most attractive test (60.7) was lower than the highest observed willingness-to-pay for the least attractive test ( $E 22.7$ ), resulting in a "megative" range.

(3) Determination of the interval

MAX, was 11.3, MEAN was 1.6, and MIN, was 0 . The latter interval cannot be applied.

(4) Calculation of the levels

Results are presented in Table 4. Three solutions could be calculated, using the $M A X_{R}-M_{1}, M_{\mathbb{R}}-\mathrm{MEAN}_{1}$ and $M \mathrm{MEN}_{\mathbb{R}}-\mathrm{MEAN}_{1}$ combinations.

(5) Comparison with consideration sets

MAX $X_{R}$ for all respondents $(100 \%)$ at least one level in the experiment would be dominant or inferior, as none of the respondents fell into the category where the range coincides with or is within the consideration set (Table 5).

MEANR: for $92 \%$ of the respondents at least one level would be dominant or inferior. Consequently, the MEAN-rule is the preferred rule to determine the range. $\mathrm{MAX}_{1}$ : cost-attribute would be fully dominant for $96 \%$ of respondents.

MEAN : cost-attribute would be fully dominant for $72 \%$ of respondents. Consequently, the MEAN-rule is the preferred rule to determine the interval.

(6) Choice of ultimate levels for the cost-attribute

Combining MEAN $\mathrm{N}_{\mathrm{R}}$ with MEAN yielded the optimal solution with respect to the levels for the cost-attribute.

\section{Discussion}

To our knowledge, this is the first study exploring a method to set the levels for the cost-attribute in a non-adaptive discrete choice experiment in such a way that they be subject to trading decisions. Application of the method provided information about respondents' consideration sets. Using this information, three rules were formulated to determine the range and interval, and these rules were assessed against the criterion of levels being subject to trading decisions. Combining the MEAN-rule for the range with 
Table 4 Calculation of the levels

\begin{tabular}{|c|c|c|c|}
\hline & $\mathrm{MAX}_{3}: 11.3$ & MEAN: 1.6 & $\mathrm{MNN}_{\mathrm{B}}: 0$ \\
\hline $\begin{array}{l}\text { MAX: } 0.7-22.7 \\
\text { Number of intermediate levels } \\
\text { Definite interval }\end{array}$ & $\begin{array}{l}\mathbb{1}^{*} \\
\| 1\end{array}$ & $\begin{array}{l}13^{*} \\
1.57\end{array}$ & $\mathrm{~N} / \mathrm{k}$ \\
\hline $\begin{array}{l}\text { MEAN }: 9.3-10.9 \\
\text { Number of intermediate levels } \\
\text { Defhite interwal }\end{array}$ & $\mathrm{N} / \mathrm{p}$ & $\begin{array}{l}0^{\text {族 }} \\
1.6\end{array}$ & Nip \\
\hline $\mathrm{MIN}_{\mathrm{R}}: 22.7-0.7$ & $\mathrm{~N} / \mathrm{p}$ & $\mathrm{N} / \mathrm{p}$ & $N_{p}$ \\
\hline
\end{tabular}

N/a not applicable; $\mathrm{N} / \mathrm{p}$; not possible

Specinclewels: $0.7 ; 11.7 ; 22.7$

Specific levels: $0.7 ; 2.3 ; 3.8 ; 5.4 ; 7.0 ; 8.6 ; 10.1 ; 11.7 ; 13.3 ; 14.8 ; 16.4 ; 18.0 ; 19.6 ; 21.1 ; 22.7$

Specinc lewets: $9.3 ; 10.9$

Combining MEAN with MEAN will always result in zero intermediate levels.

Table 5 Comparison with consideration sets

\begin{tabular}{|c|c|c|}
\hline Range & $\mathrm{MAX}_{\mathrm{R}}$ & MEAN \\
\hline$R<\mathrm{CS}$ & $\mathrm{N} / \mathrm{p}$ & $11(44 \%)$ \\
\hline $\mathrm{R} \leq \mathrm{CS}$ & $5(20 \%)$ & $\mathrm{N} / \mathrm{p}$ \\
\hline $\mathbb{R}=\mathrm{CS}$ & $0(0 \%)$ & $2(8 \%)$ \\
\hline $\mathrm{CS}<\mathrm{R}<\mathrm{CS}$ & $19(76 \%)$ & $N / p$ \\
\hline$R \geq \operatorname{CS}$ & $1(4 \%)$ & $N / p$ \\
\hline $\mathrm{R}>\mathrm{CS}$ & N/p & $12(48 \%)$ \\
\hline Total & $25(100 \%)$ & $25(100 \%)$ \\
\hline Interval & $\mathrm{MAX}_{1}$ & MEAN \\
\hline Interval > individual interval & $24(96 \%)$ & $18(72 \%)$ \\
\hline Interval $\leq$ individual interval & $14 \%)$ & $7(18 \%)$ \\
\hline Total & $25(100 \%)$ & $25(100 \%)$ \\
\hline
\end{tabular}

No: not possible.

$\mathrm{R}<\mathrm{CS}$ : nange fully below lower bound of consideration set; $\mathrm{R} \leq \mathrm{CS}$ : range party below lower bound of consideration set; $\mathrm{R}=\mathrm{CS}$ : range coincides with or ts within consideration set; CS $<\mathrm{R}$ < CS: range below lower AND boyond upper bound of considenation set; $R \geq$ CS: range party beyond appen bouril of consideration set; $\mathrm{K}>\mathrm{CS}$ : range whlly beyond upper bound of consideration set.

"Party is defined as at least one level of the range.

the MEAN-rule for the interval yielded the optimal solution with respect to levels being subject to trading decisions.

A major finding of the study was that application of the method led to a high proportion of respondents for whom at least one level would be outside the consideration set, irrespective of which rule was used for determination of the range. Also, both the MAX-rule and MEAN-rule resulted in an interwal between the levels being too large for most respondents. These findings were mainly caused by the fact 
that $68 \%$ of the respondents did not discriminate between the worst and best diagnostic imaging test. These respondents with an individual interval of zero actually provided only one value, so each level in a discrete choice experiment higher or lower than that particular value would become dominant or inferior. The problem of non-discriminating willingness-to-pay values is well known in studies that ask individuals to perform multiple valuation tasks [28-31]. Although individuals may prefer one of the alternatives, this does not always result in higher willingness-to-pay values. This is especially true for health care commodities that are quite similar, allso referred to as "narrow policy options" or "close substitutes" [28-30]. However, in this study it was a worrying finding, since it was expected that a maximum preference contrast, by asking respondents to explicitly define their least and most attractive test, would result in differential willingness-to-pay values. Future research with respect to the proposed method should focus on more discriminative health care commodities and maybe some "warm up" exercises would help respondents in understanding the willingness-to-pay principle.

This study also has some limitations that should be discussed. First, in the proposed method the willingness-to-pay values for the worst and best diagnostic imaging test that could be conposed of the given attributes and levels, were used as basis in setting the levels for the cost-attribute. From an individual perspective it can be argued that actually using these willingness-to-pay values in the range may cause the highest level to become dominant and the lowest level to become inferior, because the worst and best alternative will possibly not occur in the experiment. Although this argument may well be true, according to our assumptions, levels lower than the maximum willingness-topay value for the worst diagnostic imaging test should be inferior, levels higher than the maximum willingness-to-pay for the best diagnostic imaging test should be dominant, whereas levels equal to or in between the extreme values create possibilities for trading. The same applies to the interval. An interval larger than the individual interval was assumed to result in the cost-attribute becoming fully dominant. Again, from an individual perspective it can be argued that the cost-attribute will also be fully dominant when the interval is equal to the individual interval, as the latter represents the maximum marginal willingness-to-pay in moving from the worst to the best alternative. Nevertheless, according to our assumptions a larger interval should lead to dominance, whereas an interval equal to or smaller than the individual interval creates possibilities for trading. Second, due to the small sample size one can argue that the results from this study were not valid. Although hundred and ten people were invited to participate in the 
study, only twenty-five respondents were included in the final analysis. By using a small sample, the validity of our results can be questioned. However, this does not compromise application of the method per se. Nevertheless, future research with respect to the proposed method would benefit from using a greater sample size. Finally, the fact that open-ended willingness-to-pay questions were used might be considered as a limitation of this study, as it is argued that this approach leads to biased and erratic results, and a large number of protest answers [32]. Therefore, several closed-ended elicitation methods have been introduced, like payment cards, bidding games and discrete choice questions $[27,33]$. However, these methods may be subject to starting point and range bias, although studies on this matter are not conclusive $[34,35]$. In this study, open-ended willingness-to-pay questions were used in order not to constrain the range a priori. An additional argument in favour of the open-ended method was that results were intended to determine the levels for the cost-attribute and not for analysis of stated preferences. Other studies have also applied a comparable open-ended willingness-to-pay elicitation method in order to establish the bid vector for the willingness-to-pay study [36,37].

Apart from the requirement that levels should be subject to trading decisions, another frequently mentioned statement in conjoint analysis is that levels should be realistic $[3,6,11,17]$, which means that they should reflect what might happen in the real world. When once-only payments are used as the payment vehicle, levels for the costattribute can be considered as realistic by including the actual costs of the commodity. However, using an insurance-based perspective the real costs of the diagnostic imaging techniques are not relevant for determination of the levels. So, using willingness-to-pay to determine the levels seemed appropriate here. However, this leaves the question whether the willingness-to-pay values obtained with the method are realistic. In this study a considerable number of respondents stated high willingness-to-pay values, compared to their monthly health care insurance premium. Possibly, respondents may not have fully understood the insurance-based context. Once-only payments confront respondents immediately with the opportunity costs, whereas the (long-term) consequences of a supplementary monthly health insurance premium may be less obvious. On the other hand, when using willingness-to-pay in a cost-benefit framework a decision-maker is interested in consumer surplus, and the main objective is to investigate whether respondents' willingness to pay exceeds actual costs. Following this line of reasoning, high willingness-to-pay values indicate a strong preference and should be considered as realistic. Some researchers have stated that levels for the cost-attribute 
should include some extreme values to be able to estimate maximum willingness-lo-pay $[5,38]$.

Another statement is that each attribute in a discrete choice experiment should have a comparable number of levels [8]. Research shows that, while holding the range constant, manipulating the number of attribute levels has an autonomous effect on the estimated importance of that attribute $[39,40]$. This suggests that increasing the number of (intermediate) levels may increase the attention given to the attribute, which increases its subjective importance. So, this might be an important additional argument, besides the requirement that levels should be subject to trading decisions. Our study yielded two levels to be implemented in a discrete choice experiment, which is comparable with the number of levels for the other attributes.

We implicitly assumed that range and interval act independently of each other. However is not clear for example to what extent the range for the cost-attribute still matters when the interval between the levels is too large. In other words, maybe a respondent is willing to trade-off options with price levels beyond the consideration set, provided that the interval between the levels is perceived as acceptable. Future research with respect to the cost-attribute should focus on how respondents actually combine range and interval information an their trading decisions.

To determine the validity of the method the first step would be to investigate the assumptions underlying the method. The assumptions were (1) from an individual perspective, the levels for the cost-attribute in a discrete choice experiment should be within the individual's consideration set, and (2) an individual should be willing to trade between alternatives provided that the interval between levels for the cost-attribute does not exceed the individual interval. To test these assumptions the individual willingnessto-pay values (step 1) should be inplemented directly as "individual" levels for the cost-attribute in a discrete choice experiment. The finding that respondents actually make trade-offs would provide evidence for the validity of the assumptions. On the other hand, using values beyond or below the individual's consideration set should result in non-trading behaviour. Only if the assumptions prove to be valid, a next step would be to implement the resulting levels (step 6) in a discrete cholce experiment, and investigate to what extent the cost-atribute is subject to trading. The final goal is to use the method in practice to set the levels for the cost-attribute, and to implement the resulting levels in a discrete choice experiment.

In this study the proposed method was designed to serve as a pre-study for a nonadaptive discrete choice experiment. Alternatively, the search for levels being subject to 
trading decisions could also be done by means of an adaptive approach, which was recently explored by Caims and Van der Pol [41]. Although this may be a more flexible tool to establish the appropriate levels, it requires a computer-based approach and the design may become unbalanced.

In conclusion, the proposed method can be used to determine the levels for the costattribute in such a way that they be subject to trading. However, in this study, even the optimal solution would provoke only a small proportion of respondents to make tradeoffs. Further research should prove whether the method is valid and has any practical walue in the design phase of a discrete choice experiment. Also interaction between range and interval effects on trading behaviour should be further investigated. Future research would benefit from using larger sample sizes, applying the once-only payment vehicle and investigating more discriminative health care alternatives.

\section{Notes}

1. These three rulles are not exhaustive, but merely intended to provide a direction for researchers in finding the appropriate levels for the cost-attribute. For example, in this study the mean is used as a measure of centrality. However, researchers may also use the median vallue. Also, instead of the minimum and maximum, other measures may be suitable (e.g. mean \pm 2 standard deviations, $10^{\text {th }}$ and $90^{\text {th }}$ percentille).

2. The least attractive and most attractive diagnostic test varies among individual respondents. However, for the sake of readability it was decided to use the terms "the least attractive test" and "the most attractive test" throughout the paper.

3. Respondents who stated that they were not willing to take a supplementary private insurance (and thus were not willing to pay, i.e. zeros) were excluded from the analysis. The study was performed in the context of a supplementary private insurance, so the cost-benefit question should be whether the willingness to pay of respondents who are willing to take a supplementary private insurance exceeds or at least equals the costs of the subgroup of the actual (future) users. In case of a public insurance the zero answers are of major importance and should be analyzed carefully. For exploration of the proposed method, however, this issue is of minor importance. 


\section{References}

1. Johnson $\mathrm{F}$, Banzhat MR, Deswousges WH. Willingness to pay for improved respiratory and cardiovascular health: a multplie-format, stated-preference approach. Health Econ 2000; 9 : $295-317$

2. Klemman $L_{1}$ Melntosh $\mathrm{E}$, Ryan $M$, et al. Willingness to pay for complete symptom relief of gastroesophageal reflux disease. Arch Intern Med 2002; 162: 1361-1366.

3. Ryan $M$, Hughes $J$. Using conjoint analysis to assess women's preferences for miscarriage management. Health Econ 1997; 6:261-273.

4. Ryan M, McIntosh $\mathrm{E}$, Shackley P. Methodological issues in the application of conjoint analysis in heztth care. Health Econ 1998; 7:373-378.

5. Ryan M. Using conjoint analysis to take account of patient preferences and go beyond health outcomes: an application to in vitro fertilisation. Soc Sci Med 1999; 48: $535-546$

6. San Miguel F, Ryan M, Mcintosh E. Applying conjoint analysis in economic evaluations: an application to menorrhagia. Appl Econ 2000; 32:823-833.

7. Telser $\mathrm{H}$, Zweifel P. Measuring willingness-to-pay for risk reduction: an application of conjoint analysis. Health Econ $2002 ; 11: 129-139$

8. American Marketing Association. Conjoint analysis: a guide for designing and interpreting conjoint studies. Market Research Division; Marketing Research Technique Series, 1992.

9. Hair JF, Anderson RE, Tatham RL, Black WC. Multivariate Data Analysis, $5^{\text {th }}$ edition. New Jersey, Prentice Hall, 1998.

10. Louviere JJ, Hensher DA, Swait JD. Stated choice methods: analysis and application. Cambridge University Press, 2000.

11. Phillips KA, Maddala T, Johnson FR. Measuring preferences for health care interventions using conjoint analysis: an application to HIV testing. Health Serv Res 2002; 37:1681-1705.

12. Salkeld $G$, Ryan $M$, Short $L$. The veil of experience: do consumers prefer what they know best? Health Econ 2000; 9: 267-270

13. Altistides $M$, Chen $J$, Schulz $M$, et al. Conjoint analysis of a new chemotherapy: willingness to pay and preference for the features of raltitrexed versus standard therapy in advanced colorectall cancer. Pharmacoeconomics $2002 ; 20 ; 775-784$

14. Slothuus U, Larsen ML, Junker P. The contingent ranking method -- a feasible and valid method when eliciting preferences for health care? Soc Sci Med 2002; 54: 160l-1609.

15. Bryan $\mathrm{S}$, Buxton $\mathrm{M}$, Sheldon R., Grant A. Magnetic resonance imaging for the investigation of knee injuries: an investigation of preferences. Health Econ 1998; 7: 595-603.

16. Ratcliffe J. The use of conjoint analysis to elicit willingness-to-pay values. Proceed with caution? Int J Technol Assess Health Care 2000; 16: 270-275 
17. Scott A. Identifying and analysing dominant preferences in discrete ohoice experiments: An application in health care J Econ Psych 2002; 23: 383-398.

18. McIntosh $E$, Ryan M. Using discrete choice experinents to derive wellawe estimates for the provision of elective surgery: Implications of discontimuous preferences. I Econ Psych 2002; 23: $367-382$.

19. Pol van der M, Cairns J. Estimating time preferences for health using discrete choice experiments. Soc Sci Med 2001; 52: 1459-1470.

20. Lockwood M. Humans valuing nature: synthesizing insights from philosophy, psychology and economics. Environ Values 1999; 8: 381-401.

21. Edwards SF. Ethical preferences and the assessment of existence values: does the neoclassical model fit? Northeastern Journal of Agricultural and Resource Economics (currently Agr Resource Econ Rev) 1986; 15: 145-150.

22. Gigerenzer $G$, Todd $P M$, and the $A B C$ Research Group. Simple heuristics that make us smart. New York, Oxford University Press, 1999.

23. Tversky A, Kahneman D. The framing of decisions and the psychology of choice. Science $1981 ; 211: 453-458$.

24. Scott A. Eliciting GPS' preferences for pecuniary and non-pecuniary job characteristics. J Health Econ 2001; 20: 329-347.

25. Vasbinder GBC, Nelemans PJ, Kessels $A G H$, et al., for the Renal Artery Diagnostic lmaging Study in Hypertension (RADISH) Study Group. Accuracy of computed tomographic angiography and magnetic resonance angiography for diagnosing renal artery stenosis. Ann Intern Med 2004; 141: 674-682.

26. Gafini A. Wullingness-to-pay as a measure of benefits. Relevant questions in the context of public decisionnaking about bealth care programs. Med Care 1991; 29: 1246-1252.

27. O'Brien B, Gafni A. When do the "dollars" make sense? Toward a conceptual framework for contingent valuation studies in health care. Med Decis Making 1996; 16:288-299.

28. Donaldson $C_{\text {, Shackley }} \mathrm{P}_{\text {, Abdalla }}$ M. Using willingness to pay to value close substitutes: carrier screening for cystic fibrosis revisited. Health Econ 1997; 6: 145-159.

29. Donaldson C, Shackley P, Abdalla M, Miedzybrodzka Z. Willingness to pay for antenatal carrier screening for cystic fibrosis. Health Econ $1995 ; 4: 439-452$.

30. Ryan $M$, Ratcliffe J, Tucker J. Using willingness to pay to value alternative models of antenatal care. Soc Sci Med 1997; 44: 371-380.

31. Ryan $M$, San Miguel $F$. Testing for consistency in willingness to pay experiments. J Econ Psych 2000; 21: 305-317. 
32. Arrow $K$, Solow $R$, Leamer E, Portney $P$, Randner $R$, Schuman $H$. Report of the NOAA panel on contingent valuation. Fed Reg 1993; $58: 4602-4614$

33. Smith $R$. The discrete-choice willingness-to-pay question format in health economics: should we adopt environmental guidelines? Med Decis Making 2000; 20: 194-206.

34. O'Brien B, Viramontes JL. Willingness to Pay: a valid and reliable measure of heallh state preference? Med Decis Making 1994; 14: $289-297$.

35. Stalhammar NO. An empirical note on willingness to pay and starting-point bias. Med Decis Making 1996:16:242-247.

36. Donaldson $\mathrm{C}$, Jones $\mathrm{AM}$, Mapp TJ, Olson JA. Limited dependent variables in willingness to pay studies: applications in health care. Appl Fcon 1998; 30: 667-677.

37. Ryan M. Valuing psychological factors in the proviston of assisted reproductive techniques using the economic instrument of willingness to pay. $\mathbf{J}$ Econ Psych $1998 ; 19: 179-204$.

38. Gyrd-Hansen D, Sogaard 1. Analysing public preferences for cancer screening programmes. Health Fcon $2001 ; 10: 617-634$.

39. Ratcliffe J, Longworth L. Investigating the structural reliability of a discrete choice experiment within health technology assessment. Int J Technol Assess Health Care, 2002; $18: 139-144$.

40. Verlegh PWJ, Schifferstein HNJ, Wittink DR. Range and number-of-levels effects in derived and stated measures of attribute importance. Market Lett 2002; 13:41-52.

41. Caurns J, Pol van der $M$. Repeated follow-up as a method for reducing non-trading behaviour in discrete choice experiments. Soc Sei Med 2004; 58: 2211-2218. 


\section{Chapter 5}

\section{A comparison between conjoint analysis and direct willingness-to-pay}

D. van Helvoort-Postulart, J. Ouwersloot, J.D.P. Kasper, J.M.A. van Engelshoven, C.D. Dirksen 


\section{Abstract}

Aim of this paper was to compare the contingent valuation method to estimate willingness-to-pay, referred to as direct willingness-to-pay, with the conjoint analysis method to estimate willingness-to-pay indirectly, the latter method referred to as indirect willingness-to-pay. Respondents were randomly selected members of the general population. They were randomized to either the direct or indirect willingness-topay questionnaire. The ex-ante insurance-based perspective was used. Resulting willingness-to-pay estimates are monthly insurance premiums for a supplementary private insurance. Preferences were elicited for three diagnostic imaging techniques to detect renal artery stenosis: digital subtraction angiography (DSA), magnetic resonance angiography (MRA) and computed tomography angiography (CTA). Data were gathered using telephone interviews. Main finding was that direct willingness-to-pay and conjoint analysis yielded opposite findings. According to conjoint analysis, the incremental willingness-to-pay was 99.88 for MRA and $€ 13.67$ for CTA. Using the direct willingness-to-pay method, incremental willingness-to-pay was - 60.78 for MRA, and -60.69 for CTA. A secondary finding was that incremental direct willingness-to-pay values were lower than incremental willingness-to-pay values obtained with conjoint analysis. The conjoint analysis method performed slightly better on the theoretical validity tests than direct willingness-to-pay. The finding that the level of education influenced direct willingness-to-pay responses raises questions with respect to the use of direct willingness-to-pay in a broad decision-making context. Altogether the conjoint analysis technique seemed a more credible technique although this statement should be interpreted with caution. 


\section{Introduction}

In recent years there has been a rapid growth in the application of economic evaluation studies for health care programs. One evaluation method is cost-benefit analysis. In cost-benefit analysis both costs and benefits are measured in monetary terms, enabling to directly ascertain whether the benefits of a health care program justify the costs. Although cost-benefit analysis is potentially the broadest form of analysis, the historical lack of popularity of cost-benefit analysis in the health care sector is mainly due to the practical difficulties inherent in placing money values on program benefits [1].

The theoretical basis for the measurement of benefits in cost-benefit analysis is economic welfare theory and the concept of consumer surplus. According to welfare economic theory benefits should be measured as the maximum amount of money an individual is willing to pay for a program or willing to accept in order to forgo a benefit. For this reason willingness-to-pay is also called compensating variation, meaning that a program is considered to be welfare enhancing if gainers are willing to pay enough for their gains in order to compensate the losers. Willingness-to-pay, which we focus on in this paper, is based on the premise that the maximum amount of money an individual is willing to pay is an indicator of the utility or satisfaction he or she derives from program benefits, such as improvements in health status, the value of information or the value associated with the process of care.

Currently, two approaches are described in the health care literature to estimate willingness-to-pay: (1) direct willingness-to-pay and (2) the indirect willingness-to-pay method, the latter obtained with the technique of conjoint analysis. Direct willingnessto-pay and conjoint analysis are potentially very useful tools for benefit assessment in health care. However, up till now, in the Netherlands neither method has actually been used within the framework of cost-benefit analysis as the sole basis for resource allocation decisions in health care. One of the major problems in assessing the feasibility of the willingness-to-pay concept in health care is that, in general, there is no reference standard, i.e. what consumers would actually pay. Consequently, mostly criterion validity cannot be established.

The objective of the present study was to investigate the convergence between direct willingness-to-pay and indirect willingness-to-pay, the latter obtained with conjoint analysis. It should be noted that the results with respect to the convergent validity are in itself not useful to decide upon which of the two instruments is the best. Therefore, also the theoretical valudity of both measures was determined. 


\section{Methods}

\section{Perspective and clinical setting}

Aim was to study the willingness-to-pay concept from the societal perspective. In this approach all persons that are affected by a particular health care program should be considered. Therefore, preferences were gathered from a representative sample of the general population.

The clinical setting was the diagnosis of renal artery stenosis. Renal artery stenosis may cause hypertension and renal disease. The prevalence of renal artery stenosis varies from $1 \%-5 \%$ in a general hypertensive population to $20 \%-40 \%$ in patients with clinical characteristics suggestive of stenosis [2-4]. To prevent patients from developing cardiovascular complications and worsening renal function, it is important to detect and treat renal artery stenosis. Treatment objectives are blood pressure reduction and protection of the renal function that is mostly achieved by means of revascularization of the renal artery. Digital subtraction angiography (DSA) is considered the reference standard for detecting renal artery stenosis. However, DSA has a risk of morbidity and mortality. Currently, magnetic resonance angiography (MRA) and computed tomography angiography (CTA) are available for the diagnostic work-up for patients suspected of having stenosis. The validity of MRA and CTA was investigated in a prospective clinical trial [5]. In the present study, the willingness-to-pay concept was applied to the field of diagnostic imaging, comparing the three aforementioned diagnostic tests that are used in clinical practice to detect renal artery stenosis.

\section{Conjoint analysis study}

Conjoint analysis studies consist of five stages: identifying the attributes of interest, assigning levels to the attributes, presenting scenarios to individuals which involve different levels of the attributes, obtaining preferences for the scenarios, and analyzing the responses. The relevant attributes and levels were determined by means of expert opinion (clinicians, patients), literature review, and results from the aforementioned clinical trial [5]. Table 1 presents the selected attributes and levels. The cost-attribute was expressed as a monthly insurance premium for a supplementary private insurance. An explorative study was conducted to determine the levels for the cost-attribute in conjoint analysis [6].

The number of possible scenarios amounted to a total of 864. The ORTHOPLAN procedure (SPSS Inc., release 11.0.1) was used, resulting in an orthogonal main effects design, assuming no interactions between the attributes. The 20 scenarios produced by 
Table 1 Attributes and levels of the diagnostic imaging techniques

\begin{tabular}{lll}
\hline Attributes & Levels & Diagnostic test \\
\hline Sensitivity & $51 \%$ & MRA \\
& $62 \%$ & CTA \\
Hospital stay & $100 \%$ & DSA \\
& one overnight stay & DSA \\
Premium & return home same day & MRA, CTA \\
& $€ 11.34$ & \\
& 66.81 & \\
Access to blood vessel & $€ 2.27$ & DSA \\
& artery in groin area & MRA, CTA \\
Radiation & blood vessel in arm & DSA, CTA \\
& $x$-ray & MRA \\
Risk of death & magnetic & DSA \\
& $0.03 \%$ & MRA, CTA \\
Risk of complications & no risk & DSA \\
& $7.4 \%$ & CTA \\
& $2.4 \%$ & MRA \\
Space surrounding the patient & $1 \%$ & MRA \\
& tunnel & DSA, CTA \\
\hline
\end{tabular}

DSA: digital subtraction angiography; MRA: magnetic resonance angiography; CTA: computed tomography angiography.

ORTHOPLAN were randomly paired into 10 choices. The scenarios were labelled "A" and " $B$ " to avoid a general bias towards a specific diagnostic test, irrespective of the attributes of the tests. For each choice, respondents were asked to state whether they would prefer a supplementary insurance for diagnostic test $A$ or a supplementary insurance for diagnostic test $B$, thus reconciling the discrete choice exercises with the so-called "ex-ante insurance-based" approach [7,8], which is used in direct willingnessto-pay studies (see next paragraph). In addition, respondents were allowed to choose the "no preference" option. An example of one of the discrete choice tasks is shown in Appendix 1.

Estimation of the model was based on discrete choice modelling. For each choice the respondent prefers the alternative that leads to the highest level of utility. Thus, the individual would choose scenario $\mathrm{A}$ over scenario $\mathrm{B}$ if

$$
U\left(M_{A}, Y, C\right)>U\left(M_{B}, Y, C\right)
$$

where $U\left(\right.$ ) represents the individual's indirect utility function, $M_{A}$ the attributes of scenario $A$ and $M_{B}$ the attributes of scenario $B, Y$ the individual's income and $C$ the socio-economic characteristics of the individual that influence utility. An error term is 
included in the utility function to reflect the unobservable factors in the individual's utility function. Thus, within the random utility framework, the individual will choose scenario A over scenario B if

$$
\mathrm{V}\left(\mathrm{M}_{\mathrm{A}}, \mathrm{Y}, \mathrm{C}\right)+\varepsilon_{\mathrm{A}}>\mathrm{V}\left(\mathrm{M}_{\mathrm{B}}, \mathrm{Y}, \mathrm{C}\right)+\varepsilon_{\mathrm{B}}
$$

where $V()$ is the measurable component of utility estimated empirically, $\varepsilon_{J}(J=A, B)$ reflects the unobservable factors in the utility function and $M_{A}, M_{B}, Y$ and $C$ are defined as above. Assuming a linear additive utility function, the difference in utility between scenario $A$ and scenario $B$ is

$$
\begin{gathered}
\Delta V=\alpha_{1} \Delta \text { SENS }+\alpha_{2} \Delta \text { LENGHT }+\alpha_{3} \Delta \text { PREMIUM }+\alpha_{4} \triangle \text { ACCESS }+\alpha_{5} \Delta \text { COMPL }+ \\
\alpha_{6} \Delta \text { DEATH }+\alpha_{7} \Delta \text { RAD }+\alpha_{8} \Delta \text { SPACE }+e+u
\end{gathered}
$$

where $\Delta V$ is the change in utility in moving from scenario $B$ to scenario $A, \triangle S E N S$ is the difference in the level of sensitivity of the diagnostic test, $\triangle$ LENGTH is the difference in length of hospital stay, $\triangle P R E M I U M$ is the difference in insurance premium, $\triangle A C C E S S$ is the difference in how access to blood vessel is acquired (artery in groin area versus blood vessel in arm), $\triangle C O M P L$ is the difference in complication rate, $\triangle D E A T H$ is the difference in the probability to die, $\triangle R A D$ is the difference between magnetic and $x$-ray, $\triangle S P A C E$ is the difference between a tunnel and open space, $\alpha_{1}-\alpha_{8}$ are the parameters of the model to be estimated. The ratio of any pair of these shows the marginal rate of substitution between attributes and $\alpha_{3} / \alpha_{3}(J=1,2,4,5$, $6,7,8)$ is an estimate of the willingness to pay for levels of individual attributes. Terms $\mathrm{e}$ and $\mathrm{u}$ are the unobservable error terms, $\operatorname{corr}[\mathrm{e}, \mathrm{u}]=p$ and $p$ takes account of any correlation between observations from any one individual. The respondent will choose scenario $A$ if $\Delta V<T_{1}$, scenario $B$ if $\Delta V>T_{2}$ and is indifferent if $T_{1}<\Delta V<T_{2}$ ( $T=$ threshold). Thus, the "no preference" option is interpreted as respondents being indifferent between the two scenarios. Given that the discrete choice model involves a comparison of two indirect utility functions, and assuming a linear additive model, terms common to both utility functions will drop out of the measurable part of the utility function. Thus, individual income $(Y)$ and personal characteristics (C) drop out of equation. Since multiple observations were obtained from each respondent, a random effects ordered probit regression analysis was used to estimate the model parameters (LIMDEP 7.0).

\section{Direct willingness-to-pay study}

According to welfare economic theory, the benefit to an individual of a service or an intervention is defined as that individual's maximum willingness to pay for the service 
or intervention. The benefit to society of the intervention is the sum of each individual's willingness to pay.

Direet willingness-to-pay was estimated using the ex-ante insurance-based approach $[7,8]$. Persons at risk for a disease, and therefore at risk of consuming the health care program, were asked to state a willingness-to-pay value as a monthly insurance premium to have the program available. The availability of the diagnostic imaging modalities was described in the context of a supplementary private insurance. The elicitation process involved a payment card. Each respondent chose a value from a specified and ordered list, and all respondents chose from the same list, including five willingness-to-pay amounts, i.e. monthly insurance premiums: $60.68,62.27,66.81$, E11.34 and 622.69 . An example of one of the direct willingness-to-pay questions is shown in Appendix 2. The range was derived from an explorative study that was performed to determine the levels for the cost-attribute in conjoint analysis [6]. As in the conjoint analysis study, the diagnostic tests were named " $A$ ", " $B$ " and " $C$ ". Furthermore, test A (DSA), B (MRA) and C (CTA) were presented in terms of the same attributes and levels as used in the conjoint analysis study (Table 1).

Descriptive statistics were computed for the willingness-to-pay for DSA, MRA and CTA. Willingness-to-pay values were compared using the non-parametric relatedsamples Friedman test. Statistical significance was defined as $\mathrm{p}<0.05$. Willingness-topay amounts are presented in 2002 Euros.

\section{Validity}

\section{Conjoint analysis}

First, the theoretical validity, i.e. the extent 10 which results are consistent with a priori expectations, was investigated by examining the signs and significance of parameter estimates. The attributes SENS, PREMIUM, DEATH and COMPL were defined as continuous variables. LENGTH ( 0 =return home same day; $1=$ one overnight stay), ACCESS ( 0 =artery in groin area; $1=$ blood vessel in arm), RAD ( $0=x$-ray; $1=$ magnetic fields) and SPACE (0=open space; 1=tunnel) were coded as dummy variables. Assuming that lower levels of duration of hospital stay (LENGTH), premium (PREMIUM), probability to die (DEATH), probability that complications occur (COMPL) and space surrounding the patient (SPACE) are preferred, it was expected that these attributes would have a negative sign in the regression equation. Similarly, given that higher levels of sensitivity (SENS), access to blood vessel (ACCESS) and radiation (RAD) are to be preferred, it was expected that these attributes would have a 
positive sign. Assuming diminishing marginal utility of income, it was expected that higher income groups would have a lower marginal valuation of PREMIUM, and therefore, the coefficient would be lower for higher income groups as compared to lower income groups. Assuming that respondents with cardiovascular disease place a lower value on the level of the insurance preminm, it was expected that the coefficient of PREMIUM would be lower for individuals with cardiovascular disease (CARDIO; $0=$ absence of cardiovascular disease; 1 -presence of cardiovascular disease). This expectation was based on the supposition that people with cardiovascular disease have a higher probability that the diagnostic test will be beneficial to them, indicating that they would be willing to pay higher insurance premiums. Hence the negative impact of the premium in their utility function will be smaller in absolute terms for people with cardiovascular disease. Also, assuming people with claustrophobia to place a higher value on the space surrounding the patient during the diagnostic test, it was expected that the coefficient of SPACE would be higher for people with claustrophobia (CLAUSTRO; 0=absence of claustrophobia; 1-presence of claustrophobia). Assuming that higher socio-economic groups have a higher marginal valuation of time, it was expected that the coefficient of LENGTH segmented by income (INCOME; continuous) would be higher for higher income groups. Finally, assuming that older people place a lower value on the probability to die as a result of a diagnostic test, it was expected that the coefficient of DEATH segmented by age (AGE; continuous) would decrease with age. This expectation was based on the supposition that life expectancy is an element of the utility function. Furthermore, the probability to die as a result of a diagnostic imaging test relates negatively to life expectancy. So, the impact of the probability to die on life expectancy is larger for younger people than for older people, hence the reduction in utility derived from life expectancy is larger for younger people than for older people. The following interactions were included without a priori assumptions: PREMIUM and level of education (EDUC; 0-low; 1-high), PREMIUM and type of health insurance (INSUR; 0=public; 1-private), PREMIUM and current monthly health insurance premium (PAYMENT; continuous), PREMIUM and gender (GENDER; $0=$ male; $1=$ female), and PREMIUM and AGE.

Second, it was investigated to what extent respondents always chose a scenario in terms of one attribute, irrespective of the level of the other attributes (non-traders). Such an attribute is said to be dominant and the individual is said to show lexicographic preferences $[9,10]$. 
Third, to determine whether respondents appear to understand the technique and are taking the choice tasks seriously, the internal consistency was measured by means of a reliability test. Respondents were asked to consider the same discrete choice exercise twice. It was expected that respondents would make the same choice both times the question was offered. A shift from scenario A or B to "indifferent" - and vice versa was considered consistent.

\section{Direct willingness-ro-pay}

Contingent valuation studies typically measure theoretical validity by regressing willingness-to-pay responses on a set of independent variables believed to be determinants of respondents' willingness to pay. According to economic theory, willingness-to-pay values were expected to increase with income. Also, people with cardiovascular disease were expected to state higher willingness-to-pay values compared to people without cardiovascular disease. Therefore, INCOME and CARDIO were hypothesized to have a positive sign. Furthermore, it was expected that respondents' willingness to pay for MRA would be influenced by the absence or presence of claustrophobia. Therefore, only for MRA, the variable CLAUSTRO was included in the regression analysis. As in the conjoint analysis study, the following predictor variables were additionally examined: AGE, GENDER, INSUR, PAYMENT, and EDUC. For each diagnostic test, logistic regression was performed to predict the likelihood of respondents to take a supplementary private insurance, i.e. modelling zero willingness-to-pay values. Subsequently, the influence of determinants on the positive willingness-to-pay values was determined using linear regression modelling.

\section{Data collection}

Two questionnaires (available in Dutch) were developed that consisted of four parts. In the first part information was provided with respect to the prevalence and risks of hypertension and renal artery stenosis, such as myocardial infarction, stroke, and loss of renal function. Furthermore information was provided with respect to the number of patients per year that is referred to the university hospital Maastricht for the diagnostic work-up for renal artery stenosis. Also treatment benefit was mentioned. Furthermore, the hypothetical nature of the questions was explained. Respondents were asked to imagine that the health insurance company did not cover diagnostic tests to detect renal artery stenosis, and thus that they would have to pay the full price as soon as they need to undergo a diagnostic test. Alternatively, taking a supplementary insurance would 
mean that the health insurance premium rises but that the test is free of charge at the point of consumption. No information was prowided with respect to the "real world" costs of the diagnostic imaging techniques. Since it was considered of major importance that the respondents understood the hypothetical nature and insurance-based context very well this information was repeated in part 3 of the questionnaires. In part 2 the attributes and levels of the diagnostic tests were explained in great detail since the questionnaires contained some difficult concepts such as sensitivity and risk. Percentage values were clarified throughout the questionnaires by also using numbers. For example, a complication rate of $2.4 \%$ was also expressed as " 24 out of 1000 ". In the direct willingness-to-pay questionnaire the diagnostic imaging modalities were described in terms of the attributes and levels that were also used in the conjoint analysis study. In part 3 of the conjoint analysis questionnaire respondents were presented with a series of pair-wise scenarios (A and B), and were asked to state whether they would prefer a supplementary insurance for diagnostic test $A$ or a supplementary insurance for diagnostic test $\mathrm{B}$, or had no preference. In part 3 of the direct willingness-to-pay questionnaire respondents were asked to imagine the situation without insurance for diagnostic test $A$. They were offered the opportunity to take a supplementary private insurance for diagnostic test $\mathrm{A}$. Respondents were provided with a payment card and were asked to state their maximum willingness-to-pay amount as a monthly insurance premium. The same steps were repeated for diagnostic tests $B$ and $C$. In part 4 respondents were asked to provide some demographic and socio-economic information. Furthermore respondents were asked about their health status regarding hypertension.

Data were gathered using telephone interviews. Telephonists of the Centre for Data and Information Managenent (MEMIC) in Maastricht, the Netherlands, performed the interviews. The interview protocol was standardized using the BLAISE system. BLAISE is a software system for survey processing on microcomputers. The system supports computer-assisted telephone interviewing and was developed by the Dutch Bureau of Statistics (CBS). The procedure was as follows: a random sample of 800 adult (18 years and older) residents of the Heuvelland region (adherence of the university hospital Maastricht) received an information letter to explain the aim of the study. An independent company, Cendris in The Hague, the Netherlands, performed the sampling task. Addresses were randomized to either conjoint analysis or direct willingness-to-pay. Following the letter residents were called to give informed consent. After setting an appointment for the telephone interview, the questionnaire was sent to 
the participants (i.e. those who gave informed consent). The participants were instructed to read the questionnaire before the interview took place. We did not perform sanple size calculations since, to our knowledge, there are no guidelines with respect to the minimun sample size needed for willingness-to-pay studies.

\section{Results}

\section{Response}

Within two weeks following the information letter, 649 participants could be contacted by telephone $(81 \%)$. Of them, 320 subjects were willing to take part in the telephone interview, 158 conjoint analysis and 162 direct willingness-to-pay. Based on the total. number of information letters sent ( 800 ), the overall response rate was $40 \%$, both for the conjoint analysis and direct willingness-to-pay questionnaire. Data were collected between February 2002 and June 2002. The characteristics of the respondents are presented in Table 2. Overall, the characteristics of the respondents that completed the direct willingness-to-pay and conjoint analysis questionnaire were comparable.

\section{Conjoint analysis}

Of the 158 respondents that participated in the conjoint analysis study one respondent by mistake received the direct willingness-to-pay questionnaire. This respondent completed the direct willingness-to-pay questions. Five respondents were indifferent with respect to each of the choice tasks. These responses could not be analyzed. One respondent refused to engage in the choice tasks and one respondent was not able to perform any of the choice tasks. As a result, the responses of 150 subjects were available to estimate the model parameters.

The estimates for the full sample main effects ordered probit model are presented in Table 3. The coefficients for LENGTH and RAD were not significant $(p=0.632$ and $p=0.230$, respectively). The remaining coefficients had the expected signs and were highly significant, implying that the concerning attributes are relevant in the provision of diagnostic imaging modalities. Against expectation, the valuation of PREMIUM was independent of income $(p=0.900)$. As expected, people with cardiovascular disease valued PREMTUM lower than respondents without cardiovascular disease $(p=0.040)$. Respondents with claustrophobia valued SPACE more highly than individuals without claustrophobia $(p<0.001)$. Against expectation, the valuation of LENGTH was independent of income $(p=0.111)$. As expected, the valuation of DEATH decreased with age $(p=0.011)$. The interactions without a priori assumptions were not significant. 


\section{Chapter 5}

Table 2 Population characteristics

\begin{tabular}{lll}
\hline & Conjoint analysis & Direct willingness-to-pay \\
\hline Age & $52 \pm 13$ & $53 \pm 16$ \\
Males & $56 \%$ & $53 \%$ \\
Net household income & 62047 & 62046 \\
Cardiovascular disease & $26 \%$ & $31 \%$ \\
Claustrophobia & $17 \%$ & $11 \%$ \\
Public insurance & $63 \%$ & $60 \%$ \\
Higher education & $38 \%$ & $37 \%$ \\
Premium (Euros; monthly) & 6115 & $€ 115$ \\
\hline
\end{tabular}

"In the data set education consisted of 8 classes that were recoded into 2 classes, i.e. lower education (clatsses $1-4$ ) and higher education (classes 5-8).

Twenty-nine respondents showed lexicographic preferences for the variables DEATH $(\mathrm{N}=13)$, SENS $(\mathrm{N}=8)$. PREMIUM $(\mathrm{N}=7)$ and COMPL $(\mathrm{N}=1)$. The reliability test revealed that 125 out of 148 respondents $(84 \% ; 2$ missing values) were consistent, thus providing the same answer to the choice task offered twice. Excluding respondents exhibiting lexicographic preferences and excluding inconsistent respondents yielded similar coefficients and significance levels as compared to the full sample main effects model. Because the lexicographic and inconsistent respondents did not have a major impact on the coefficients, willingness-to-pay estimates were calculated based on the full sample parameters.

In the last column of Table 3, marginal willingness-to-pay values for one unit of change are presented. For example, respondents were willing to pay $€ 1.52$ per month for a $1 \%$ reduction of the complication rate. The incremental willingness-to-pay was calculated as the willingness-to-pay for a supplementary private insurance for MRA or CTA compared with a supplementary private insurance for DSA (Table 4). Adding up the willingness-to-pay values for the statistically significant attributes yielded an incremental willingness-to-pay for MRA and CTA of $€ 9.88$ and 613.67 , respectively. The positive willingness-to-pay values mean that respondents preferred both MRA and CTA to DSA. The higher incremental willingness-to-pay for CTA as compared to MRA shows that respondents preferred CTA to MRA.

\section{Direct willingness-to-pay}

One hundred and sixty-three respondents completed the direct willingness-to-pay questions. For DSA, MRA and CTA, respectively 10,10 and 12 respondents were not 
Table 3 Results from the full sample main effects ordered probit model

\begin{tabular}{lcrll} 
& Coefficient & \multicolumn{1}{c}{$\mathrm{P}$} & Marginal willingness-to-pay $(\in)$ \\
\hline SENS & 0.01374 & $<0.001$ & 0.21 \\
LENGTH & 0.04259 & 0.632 & $\mathrm{~N} / \mathrm{a}$ \\
PREMIUM & -0.06461 & $<0.001$ & $\mathrm{~N} / \mathrm{a}$ \\
DEATH & -0.188 & $<0.001$ & 2.92 \\
COMPL & -0.09829 & $<0.001$ & 1.52 \\
SPACE & -0.239 & 0.002 & 3.71 \\
ACCESS & 0.348 & $<0.001$ & 5.39 \\
RAD & 0.06889 & 0.230 & $\mathrm{~N} / \mathrm{a}$ \\
Log likelihood & -1318.688 & & \\
Correct predictions & $52.6 \%$ & & \\
\hline
\end{tabular}

Na: not applicable.

Table 4 Incremental willingness-to-pay for MRA and CTA

\begin{tabular}{lcc}
\hline Attribute & MRA & CTA \\
\hline SENS & $-€ 10.29^{*}$ & $-€ 8.08$ \\
DEATH & $€ 8.76$ & $€ 8.76$ \\
COMPL & $€ 9.73$ & $€ 7.60$ \\
SPACE & $-€ 3.71$ & $\dagger$ \\
ACCESS & $€ 5.39$ & $€ 5.39$ \\
Total monthly willingness-to-pay & $€ 9.88$ & $€ 13.67$ \\
\hline
\end{tabular}

MRA: magnetic resonance angiography: CTA: computed tomography angiography; DSA: digital subtraction angiography.

"Respondents were willing to pay e0.21 per month for a sensitivity increase of $1 \%$ (Table 3). Moving from DSA to MRA means that the sensitivity decreases with $49 \%$ and results in a negative willingness-to-pay of E10.29.

"DSA and CTA do not differ with respect to the SPACE atribute.

able to state a willingness-to-pay value. Therefore, the results of respectively 153,153 and 151 respondents could be analyzed.

Descriptive statistics are presented in Table 5. Twenty-nine (19\%), 37 (24\%) and 34 (23\%) respondents were not willing to take a supplementary insurance for DSA, MRA and $\mathrm{CTA}$, respectively. Including zero willingness-to-pay responses and excluding zero willingness-to-pay responses, the willingness-to-pay estimates for DSA, MRA and CTA differed significantly (Friedman; $p<0.001$ ). Twenty-one respondents were not willing to take a supplementary private insurance for any test. Eighty-eight respondents stated the same willingness-to-pay amount for each of the three diagnostic tests (mean 63.07 ; SD E4.48). For respondents that stated a different willingness-to-pay amount for at 
Table 5 Willingness-to-pay for DSA, MRA and CTA

\begin{tabular}{llll} 
& DSA & MRA & CTA \\
\hline Including zeros (median) & $3.48 \pm 4.26(2.27)$ & $2.70 \pm 3.94(0.68)$ & $2.79 \pm 4.17(0.68)$ \\
Excluding zeros (median) & $4.29 \pm 4.35(2.27)$ & $3.56 \pm 4.18(2.27)$ & $3.61 \pm 4.42(2.27)$ \\
\hline
\end{tabular}

DSA : digitwil subtraction angiography; MRA: magnetic rosonimee angrography; CTA: computed tomograptiy andigiogentaphy.

Jeast one of the tests mean willingness-to-pay was 64.00 (SD 63.92 ), 62.23 (SD 63.04 ), and $E 2.41$ (SD E3.69) for DSA, MRA and CTA, respectively.

Incremental willingness-to-pay for MRA, as compared to DSA, was - 60.78 . The negative willingness-to-pay amount indicates that respondents should receive 60.78 per month (insurance premium reduction) to maintain the same level of utility when taking a supplementary private insurance for MRA as compared to taking a supplementary private insurance for DSA. The incremental willingness-to-pay for CTA, as compared to DSA, was - E0.69. Thus DSA was the most preferred test, whereas MRA was the least preferred diagnostic imaging test.

For each diagnostic test logistic regression analysis was performed to predict the likelihood of respondents to take a supplementary private insurance. None of the a priori expectations could be confirmed. Respondents with cardiovascular disease were less likely to take a supplementary private insurance for MRA $(\mathrm{p}=0.020)$. Privately insured respondents were less likely to take a supplementary private insurance for each of the diagnostic tests (DSA: $p=0.016 ;$ MRA: $p=0.001$; CTA: $p=0.001$ ). For CTA, women were more likely to take a supplementary private insurance $(p=0.029)$. Linear regression analysis was performed to explain the magnitude of the positive willingnessto pay values. Since the distribution of positive willingness-to-pay values was skewed, a transformation to natural logarithms seemed appropriate prior to further analysis. None of the a priori expectations could be confirmed. For DSA and CTA, higher educated respondents stated lower willingness-to-pay values (DSA: $p=0.018$; CTA: $p=0.049$ ). For MRA and CTA, older respondents stated higher willingness-to-pay values (MRA: $p=0.003 ;$ CTA: $p=0.016)$.

\section{Discussion}

The current study could not provide evidence for the comparability of the direct willingness-to-pay method and the conjoint analysis discrete choice approach to estimate willingness-to-pay. A major finding was that the discrete choice method 
indicated CTA as the most preferred diagnostic imaging test whereas using direct willingness-to-pay, DSA was the most preferred diagnostic imaging technique, thus resulting in different policy decisions. A secondary finding was that incremental willingness-to-pay values obtained with direct willingness-to-pay were substantially lower compared to incremental willingness-to-pay values obtained with conjoint analysis.

Up till now, studies that have compared direct willingness-to-pay with indirect willingness-to-pay [11-15] yielded willingness-to-pay estimates that would lead to the same decision with respect to the most preferred alternative. Nevertheless, three of these studies $[11,13,14]$ also found higher incremental willingness-to-pay values for conjoint analysis. As results of willingness-to-pay studies are mainly used to provide decisionmakers with rank ordering information, rather than actual numbers to be included in cost-benefit analysis, especially the finding that both methods would lead to different policy decisions, is striking and worrying.

In the current study there are four possible explanations for the opposite findings for direct willingness-to-pay and conjoint analysis. First, our study compared the results from a discrete choice experiment with payment card data. Whereas discrete choice modelling is based on random utility theory, the payment card does not share this random utility basis, indicating that willingness-to-pay estimates from discrete choice experiments and payment cards are not directly comparable. On the other hand, dichotomous choice willingness-to-pay is actually based on random utility theory so one could argue that this approach should have been the elicitation method of choice in our comparative study. However, studies have indicated that dichotomous choice willingness-to-pay resulted in an inflation of the welfare estimates since this approach has been shown to yield significantly higher willingness-to-pay estimates than the payment card $[16,17]$. This may be explained by "yeah-saying", i.e. accepting an offer in order to give a socially desirable response, and has resulted in concern about the use of dichotomous choice willingness-to-pay at the policy level [11]. Furthermore, the dichotomous choice format has relatively low statistical efficiency meaning that huge samples are required which is time consuming and expensive. Although recommendations from the National Oceanographic and Atmospheric Administration (NOAA) panel [18] led to an increased use of dichotomous choice willingness-to-pay in the 1990 s, interest remained in the payment card technique, which has been widely applied in health economics [19]. So, although the payment card technique may be conceptually different from discrete choice modelling, it is worthwhile to investigate 
whether both techniques to estimate willingness-to-pay lead to (systematically) different outcomes.

Second, in the direct willingness-to-pay study for each diagnostic imaging technique a willingness-to-pay estimate was determined. In direct willingness-to-pay tasks respondents are generally presented with the status quo or current situation, and are asked to value in money terms one alternative health care intervention [20-26]. In such studies, respondents are (unconsciously) provoked to state positive willingness-to-pay values for the alternative option as compared to the status quo. This seems reasonable when all aspects of the alternative health care program are better than the reference program $[21,26]$. However, most health care programs will offer a combination of both utility gains and losses, which was also the case with respect to the comparison of DSA. with MRA and CTA. Therefore, the willingness-to-pay questions were presented in such a way that both positive and negative incremental willingness-to-pay values could. be estimated. This was considered more realistic and moreover enhanced the comparability with the conjoint analysis study. As a result, the way the direct willingness-to-pay questions were asked may have contributed to the opposite findings.

A third possible explanation for the opposite results is that a question order effect may have occurred in the direct willingness-to-pay study, although studies on this subject are not conclusive $[27,28]$. The first question always concerned DSA followed by MRA and CTA. As the results pointed out, most respondents valued DSA more highly than CTA and MRA. To prevent a question order effect in direct willingness-topay, further studies should randomize the order of questions. In conjoint analysis, results were not sensitive to the ordering of scenarios [29]. Another type of ordering effects that may have occurred in the direct willingness-to-pay study is the ordering of attributes. In the description of the diagnostic tests, the sensitivity was always mentioned first. Therefore, respondents may have perceived this attribute as the most important. This attribute ordering effect seems an obvious explanation since the sensitivity of DSA was higher than the sensitivity of CTA, and the sensitivity of CTA was higher than that for MRA, although we cannot explore this hypothesis with our data. To our knowledge no studies have investigated attribute ordering related to direct willingness-to-pay. Regarding conjoint analysis several studies have investigated attribute ordering [30-32] with one study providing some evidence for the presence of ordering effects [32]. Although in the current conjoint analysis study the sensitivity attribute was also presented first and had the highest relative importance, respondents made trade-offs between this attribute and the risk of complications (presented fifth) and 
Whe risk of death (presented fourth), suggesting that attribute ordering did not occur in our conjoint analysis experiment.

Finally, preference reversals may have occurred in the direct willingness-to-pay study, indicating that, within a subject, inconsistency exists between the rank ordering of the programs and willingness-to-pay. This phenomenon has occurred in several studies in which subjects were asked to provide a willingness-to-pay value for more than one intervention [33-35]. To improve consistency between ranking of the programs and direct willingness-to-pay values, Shackley and Donaldson [36] have investigated the marginal approach. Respondents were asked to indicate their preferred treatment option and were subsequently asked to state how much they would be willing to pay to have that treatment rather than their less preferred option. However, application of the marginal approach did not result in a reduction of the number of preference reversals. Preference reversals in conjoint analysis cannot be established the same way as in direct willingness-to-pay, since respondents are not asked to provide willingness-to-pay values. Bryan et al. [37] compared the results of two conjoint analysis questionnaires, one including and one excluding a cost-attribute. This resulted in comparable coefficients for all other attributes, although the cost-attribute was not significant. On the contrary, Slothuus Skjoldborg and Gyrd-Hansen [38] found that including a dummy variable to represent the utility associated with payment per se had significant effects on the model in that some attributes became insignificant, and others changed of sign.

A secondary finding of the current study was that the incremental direct willingness-topay values were substantially lower than the incremental willingness-to-pay estimates obtained with conjoint analysis. A first explanation for the lower incremental willingness-to-pay values in the direct willingness-to-pay study is that 88 respondents $(54 \%)$ stated the same willingness-to-pay for each diagnostic test. of course, respondents may have actually been indifferent between the tests. Also, respondents may have preferred one of the diagnostic tests, but their preferences may not have been strong enough to pay more for the preferred option [39]. Further, individuals "at risk" for consuming a health care program were interviewed. Hence, a majority of the respondents will have had no affinity with the program being evaluated. Thus, respondents may have been indifferent regarding the type of test provided that "some test" would be available. Also, the insurance-based format may have caused difficulties for respondents. Monthly premiums, as opposed to once-only payments, generally inwolve smaller amounts of money. This may have weakened the sensitivity of the direct 
willingness-to-pay questions to differences in preference. Finally the nature of the health care intervention may have contributed to the results. The focus of the current study was on the intermediate outcomes of diagnostic imaging techniques. The effects of diagnostic testing on health status, in terms of survival and quality of life, were not made explicit in the questionnaire. It is expected that direct willingness-to-pay will discriminate better when health care services with more pronounced effects on health status are valued. Using conjoint analysis, aggregate willingness-to-pay values were determined indirectly. Therefore, it was not possible to assess on the individual level whether respondents would express different incremental willingness-to-pay values for CTA and MRA.

A second possible explanation for the disparity between direct willingness-to-pay and conjoint analysis may be the use of the payment card. An assessment of responses revealed that the distribution of willingness-to-pay values for all three diagnostic tests was skewed by a small number of high-value cases. By explicitly indicating a range, the payment card format provides subjects with cues that make the valuation task more comprehensible. However, a low starting point, for example, might lead a subject to infer that these low levels are actually the most appropriate valuations, and responses may accordingly be biased downwards. This phenomenon may have been exacerbated by the fact that the interval between the levels was smaller at the lower bound of the payment card. Also, differences in willingness-to-pay may not have been detected because the number of levels specified in the payment card was too small, that is, the interval between the levels may have been too large. In that case, the payment card was not sensitive enough to detect differences in willingness-to-pay. Whynes et al. [40] found that a difference in willingness-to-pay between two screening tests for colorectal cancer was less likely if the payment scale format, as compared to the open-ended question, was used.

Third, one might argue that the higher incremental willingness-to-pay values arising from the conjoint analysis study were caused by the omission of an opt-out option, whereas in the direct willingness-to-pay study respondents were permitted to select the option not to take a supplementary insurance. The design of our conjoint analysis study, however, did not allow us to specify an opt-out alternative. Generally, in conjoint analysis studies including an opt-out alternative, which is usually the "status quo", the opt-out option can be described in terms of attributes and levels. In the current study, to prevent "status quo" bias [41], respondents were asked to imagine that the health insurance company did not cover" any of the diagnostic tests to detect renal artery 
stenosis, and that, without supplementary insurance, they would have to pay the full price as soon as they would need a test. Which test that would be was not further specified, thus the opt-out option would be "some test", which cannot be deseribed in terms of attribute levels. Moreover, the level assigned to the cost-attribute of the opt-out option would be a (relatively high) once-only payment, as opposed to the insurancebased payment vehicle used in the experiment. It should be noted that we excluded five respondents from the analysis. These respondents were indifferent with respect to each of the choice tasks, and thus did not make trade-offs. All these respondents were considered "protesters", whereas some of them may have actually opted out. Future conjoint analysis studies should make efforts to get more insight into respondents" motives.

A final possible explanation for the lower incremental willingness-to-pay values for direct willingness-to-pay may be that in conjoint analysis a smaller range was applied for the cost-attribute. This was decided in order to achieve a comparable number of levels for each attribute while maintaining appropriate intervals between the levels [6]. Verlegh et al. [42] showed that applying a wider range for the cost-attribute led to a higher importance of the cost-attribute. Also, using a wider range for the cost-attribute means that more levels are required to prevent that the interval between the levels becomes too large and, consequently, trade-offs will not be made. An increase in the number of intermediate levels may increase the attribute importance and thus leads to lower willingness-to-pay estimates [42-44]. On the contrary, Slothuus Skjoldborg and Gyrd-Hansen [38] found that a wider cost range including higher payments was associated with lower parameter weights associated with the cost variable, and thus led to increased willingness-to-pay values. Given these inconclusive results, is is not clear how a wider range for the cost-attribute would have affected overall incremental willingness-to-pay values for MRA and CTA compared to DSA. Furthermore, using conjoint analy sis it is possible to calculate incremental willingness-to-pay values outside the range of values used for the cost-attribute. Three of the aforementioned comparative studies [11-15] also used different ranges for the cost-attribute. [11,12,15]. Hanley et al. [13] only reported the bid amounts that were used in the dichotomous choice willingness-to-pay survey, and Hanley et al. [14] did not mention the range and levels for the cost-attribute at all.

With respect to the theoretical validity of direct willingness-to-pay and conjoint analysis, the following issues arose. First, for neither method the assumed positive 
influence of income on willingness-to-pay could be confirmed. A possible explanation may be the use of monthly insurance premiums. An insurance-based context involves relatively low amounts of money, which possibly do not affect actual budget of the respondents. Accordingly, it can be speculated that income is a predictor of willingnessto-pay only when higher amounts of money are involved. Another explanation may be that we did not measure income well. Measurement error may for example have occurred due to the division into categories. In the data set income was categorized into eight classes. By using the arithmetic mean income was considered a continuous variable. Measurement error may also have occurred due to respondents who did not state the right income. Many direct willingness-to-pay studies have confirmed the relation between willingness-to-pay and income $[20,21,25,45-52]$. Also, several conjoint analysis studies have investigated the diminishing marginal utility of income $[9,53-57]$, and three studies could confirm a statistical significant positive infuence of income on willingness-to-pay. Second, the conjoint analysis study revealed that respondents with cardiovascular disease had a higher willingness-to-pay than respondents without cardiovascular disease. Furthermore, respondents with claustrophobia had a higher willingness-to-pay for an open space as opposed to a tunnel than respondents without claustrophobia. Third, in the direct willingness-to-pay study none of the a priori expectations could be confirmed. Respondents with cardiovascular disease were even less likely to take a supplementary private insurance for MRA. Fourth, an important finding for direct willingness-to-pay was that the levell of education was a negative predictor of willingness-to-pay for DSA and CTA. In the conjoint analysis study the level of education was not related to the cost-attribute. A probable explanation is that the direct willingness-to-pay tasks were too difficullt for lower educated persons. The rellationship between direct willingness-to-pay and education thas been investigated in several direct willingness-to-pay studies, with varying results $[16,25,46,47,51,52,58]$. In order to establish public preferences for health care programs, the willingness-to-pay concept should be understandable for all members of society. Therefore, the association between direct willingness-to-pay and level of education is worrying.

\section{Conclusion}

Main finding of the current study was that direct willingness-to-pay and conjoint analysis yielded opposite findings. The direct willingness-to-pay method suggested that DSA was the most preferred test, whereas conjoint analysis indicated DSA as the least 
preferred test. CTA is preferred to MRA irrespective of the method used. A secondary finding was that incremental direct willingness-to-pay values were lower than incremental willingness-to-pay values obtained with conjoint analysis. The conjoint analysis technique performed slightly better on the theoretical validity tests than direct willingness-to-pay. Also the finding that the level of education influenced direct willingness-to-pay responses raises questions with respect to the use of direct willingness-to-pay in a broad decision-making context. Altogether the conjoint analysis technique seemed a more credible technique although this statement should be interpreted with caution. There appears to be more critical appraisal to the use of the direct willingness-to-pay in the context of policy decisions as compared to conjoint analysis. Up till now relatively little attention has been paid to the validity of the resulting willingness-to-pay estimates in conjoint analysis, and consequently to the feasibility of conjoint analysis in a cost-benefit perspective. 
Appendix 1 Example of a discrete choice task

\begin{tabular}{|c|c|c|}
\hline Afirbules & Supplementary insurance A & Supplententary insurance \\
\hline Sensituity & $100 \%$ & $62 \%$ \\
\hline Hospital stay & retum home same day & one owernight stay \\
\hline Preminum & 66.81 & 66.81 \\
\hline Access u blood wessel & blood vessel in anm & artery in groin area \\
\hline Radiration & $x-$ ray & magnetic \\
\hline Risk of: death & no risk & no risk \\
\hline Ristle of complications & 2. $4 \%$ & $1 \%$ \\
\hline Space surrounding the patient & tunnet & open space \\
\hline
\end{tabular}

Which supplementary insunance would you prefter?

I No preference for either one of the supplementary ingurances

\section{Appendix 2 Example of a direct willingness-to-pay question}

\begin{tabular}{|c|c|c|}
\hline Atteibutes & Dingnostic test A & No supplementary insurance \\
\hline Sensitivity & $100 \%$ & Without supplementary insurance you \\
\hline Hospilat stay & one owerrilght stay & whill have to pay the full price of test $A$ ats \\
\hline Acoess to blood wesisel & artery in groin anea & soon as you need to undergo this \\
\hline Radiation & $x-m a y$ & diagnostic test. \\
\hline Risk of death & $0.03 \%$ & \\
\hline Rusk of complications & $7.4 \%$ & \\
\hline Space surrounding the patient & open space & \\
\hline
\end{tabular}

Suppose that your health insurance does not cover diagnostic test A. You are offered the opportunity to lake a supplementary insurance for lest $A$. What is he maximum amount of insurance premium you would be willing to pay per montlli for a supplementary insurance for diagnostic test $\mathrm{A}$ ?

\begin{tabular}{|l|l|l|l|l|}
\hline 60.68 & 62.27 & 66.81 & 611.34 & 622.69 \\
\hline
\end{tabular}

L I would not take a supplementary insumance for diagnostic test A. 


\section{References}

1. O'Brien $B$, Viramontes $\mathfrak{l}$. Willingness to Pay: a valid and reliable measure of health state preference? Med Decis Making 1994; 14:289-297.

2. Derkx FH, Schalekamp MA. Renal artery stenosis and hypertension. Lancet 1994; 344:237239.

3. Eardley $\mathrm{KS}$, Lipkin GW. Atherosclerotic renal artery stenosis: is it worth diagnosing? J Hum Hypertens 1999; $13: 217-220$.

4. Working Group on Renovascular Hypertension. Detection, evaluation, and treatment of renovascular hypertension. Final report. Arch Intern Med 1987; 147: 820-829.

5. Vasbinder GBC, Nelemans PI, Kessels AGH, et al., for the Renal Artery Diagnostic Imaging Study in Hypertension (RADISH) Study Group. Accuracy of computed tomographic angiography and magnetic resonance angiography for diagnosing renal artery stenosis. Ann Intern Med 2004; 141: 674-682.

6. Dirksen CD, Helvort-Postulart van D, Ouwersloot $\mathbb{~ E n g e l s h o v e n ~ v a n ~ I M A , ~ K a s p e r ~ I D P . ~}$ Between best and worst: trading levels in conjoint analysis. Submitted for publication.

7. Gafini A. Willingness-to-pay as a measure of benefits. Relevant questions in the context of public decisionmaking about health care programs. Med Care 1991; 29:1246-1252.

8. O'Brien B, Gafni A. When do the "dollars" make sense? Toward a conceptual framework for contingent valuation studies in health care. Med Decis Making 1996; 16:288-299.

9. Ryan M, Hughes J. Using conjoint analysis to assess women's preferences for miscarriage management. Health Econ 1997; 6: 261-73.

10. Drakapoulas SA. Hierarchical choice in economics. J Econ Surv 1994; 8: 133-153.

11. Ryan M. A comparison of stated preference methods for estimating monetary values. Health Econ 2004; 13: 291-296.

12. Adamowicz W, Boxall P, Williams $M$, Louviere I. Stated preference approaches for measuring passive use valises: Choice experiments and contingent valuation. Amer I Agr Econ 1998; 80: 64-75.

13. Hanley $N$, MacMillan $D$, Wright $R E$, et al. Contingent valuation versus choice experiments: Estimating the benefits of environmentally sensitive areas in Scotland. I Agr Econ 1998; 49: $1-15$.

14. Hanley N, Wright RE Adamowicz V. Using choice experiments to value the environment. Environ Resource Econ 1998; 11:413-428.

15. Boxall $\mathrm{PC}$, Adanowicz $\mathrm{WL}$, Swait $J$, Williarns $\mathrm{M}$, Louviere J. A comparison of stated preference methods for environmental valuation. Ecolog Econ 1996; 18. 243-253. 


\section{Chapter 5}

16. Frew $\mathrm{E}$, Whynes $\mathrm{DK}$, Wolstenholme $\mathrm{JL}$. Eliciting willingness to pay: comparing closedended with open-ended and payment scale formats. Med Decis Making 2003; 23: 150-159.

17. Ryan $M$, Scotk DA, Donaldson $C$. Valluing health care using willingness to pay: a comparison of the payment card and dichotomous choice methods. I Health Econ 2004; 23: $237-258$.

18. Arrow K, Solow R, Leamer $E$, Portney $P$, Randner $R$, Schuman $H$. Report of the NOAA panel on contingent waluation. Fed Reg $1993 ; 58: 4602-4614$.

19. Ryan M, Scott DA, Reeves $C_{\text {, }}$ et all Eliciting public preferences for healtheare: a systematic review of technigues. Health Technol Assess $2001 ; 5(5)$.

20. Donaldson C, Shackley P. Does "process" utility exist? A case study of willingness to pay for laparoscopic cholecystectomy. Soc Sci Med 1997; 44: 699-707.

21. Chestnut $L G$, Keller ML, Lambert WE, Rowe, RD. Measuring heart patients" willingness to pay for changes in angina symptoms. Med Decis Making 1996; 16: 65-77.

22. OBrien BJ, Goere R, Gafni A, et al. Assessing the value of a new pharmaceutical. A feasibility study of contingent valuation in managed care. Med Care 1998; 36: 370-384.

23. Dranitsaris G. Pamidronate for the prevention of skeletal-related events in multiple meylona. What does the public think it is worth? Int J Technol Assess Health Care 1999; 15: $108-122$.

24. Slothuus U, Larsen $M L$, Junker $P$. Willingness to pay for arthritis symptom alleviation. Comparison of closed-ended questions with and without follow-up. Int J Technol Assess Health Care $2000 ; 16: 60-72$.

25. Eastaugh SR. Willingness to pay in treatment of bleeding disorders. Int $\mathbf{J}$ Technol Assess Health Care 2000; 16: 706-710.

26. Zillich AJ, Blumenschein $K$, Johannesson M, Freeman $P$. Assessment of the relationship between measures of disease severity, quality of life and willingness to pay in asthma. Pharmacoeconomics $2002 ; 20: 257-265$.

27. Kartman $B$, Stalhammar $N O$, Johannesson $M$. Valuation of healti changes with the contingent valuation method: a test of scope and question order effects. Health Econ 1996; 5 : $531-541$.

28. Stewart IM, O'Shea $\mathrm{E}$, Donaldson $\mathrm{C}$, Shackley $\mathrm{P}$. Do ordering effects matter in willingnessto-pay studies of health care? I Health Econ 2002; $21: 585-599$.

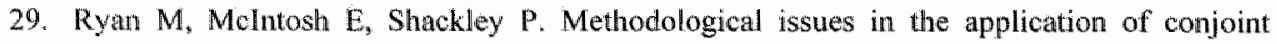
analysis in health care. Health Econ 1998; 7: 373-378.

30. Farrar $\mathrm{S}$, Ryan $\mathrm{M}$. Response-ordering effects: a methodological issue in conjoint analysis. Health Econ $1999 ; 8 ; 75-79$. 
31. Hornberger JC, Habraken $\mathrm{H}$, Bloch DA. Minimum data needed on patient preferences for accurate, efficient medical decision making. Med Care 1995; 33: 297-310.

32. Scott A, Vick S. Patients, doctors and contracts: an application of principal-agent theory to the doctor-patient relationship. Scot J Polit Econ 1999; 46: 111-134.

33. Donaldson C, Shackley P, Abdalla M. Using willingness to pay to value close substitutes: carrier screening for cystic fibrosis revisited. Health Econ 1997; 6: 145-159.

34. Olsen JA. Aiding priority setting in health care: is there a role for the contingent valuation method? Health Econ 1997; 6: 603-612.

35. Gyldmark M, Morrison GC. Demand for health care in Denmark: results of a national sample survey using contingent valuation. Soc Sei Med 2001; 53:1023-1036.

36. Shackley $P$, Donaldson $C$. Should we use willingness to pay to elicit community preferences for health care? New evidence from using a 'marginal' approach. J Health Econ 2002; 21 : 971-991.

37. Bryan $S$, Buxton $M$, Sheldon $R$, Grant, A. Magnetic resonance imaging for the investigation of knee injuries: an investigation of preferences. Health Econ 1998; 7: 595-603.

38. Slothuus Skjoldborg U, Gyrd-Hansen D. Conjoint analysis. The cost-variable: an Achilles" heel? Health Econ 2003; 12: 479-491.

39. Ryan M, San Miguel F. Testing for consistency in willingness to pay experiments. J Econ Psych 2000; $21: 305-317$.

40. Whynes $\mathrm{D}$, Frew $\mathrm{E}$, Wolstenholme $\mathrm{L}$. A comparison of two methods for eliciting contingent valuations of colorectal cancer screening. J Health Econ $2003 ; 22: 555-574$.

41. Salkeld $G$, Ryan $M$, Short $L$. The veil of experience: do consumers prefer what they know best? Health Econ 2000; 9: $267-270$.

42. Verlegh PWJ, Schifferstein HN., Wittink DR. Range and number-of-levels effects in derived and stated measures of attribute importance. Market Lett $2002 ; 13: 41-52$.

43. American Marketing Association. Conjoint analysis: a guide for designing and interpreting conjoint studies. Market Research Division, Marketing Research Technique Series, 1992.

44. Ratcliffe $J$, Longworth $L$. Investigating the structural reliability of a discrete choice experiment within health technology assessment. Int J Technol Assess Health Care 2002; 18: $139-144$.

45. Dalmau-Matarrodona E. Alternative approaches to obtain optimal bid values in contingent valuation studies and to model protest zeros. Estimating the determinants of individuals" willingness to pay for home care services in day case surgery. Health Econ 2001; $10: 101$ 118. 
46. Neumann PJ, Johannesson $M$. The willingness to pay for in vifro fertilization: a pilot study using contingent waluation. Med Care 1994; 32:686-699.

47. Frew $\mathrm{E}_{*}$ Wolstenholme $\mathrm{J}$, Whynes $\mathrm{DK}$. Willingness-to-pay for colorectal cancer screening. Eur J Cancer 2001; 37: 1746-1751.

48. Jacobs RJ, Moleski RJ, Meyerhoff AS. Valination of symptomatic hepatitis $A$ in adults: estimates based on time trade-off and willingness-to-pay measurement. Pharmacoeconomics 2002; $20: 739-747$.

49. Blumenschein K, Johannesson M. Relationship between quality of life instruments, health state utilities, and willingness to pay in patients with asthma. Ann Allergy Asthma Immunol 1998; 80: 189-194.

50. Kartman $B$, Andersson $F ;$ Johanmesson M. Willingness to pay for reductions in angina pectoris attacks. Med Decis Making 1996; 16:248-253.

51. Lee SJ, Liljas B, Neumarn PJ, Weinstein MC, Johannesson $M$. The impact of risk information on patients" willingness to pay for autologous blood donation. Med Care 1998; 36: $1162-1173$.

52. Johannesson M, Johansson P-O, Kristrơm B, Borgquist L, Jönsson B. Willingness to pay for lipid lowering; a health production function approach. App/ Econ 1993; 25: 1023-1031.

53. Ryan M. Using conjoint analysis to take account of patient preferences and go beyond health outcomes: an application to in vitro fertilisation. Soc Sci Med 1999; 48: 535-546.

54. San Miguel FS, Ryan M, McIntosh E. Applying conjoint analysis in economic evaluations: an application to menorrhagia. Appl Econ 2000; 32: 823-833.

55. Telser $H$, Zweifel P. Measuring willingness-to-pay for risk reductions: an application of conjoint analysis. Health Econ $2002 ; 11: 129-139$.

56. Gyrd-Hansen D, Sogaard J. Analysing public preferences for cancer screening programmes. Health Econ 2001; 10:617-634.

57. Slothuus U, Larsen ML, Junker P. The contingent ranking method - a feasible and valid method when eliciting preferences for health care? Soc Sci Med 2002; 54: 1601-1609.

58. Onwujekwe 0 . Searching for a better willingness to pay elicitation method in rural Nigeria: the binary question with follow-up method versus the bidding game technique. Health Econ 2001: 10: 147-158. 


\section{Chapter 6}

\section{Cost-effectiveness of the diagnosis and treatment of renal artery stenosis}

D. van Helvoort-Postulart, C.D. Dirksen, P.J. Nelemans, A.A. Kroon, A.G.H. Kessels, P.W. de Leeuw, G.B.C. Vasbinder, J.M.A. van Engelshoven, M.G.M. Hunink 


\section{Abstract}

\section{Purpose}

To determine the cost-effectiveness of performing digital subtraction angiography (DSA), computed tomography angiography (CTA), magnetic resonance angiography (MRA), or proceeding immediately to tentative revascularization in patients suspected of having renovascular hypertension.

\section{Materials and methods}

Using a Monte Carlo Markov decision model, cost-effectiveness analysis was performed from the societal perspective. Data were derived from the Renal Artery Diagnostic Imaging Study in Hypertension and from published literature. The base-case analysis evaluated a 50-year old patient with a diastolic blood pressure greater than 95 monHg and one or more clinical clues suggestive of renovascular hypertension. The outcome measures were quality adjusted life expectancy, lifetime costs, and incremental cost-effectiveness ratios.

\section{Results}

For a 50-year old male patient suspected of having renal artery stenosis proceeding immediately to tentative revascularization was the least costly and most effective strategy, i.e. it dominated all other strategies. For a 50-year old female patient immediate tentative revascularization was more effective than the DSA strategy but also more costly and had an incremental cost-effectiveness ratio of $E 7143 / \mathrm{QALY}$. The results were sensitive to the prior probability of stenosis. As the prior probability increases, the more invasive the optimal diagnostic imaging strategy becomes. The results were also sensitive to the sensitivity of CTA and MRA, and the costs associated with DSA.

\section{Conclusion}

Our results suggest that immediate tentative revascularization is cost-effective in patients with a high suspicion of renovascular hypertension, CTA is cost-effective in those with a low suspicion, and medical therapy is cost-effective in those in whom renal artery stenosis is unlikely. 


\section{Introduction}

The percentage of secondary hypertension is $4 \%$ in the general hypertensive population [1] with renovascular hypertension being the most common form of secondary hypertension. As compared to essential hypertension, renovascular hypertension seems less responsive to treatment with antilypertensive medications, has a higher risk of progression to accelerated or malignant hypertension and may result in irreversible renal failure. Hence, timely detection and treatment of renal artery stenosis is important.

Currently, percutaneous transluminal renal angioplasty (PTRA) and stent placement are accepted treatment options for renal artery stenosis. The major objectives of anatomical correction of renal artery stenosis are to normalize blood pressure with the aim to prevent cardiovascular complications, such as myocardial infarction or stroke, and to prevent or delay the loss of renal function.

Digital subtraction angiography (DSA) is considered the reference test for detecting renal artery stenosis. The major disadvantage of DSA is that the procedure has a risk of mortality and morbidity. In addition, DSA is expensive compared with other imaging modalities. At present, minimally invasive imaging techniques, such as magnetic resonance angiography (MRA) and computed tomography angiography (CTA), are available for the diagnostic work-up of renal artery stenosis. The optimal diagnostic imaging strategy, however, has not yet been defined.

The Renal Artery Diagnostic Imaging Study in Hypertension (RADISH) was performed to determine the role of MRA and CTA in comparison to DSA in patients with suspected renovascular hypertension. Sensitivity and specificity results are presented elsewhere [2]. A second goal of the RADISH study was to investigate whether CTA or MRA can replace DSA for detecting renal artery stenosis which could lead to cost savings and fewer complications during the diagnostic work-up. These advantages, however, need to be weighed against the health effects in the long-term as a result of missed diagnoses of renal artery stenosis.

The purpose of this paper was to analyze the costs, effectiveness, and costeffectiveness of various diagnostic imaging strategies (DSA, CTA or MRA) for patients suspected of having renovascular hypertension.

\section{Materials and methods}

\section{The model}

A Monte Carlo Markov decision analytic model was developed to calculate lifetime costs and benefits, expressed as quality adjusted life years (QALYs), and the 
incremental cost-effectiveness ratios associated with four diagnostic strategies for patients suspected of having renovascular hypertension: (1) DSA, (2) CTA, (3) MRA, and (4) immediate tentative revascularization. Monte Carlo analysis determines the prognoses of a large number of individual patients. The transition probabilities that govern each individual transition during each cycle are realized as a random event through computer-generated random numbers.

Suspicion of renovascular hypertension was based on a diastolic blood pressure equal to or exceeding $95 \mathrm{mmHg}$ and one or more clinical features suggestive of renovascular hypertension [3]. The clinical features are listed in Table 1. In the DSA strategy, the diagnostic DSA and subsequent revascularization were performed on different days, so patients with demonstrated renal artery stenosis on DSA required an additional intra-arterial procedure. In the minimally invasive diagnostic imaging strategies (CTA and MRA), a revascularization procedure was scheduled if CTA or MRA demonstrated a stenosis, whereas after a negative test result no further diagnostic tests were performed instantly. In the immediate tentative revascularization strategy, every patient suspected of having renal artery stenosis was referred for a percutaneous revascularization procedure. The diagnostic DSA immediately preceding the revascularization procedure determined whether or not the revascularization procedure was actually performed. A planned revascularization procedure that is terminated after the diagnostic DSA implies inefficient use of personnel, equipment, and room time, thus increasing costs. Treatment with antihypertensive medication, referred to as medical therapy, was considered the reference strategy. The analysis was performed from the societal perspective. The model was programmed in DATA Professional, Treeage Software Inc., Release 11.

The angiographic definition of a hemodynamically significant renal artery stenosis was defined as a stenosis $\geq 50 \%$. After being tested, patients with a negative test result, including both patients with a missed diagnosis of renal artery stenosis and patients who are correctly identified as not having a stenosis, were treated with antihypertensive medication. Patients with a positive test result and atherosclerotic ostial stenoses were treated with primary stent placement, whereas fibromuscular dysplasia was managed with percutaneous transluminal renal angioplasty (PTRA). Atherosclerotic non-ostial stenoses were treated with PTRA followed by immediate stent placement if PTRA was unsuccessful.

Complications may occur as a result of diagnostic procedures or revascularization. Reversible complications were major complications defined as complications that 
Table 1 Clinical features suggestive of renovascular hypertension

Systolic/diastolic epigastric, subcostal, or flank bruit

Accelerated or malignant hypertension

Unilateral small kidney

Severe hypertension in child or young adult, or after 50 years

Sudden development or worsening of hypertension at any age

Hypertension and unexplained impairment of renal function

Sudden worsening of renal function in hypertensive patient

Hypertension refractory to appropriate three-drug regimen

Impairment in renal function in response to angiotensin-converting enzyme inhibitor

Extensive occlusive disease in coronary, cerebral, and peripheral circulation

required therapy and/or prolonged the patient's hospital stay. Furthermore, two irreversible procedure-related complications were included in the model, i.e. chronic renal failure (CRF) and major stroke.

Inherent to decision modelling, various assumptions were necessary to keep the model tractable. First, patients were permitted to undergo repeat diagnostic work-up and treatment up to a maximum of three times if significant restenosis was suspected after being treated for renal artery stenosis, or significant stenosis was suspected after initially being diagnosed as having no significant stenosis. The suspicion of (re)stenosis was based on increasing diastolic blood pressure, worsening renal function, or both. Therefore, three clinical status levels were distinguished: satisfactory clinical status (diastolic blood pressure $<90 \mathrm{mmHg}$ and creatinine $<1.8 \mathrm{mg} / \mathrm{dl}$, moderate clinical status (diastolic blood pressure 90-110 $\mathrm{mmHg}$ and creatinine $<1.8 \mathrm{mg} / \mathrm{dl}$ ), and severe clinical status (diastolic blood pressure $\geq 110 \mathrm{mmHg}$ and/or creatinine $\geq 1.8 \mathrm{mg} / \mathrm{dl}$ ). Since the clinical status was defined in terms of diastolic blood pressure and renal function, it was assumed that the probability to undergo repeat diagnostic work-up was the same for all patients that reached a severe clinical status irrespective of whether the patient achieved the severe clinical status based on diastolic blood pressure or renal function. Second, if a repeat diagnostic work-up was necessary we assumed that the same imaging modalities were performed as in the initial work-up strategy. Third, percutaneous revascularization (PTRA or stent placement) for renal artery stenosis was included in the model and surgery was not considered. Fourth, restenoses were managed in the same way as the initial stenosis except that after initially having undergone PTRA for non-ostial atherosclerotic renal artery stenosis, restenoses were treated with stent placement. Finally, the underlying condition and localization of restenoses were assumed to be the same as that of the initial stenosis. 


\section{Clinical data}

Table 2 presents the variables, base case values, and ranges explored with sensitivity analyses. Follow-up data are presented in the Appendix. The model combined data from the medicall literature and original patient data from the RADISH study and the Dutch Renal Artery Stenosis Intervention Cooperative Study (DRASTIC) [8].

\section{Diagnostic work-up and treatment}

The prior probability of renal artery stenosis, the percentage of patients presenting with fibromuscular dysplasia versus atherosclerosis, and the percentage of ostial versus nonostial lesions, were derived from the RADISH study [2]. At the initial work-up the prior probability was $19.1 \%$ for male patients and $20.9 \%$ for female patients (Table 2 ). If a repeat diagnostic work-up was necessary during follow-up, the probability of restenosis was $30 \%$ in patients who had undergone a prior revascularization procedure for renal artery stenosis (expert opinion). Also based on expert opinion, the probability to develop renal attery stenosis during follow-up was $2 \%$ in patients without a stenosis at the initial work-up. DSA was considered the reference test for diagnosing renal artery stenosis. We assumed that there was no loss in accuracy of DSA interpretation when it is done in conjunction with preparations for revascularization rather than as a separate procedure. In the cost-effectiveness analysis, data from the RADISH study on the diagnostic accuracy of 3D contrast enhanced MRA were used [2]. CRF as a result of DSA or CTA was assumed to be associated with the use of contrast media. We assumed that mortality related to CTA was caused by exposure to low-osmolality contrast agents [5].

Results of PTRA and stent placement depended on the underlying condition of the stenosis, i.e atherosclerosis versus fibromuscullar dysplasia. Treatment results were defined in terms of diastolic blood pressure and renal function, referred to as the clinical status of the patient. Data on elinical status were derived from the RADISH study and original patient data from the DRASTIC study [8]. The percentage of major complications from a revascularization procedure $(8.8 \%)$ was derived from a review including 1118 patients [10].

\section{Follow wp}

Mortality in patients with essential hypertension and in patients after treatment for renal artery stenosis was expressed as annual relative hazard ratios (Appendix) compared with the mortality rate in the general population [13]. Mortality in dialysis patients was 
Table 2 Base case values and ranges used in the sensitivity analyses

\begin{tabular}{|c|c|c|}
\hline Vaniable & Base case value (range) & References \\
\hline \multicolumn{3}{|l|}{ Prior probability of RAS } \\
\hline Overall & $20.0 \%(0 \%-40 \%)$ & $\mathbb{R S}$ \\
\hline Atherosclerosis & $64.9 \%$ & $\mathrm{RS}$ \\
\hline Ostial & $56.0 \%$ & RS \\
\hline Nonmostial & $44.0 \%$ & RS \\
\hline Fibromuscular dysplasia & $35.1 \%$ & RS \\
\hline Male patients & $19.1 \%$ & RS \\
\hline Atherosclerosis & $92.3 \%(0 \%-100 \%)$ & RS \\
\hline Ostial & $55.6 \%$ & RS \\
\hline Non-ostial & $44.4 \%$ & RS \\
\hline Fibronuscular dysplasia & $7.7 \%$ & RS \\
\hline Female patients & $20.9 \%$ & RS \\
\hline Atherosclerosis & $36.8 \%(0 \%-100 \%)$ & $\mathrm{RS}$ \\
\hline Ostial & $57.1 \%$ & RS \\
\hline Non-ostial & $42.9 \%$ & RS \\
\hline Fibromuscular dysplasia & $63.2 \%$ & RS \\
\hline \multicolumn{3}{|l|}{ MRA } \\
\hline Sensitivity & $57 \%(88 \%-100 \%)$ & $\mathbb{R S}, 4$ \\
\hline Specificity & $90 \%(75 \%-100 \%)$ & $\mathrm{RS}, 4$ \\
\hline Major complications & $0.3 \%$ & RS \\
\hline \multicolumn{3}{|l|}{$\begin{array}{l}\text { Major complications } \\
\text { CTA }\end{array}$} \\
\hline Sensitivity & $69 \%(94 \%-100 \%)$ & RS, 4 \\
\hline Specificity & $91 \%(92 \%-99 \%)$ & $\mathrm{RS}_{2} 4$ \\
\hline $\mathrm{CRR}{ }^{*}$ & $0.02 \%$ & 5 \\
\hline Major complications & $1.1 \%$ & $\mathrm{RS}$ \\
\hline Mortality & $0.0011 \%$ & 5 \\
\hline \multicolumn{3}{|l|}{$\begin{array}{l}\text { Mortality } \\
\text { DSA. }\end{array}$} \\
\hline $\mathrm{CRF}^{*}$ & $0.02 \%$ & 5 \\
\hline Stroke & $0.12 \%$ & 6 \\
\hline Major complications & $1.3 \%$ & RS \\
\hline Mortality & $0.033 \%(0.162 \%)$ & 6,7 \\
\hline \multirow{2}{*}{\multicolumn{3}{|c|}{$\begin{array}{l}\text { Mortality } \\
\text { Radiological revascularization } \\
\text { Results at three months/one year }\end{array}$}} \\
\hline & & RS, 8 \\
\hline \multicolumn{3}{|l|}{$\begin{array}{l}\text { Results at three nonthis/one year } \\
\text { Atheroselerosis }\end{array}$} \\
\hline Successful & $27.9 \% / 32.8 \%$ & \\
\hline Improved & $51.9 \% / 48.4 \%$ & \\
\hline Not successful & $20.2 \% / 18.8 \%$ & \\
\hline \multicolumn{3}{|l|}{$\begin{array}{l}\text { Not successful } \\
\text { Fibromuscular dysplasia }\end{array}$} \\
\hline Successful & $56.5 \% / 50,0 \%$ & \\
\hline Improved & $43.5 \% \% 50.0 \%$ & \\
\hline Not successful & $0.0 \% / 0.0 \%$ & \\
\hline CRF & $0.3 \%$ & 9 \\
\hline Stroke & $0.44 \%$ & 9 \\
\hline Major complications ${ }^{\$}$ & $8.8 \%$ & 10 \\
\hline Mortality & $10 \%(0 \%-2 \%)$ & 11 \\
\hline Discount rate & $3 \%(0 \%-7 \%)$ & 12 \\
\hline
\end{tabular}

RAS: renal artery stenosis; RS: RADISH study, MRA: magnetic resonance angiography; CTA: computed tomography angiography; CRF: chronic renall failure; DSA: digital subtraction anglography.

CRF a a result of DSA or CTA was assumed to be associated with the use of contrast media

"It was assumed that mortality related to CTA is caused by exposure to low-osmolality contrast agents.

- Treatment results were defined in terms of diastolic blood pressure (DBP) and renal function (creatinine level). For the results at three months/one year, treatment was considered clinically suecessful/normal clinical status (DBP $<90 \mathrm{mmHg}$ without antihypertensive medication and ereatinine level $<1.8 \mathrm{mg} / \mathrm{di}$ ), improved/moderate clinical status (DBP $90-110 \mathrm{mmHg}$ and ereatinine level $<1.8 \mathrm{mg} / \mathrm{dl}$ ) or clinically not successful/severe clinical status (DBP $\geq 110 \mathrm{mml}$ lig and/or creatinine level $\geq 1.8 \mathrm{mg} / \mathrm{dll}$ ).

Including branch renal artery injury (2.2\%), main renal artery damage (2.4\%), puncture sitte injury $(2.3 \%)$ embolization (1.1\%), nephrectomy $(0.3 \%)$ and other major complications $(0.5 \%)$

The range represents the $95 \%$ confidence interval. 


\section{Chapter 6}

Table 3 Costs and utilities

\begin{tabular}{|c|c|c|}
\hline Vartable: & Base case rallize (range) & References \\
\hline \multicolumn{3}{|l|}{ Diagnositic proceduregs } \\
\hline DSA & $1711(1242 ; 1359 ; 2063)$ & RS \\
\hline MRA & 965 & $\mathrm{RS}$ \\
\hline CrA & 420 & RS \\
\hline $\begin{array}{l}\text { Additional diagnostic procedures, including } \\
\text { three outpatient vists }\end{array}$ & 440 & $\mathrm{RS}$ \\
\hline \multicolumn{3}{|l|}{ Treatmant procedures } \\
\hline Angioplasty uninlateroul & 2589 & RS \\
\hline Angioplasty bulaternl & 3231 & RS \\
\hline Stenit placement unilateral & 4296 & $\mathrm{RS}$ \\
\hline Stent placement bitateral & 608 & $\mathrm{RS}$ \\
\hline $\begin{array}{l}\text { Angioplasty unilateral and stent placement } \\
\text { unilateral }\end{array}$ & 5098 & $\mathrm{RS}$ \\
\hline Plannied angioplasity and terminated after DSA & 1917 & $\mathrm{RS}$ \\
\hline \multicolumn{3}{|l|}{ Compl ications } \\
\hline MRA & 235 & $20^{s}+$ assumption \\
\hline $\mathrm{C} \mathrm{IA}^{*}$ & 235 & $20^{5}+$ assumption \\
\hline Major complications trom invas ave procedures & 704 & $20^{3}$ \\
\hline Start dialysis therapy & 7686 & 21 \\
\hline Treatment after myocardial infaretion & $\$ 000$ & $20^{5}, 22$ \\
\hline Treatment after stroke & 11281 & 23 \\
\hline Mortalify from procedures & 2416 & $20^{8}$ \\
\hline \multicolumn{3}{|l|}{ Follow-up (aninual costs) } \\
\hline \multicolumn{3}{|l|}{ Genetral population } \\
\hline $\mathrm{DBP}<95 \mathrm{mmHg}$ & 1466 & 24 \\
\hline DBP $95-104$ minllg & 2215 & 24 \\
\hline $\mathrm{DBP}>104 \mathrm{mmllg}$ & 4242 & 24 \\
\hline \multicolumn{3}{|l|}{ Population after treatment for RAS } \\
\hline DBP $<90 \mathrm{~mm} H \mathrm{~g}$ & 3487 & $\mathrm{RS}+$ assumption \\
\hline $\mathrm{DBP} \geq 90 \mathrm{mmHg}$ & 3693 & $\mathrm{RS}+$ assumption \\
\hline Dialysis therapy"*t" & $62020(48768-75272)$ & 21 \\
\hline Nursing home & 52509 & $20^{5}$ \\
\hline Nursing home and dialysis therapy & $114529(101277-127781)$ & $20^{\text {s. }}, 21$ \\
\hline \multicolumn{3}{|l|}{ Utilities } \\
\hline Post najor stroke & 0.39 & 25 \\
\hline Chronic dialysis & 0.57 & 26 \\
\hline $\begin{array}{l}\text { Posi major stroke and dependent on dialysis } \\
\text { ther tapy }\end{array}$ & 0.20 & Assumption \\
\hline Myocardiat infarchion & 0.72 & 27 \\
\hline Population with essential hypertionsior & 0.831 & 28 \\
\hline Pationts one year after treatment for $\mathbb{R A S}^{\text {*** }}$ & $0.78(0.70-0.82)$ & $\operatorname{RS}, 29$ \\
\hline Geveral population & 0.879 & 28 \\
\hline \multicolumn{3}{|l|}{ Duration of discomfort (days) } \\
\hline DSA & 0.94 & RS \\
\hline CTA & 0.24 & RS \\
\hline MRA & 0.27 & RS \\
\hline Thermpentic interention & 5.34 & RS \\
\hline \multicolumn{3}{|l|}{ Disutility from discomfort of the procedure } \\
\hline DSA & 0.56 & RS \\
\hline $\mathrm{CTA}$ & 0.136 & RS \\
\hline $\mathrm{MFA}$ & 0.33 & RS \\
\hline Therdpeutic intervention & 0.56 & Assumption \\
\hline
\end{tabular}

DSA: digital subtration mgiography; RS: RADISH study; MRA: magnetic resonance angiography; CTA: computed tomograpity angiography; DBP diastolic blood pressure; $R$ AS: renal artery stenosis.

"Sinee the duration of hospitalization is not the same throughout the hospitals in the Netherlands" the values between brackets represent the costs of DSA if patients retum home after couple of hours of bed rest and observation (E 1242$)$, if patients are admitted for one night (e1359), and if pattents are admitted for three nights ( 2063$)$. These alternative values were used in the sensitivity analyses. 


\footnotetext{
Costs of a revascularization procedure that is terminated after the diagnostic DSA ( 61917$)$ were calculated as follows: the costs of a unilateral PTRA procedure (E1603) minus the material costs (64\%9), plus the costs of hospitalization ( $(€ 704)$, laboratory tests ( $(€ 3)$, travelling ( $(63)$, patient time $(\in 15$ ), and productivity losses ( $(e 78)$.

"Conts of complications as a result of CTA and MRA were assumyed, on average, to equal the costs of a oneday admission. The costs of a one-day admission ( $(2235)$ were assumed to be two-thirds of an ovemight
admission ( 632 ).

Guideline prices were updated with the health care price index to 2000 Dutch guilders (soure: Statline Dutch Bureau of Statistics) and subsequently converted to Euros (Euro $=2.20371$ Dutch guilder).

"For major complications from invasive procedures (DSA, PTRA with or without stent placenent) it was assumed that the hospital adnission was, on average, prolonged with two days.

Costs of dying from procedures were assumed to equal the costs of two days of admission in an intensive care unit.

"If CRF occurs, it is assumed that the patient remains dependent on diallysis therapy tor the rest of his or her remaining lifetime.

"Baseline value represents mean annual costs of dialysis therapy. Yearly costs range from 448768 10 675272 , depending on the type of dialysis. These values were used in the sensitivity analyses.

tow If major stroke occurs it is assumed that the patient is admitted into a nursing home.

*we In the sensitivity analyses, 0,82 was used for patients with a satisfactory clinical status (diastolic blood pressure $<90 \mathrm{mmHg}$ without antihypertensive medication and creatinine $<1.8 \mathrm{mg} / \mathrm{dl}$ ), whereas 0.70 was used for patients with an unsatisfactory climical status.
}

derived from a publication reporting mortality among patients starting dialysis therapy with hypertension as cause of renal failure [15]. Mortality after stroke was derived from a community-based study that examined the five-year survival after first-ever stroke [14].

\section{Costs and quality adjusted life years}

Table 3 presents the costs and utility weights. The cost calculations were performed according to the Dutch guidelines for cost calculations in health care [20]. All costs relevant to society were considered. Costs were calculated by multiplying the unit costs with volumes of use. Time costs included time spent by family and friends in providing informal care and patient time costs due to the inability to do their usual activities which was approximated with absence from work and/or inability to do the housekeeping. Informal care and inability to do the housekeeping were valued using a shadow price of E8 per hour, being the wage rate of a cleaning person [20]. Productivity losses were estimated with the friction cost method $[30,31,32]$. The time patients spent receiving care - like travelling, waiting, undergoing an intervention, and recovery time - was valued as far as patients recorded absence from work and/or inability to do the housekeeping.

Unit costs (not charges) for procedures and laboratory tests, including personnel, materials, and equipment, were available from the University Hospital Maastricht. To take housing and overhead into account, the unit costs were increased by $35 \%$ [20]. For hospitalization, outpatient visits, home care utilization, travel costs, and general. 
practitioner visits, unit costs quoted in the Dutch guidelines were used [20]. Empiricall data concerming medication use were available from the RADISH study. For the costs of medication, the Pharmacotherapeutic Compass $2000 / 2001$ was used, which prowides information about drugs available in the Netherlands and the associated unit (Defined Daily Dose) costs [33].

Data concerning costs outside the health care sector, as well ws information about general practitioner visits and home care utillization, were gathered with cost diaries. Patients with a paid housekeeper were asked to provide information about the associated out-of-pocket expenses. Future health and non-health care costs unrelated to the disease under investigation were not considered.

CRF, myocardial infarction, and major stroke resulted in once-only costs ( $€ 7686$, e5000, e11281, respectively) and disutility (Table 3). Furthermore, if CRF occurred, it was assumed that the patient remained dependent on dialysis for the rest of the remaining lifetime, thereby generating annual costs ( 662020$)$ and utility values associated with the health status of dialysis patients. Also, if major stroke occurred it was assumed that the patient was admitted into a nursing home, thereby generating annual costs (E52509) and utility values associated with the health status of post stroke patients. All costs were updated with the thealth care price index to 2000 Euros (source: Statline Dutch Bureau of Statistics; $\epsilon 1=2.20371$ Dutch Guilders).

Quality adjusted life years were calculated as the sum of the time spent in each health state, multiplied by a correction factor representing the quality of life, i.e. utility, in each of the health states. Death resulted in loss of life years. Health values for patients one year after treatment for renal artery stenosis were available from the RADISH study Quality of life adjustments were assumed to remain constant over time within a health state. Temporary disutility from diagnostic imaging techniques and percutaneous treatment procedures was included in the model as a quality of life reduction. These values were adjusted for the duration of the experienced discomfort. The effects of complications as a result of diagnostic procedures were reflected in the disutility values of the inaging tests.

\section{Analyses}

To test the internal consistency of the model, intermediate outcomes were calculated. To facilitate interpretation of the intermediate outcomes we omitted repeat diagnostic workup and repeat percutaneous revascularization from the analysis of internal consistency. 
The base case analysis evaluated a 50-year old male patient with diastolic blood pressure greater than $95 \mathrm{mmHg}$ and one or more clinical clues suggestive of renovascular hypertension [3]. Using a first order Monte Carlo analysis, the patient was simulated multiple times $(\mathrm{N}=50000$ trials) for each of the five strategies, including medical therapy (reference strategy). In addition, a 50-year old female patient was evaluated. The decision to evaluate 50-year old patients was based on the mean age of the patients enrolled in the RADISH study. Mean age was 54 and 50 years for male and female patients, respectively. To facilitate comparison the mean age of male patients was rounded down. In addition, a 60-year old male patient and a 40-year old female patient were considered. For 50-year old subjects, life expectancy was 28 and 32 years for male and female subjects, respectively. Life expectancy was 20 and 42 years for a 60-year old male patient and a 40-year old female patient, respectively (source: StatLine Dutch Bureau of Statistics, November 2003). Sensitivity analyses were performed to examine the robustness of the results.

Future costs and benefits were discounted at an annual rate of 3\% [12]. To determine cost-effectiveness of alternative diagnostic strategies incremental cost-effectiveness (CE) ratios were calculated. The strategies were ordered according to increasing effectiveness, and (extended) dominated strategies were eliminated. A strategy was considered to be dominated by another strategy if the latter yielded more QALYs at lower costs. A strategy was considered to be extended dominated if another strategy yielded more QALYs and had a lower incremental CE-ratio. Incremental CE-ratios of the remaining strategies were then calculated as the difference in costs divided by the difference in QALYs for one particular strategy compared to the next best strategy. A threshold incremental cost-effectiveness ratio of $€ 20000$ per QALY gained was considered.

\section{Results}

\section{Internal consistency}

Table 4 presents the intermediate outcomes of costs and effects associated with the diagnostic strategies conditional on the diagnostic test result. Note that DSA was considered the reference test and that repeat diagnostic work-up and repeat percutaneous revascularization were not modelled in the analyses of internal consistency of intermediate outcomes to facilitate interpretation. The diagnostic procedures differed with respect to accuracy, costs, risk of mortality and morbidity, and disutility (discomfort) experienced by the patient. 
The intermediate outcomes proved to be consistent with various prior expectations, to be illustrated with a few examples. First, given a true positive test result, the DSA strategy was more expensive as compared to immediate tentative revascularization since in the latter strategy diagnosis and subsequent revascularization were performed in one session, leading to cost savings. Also, given a true negative test result, effectiveness was highest for medical therapy since in patients without renal artery stenosis, procedurerelated morbidity and mortality are incurred whereas no favourable health effects can be expected from performing a diagnostic test. Finally, irrespective of the test result, the costs related to the MRA strategy were higher as compared to the CTA strategy, since the costs associated with a MRA procedure (€965) are considerably higher than the costs of a CTA procedure ( $E 420)$.

\section{Base case analysis}

Table 5 shows the results for a 50 -year old patient. The strategies were ordered in sequence of increasing effectiveness, defined as quality adjusted life years. For a 50year old male patient the strategy whereby a revascularization procedure was planned for every patient suspected of having renal artery stenosis, immediate tentative revascularization, was the least costly and most effective strategy, i.e. it dominated all other strategies. For a 50-year old female patient immediate revascularization was more effective than the DSA strategy but also more costly and had an incremental costeffectiveness ratio of $67143 / \mathrm{QALY}$. For a 60 -year old male patient the order of the strategies did not change and the immediate tentative revascularization strategy dominated all other strategies (costs were $€ 38783$ and the effectiveness was 8.744 QALYs). For a 40-year old female patient, immediate revascularization was the most effective (16.668 QALYs) and least costly (€75734) strategy, and dominated all other strategies.

\section{Sensitivity analyses}

Figure 1 presents the results of the sensitivity analyses when a threshold incremental cost-effectiveness ratio of $€ 20000$ was considered.

\section{Male patients}

The results were sensitive to the prior probability of renal artery stenosis (Figure la) and

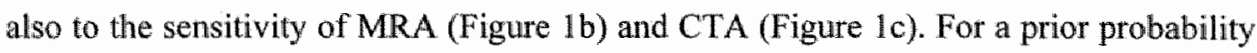
equal to or more than $10 \%$, immediate tentative revascularization was the preferred 
Table 4 Intermediate results for a 50-year old male patient

\begin{tabular}{|c|c|c|c|c|c|c|c|c|c|c|}
\hline & DSA & & CTA & & MRA & & KEVAS & & $\mathrm{MT}$ & \\
\hline & Costs & QAL $\mathrm{T}$ & Coosts & QALY & Costs & QALY & Cosis & QALV & Costs & QALY \\
\hline $\mathrm{DP}$ & 112312 & 7.812 & 110793 & 7.824 & 111590 & 7.819 & 110284 & 7.80 & $\mathrm{Na}$ & $\mathrm{Na}$ \\
\hline $\mathrm{FN}$ & $\mathrm{N} / \mathrm{a}$ & $\mathrm{N} / \mathrm{a}$ & 153996 & 6.097 & 155485 & 6.109 & Nha & N/a & 153249 & 6.079 \\
\hline $\mathrm{TW}$ & 411203 & 13,222 & 39563 & 13.261 & 39956 & 13.262 & 41323 & 13.244 & 38502 & 13.283 \\
\hline $\mathrm{FP}$ & N/a & $\mathrm{N} / \mathrm{a}$ & 41900 & 13,221 & 42700 & 13.246 & Na & $\mathrm{N} / \mathrm{a}$ & $\mathrm{N} / \mathrm{a}$ & $\mathrm{W} / \mathrm{a}$ \\
\hline
\end{tabular}

DSA: digital subtraction angiography; CTA : computed tomography anglography; MRA: magnetuc nesonance angiography; REVAS: immed late tentative revascularization; MT: medical therapy; $Q A L Y$ : discounted quality adjusted life year; TP: true positive; FN: false negative; TN: true negative; FP: false positive; N/a: not
applicable.

Table 5 Results for a 50-year old patient suspected of having renal artery stenosis

\begin{tabular}{|c|c|c|c|}
\hline Diagnostic strategies & QALYs & Costs $(C)$ & Incremental $\mathrm{CB}$-ando \\
\hline \multicolumn{4}{|r|}{ the } \\
\hline $\mathrm{MT}$ & 11.866 & 60841 & Dominated \\
\hline MRA & 12.088 & 56890 & Dominated \\
\hline CTA & 12.163 & 55191 & Dombinated \\
\hline DSA & 12.195 & 55570 & Domingted \\
\hline REVAS & 12.265 & 54415 & $\mathrm{~N} / \mathrm{sh}$ \\
\hline \multicolumn{4}{|l|}{ Fremale } \\
\hline $\mathrm{MT}$ & 13.381 & 70980 & Dominated \\
\hline MRA & 13.731 & 66731 & Donninated \\
\hline CTA & 13.749 & 63970 & Dominated \\
\hline DSA & 13.902 & 63079 & $\mathrm{~N} / \mathrm{a}$ \\
\hline REVAS & 13.937 & 63329 & $67143 / Q A L Y$ \\
\hline
\end{tabular}

QALY: discounted quality adjusted ife year; CE-ratio: cost-effectiveness ratio; MT: medical therapy; MRA: magnetic resonance angiography; CTA: computed tomography angiography; DSA: digital subtraction angiography; REVAS: immediate tentative revascularization; N/a: not applicable.

strategy. If the prior probability was equal to or more than $3 \%$ but less than $10 \%$, the strategy of choice was CTA. If the prior probability was less than $3 \%$, medical therapy was the preferred option with cost-effectiveness ratios below $620000 / \mathrm{QAL} Y$. When the model was recalculated assuming $98 \%$ sensitivity for CTA and MRA, the CTA strategy was preferred when the prior probability ranged from $19.1 \%$ (base case value) up to and including $33 \%$, whereas immediate tentative revascularization was the strategy of choice when the prior probability was $35 \%$ or higher.

If the sensitivity of MRA increased from $57 \%$ to $100 \%$, the effectiveness of the MRA strategy increased with 0.148 QALY and the costs decreased with $€ 2660$. However, immediate tentative revascularization was still more effective with an incremental cost-effectiveness ratio of $66379 / \mathrm{QALY}$. Since the cost-effectiveness ratio was below $620000 / \mathrm{QALY}$, immediate tentative revascularization was the preferred strategy, so the decision did not change. If the sensitivity of CTA increased from $69 \%$ to 


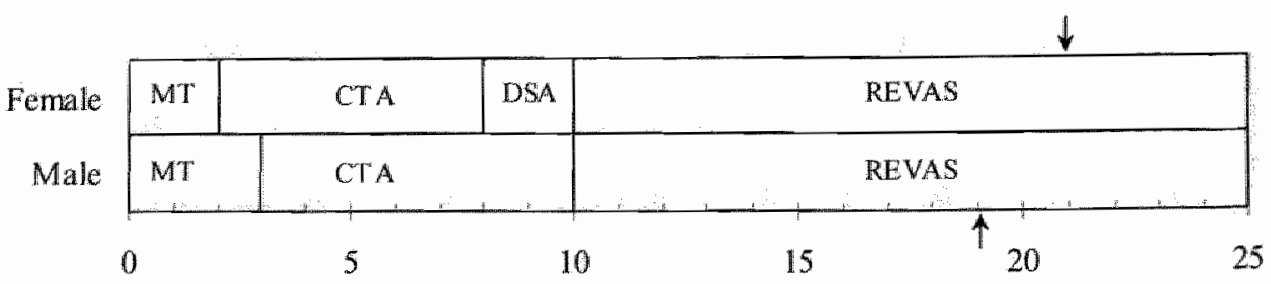

(a) Prior probability of renal antery stenos is $(\%)$

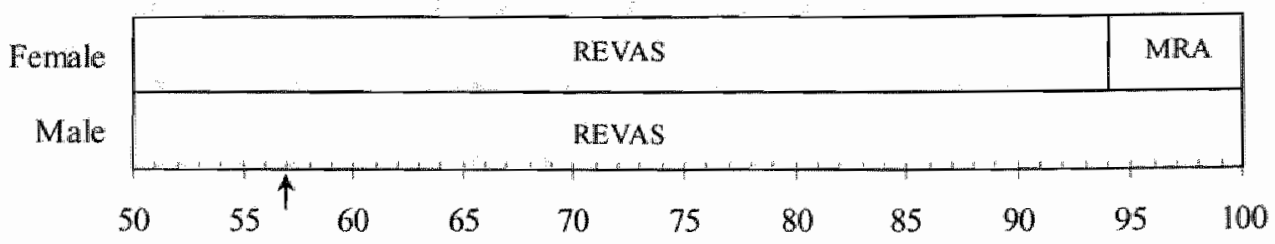

(b) Sensitivity of MRA $(\%)$

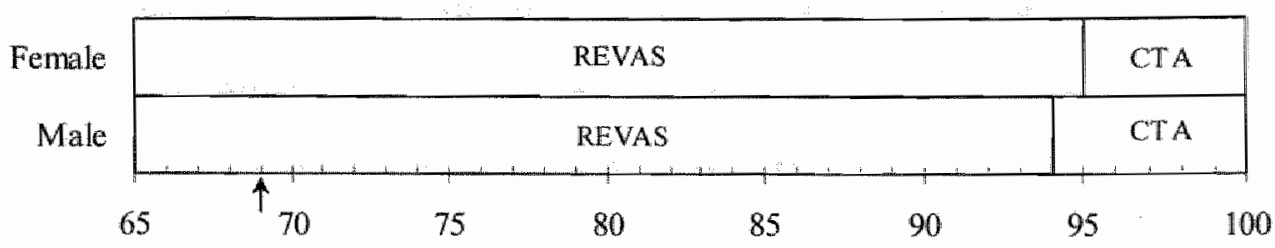

(c) Sensitivity of CTA $(\%)$

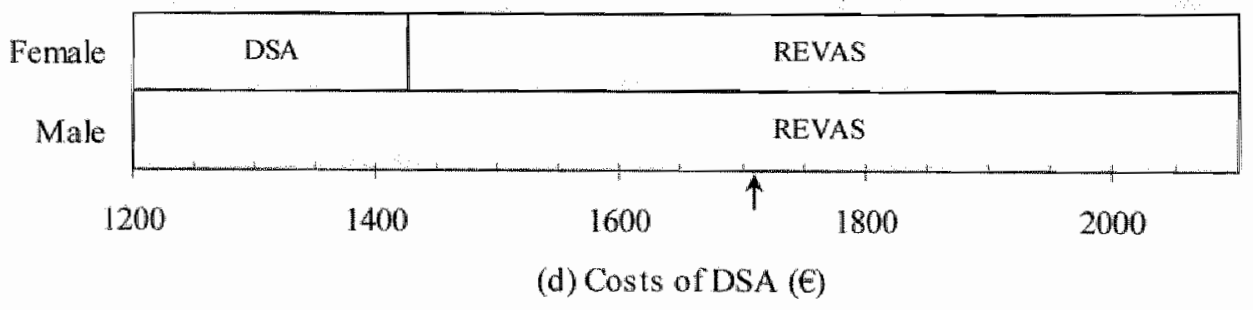

Figure 1 Sensitivity analyses of the influential variables. MT: medical therapy; CTA: computed tomography anglography; DSA: digital subtraction angiography; REVAS: immediate tentative revascularization; MRA: magnetic resonance angiography. The black arrows represent the base case values. 
$94 \%$ and $100 \%$, immediate tentative revascularization was more effective as compared to the CTA strategy but with incremental cost-effectiveness ratios of $€ 23043 / \mathrm{QALY}$ and $660625 / \mathrm{QALY}$, respectively, and therefore CTA was the strategy of choice. If the sensitivity of CTA was $93 \%$, immediate tentative revascularization was more effective with an incremental cost-effectiveness ratio of $19196 /$ QALY. Thus the sensitivity of CTA must be at least $94 \%$ for the decision to switch from immediate tentative revascularization to the CTA strategy.

Varying other important variables did not affect the conclusions and immediate tentative revascularization remained dominant.

\section{Female patients}

The results were sensitive to the prior probability of renal artery stenosis (Figure 1a), the sensitivity of MRA (Figure 1b) and CTA (Figure Ic), and also to the costs associated with a DSA procedure (Figure Id). If the prior probability was equal to or more than $10 \%$, immediate tentative revascularization was the preferred strategy. DSA was the strategy of choice if the prior probability was $8 \%$ or $9 \%$. If the prior probability was equal to or more than $2 \%$ but less than $8 \%$, CTA was the preferred strategy. When the prior probability was $1 \%$, medical therapy was the most cost-effective strategy. When the model was recalculated assuming $98 \%$ sensitivity for CTA and MRA, the MRA strategy was the preferred option when the prior probability was $20.9 \%$ (base case value). CTA was the strategy of choice if the prior probability ranged from $22 \%$ up to and including $33 \%$, whereas immediate tentative revascularization was the strategy of choice if the prior probability was $35 \%$ or higher.

If the sensitivity of MRA increased from $57 \%$ to $100 \%$, the MRA strategy dominated all other strategies. If the sensitivity of MRA was $93 \%$ and $94 \%$, immediate tentative revascularization was more effective with incremental cost-effectiveness ratios of $€ 12536 / \mathrm{QALY}$ and $€ 20625 / \mathrm{QALY}$, respectively. Thus the sensitivity of MRA must be at least $94 \%$ for the decision to switch from immediate tentative revascularization to the MRA strategy. If the sensitivity of CTA increased from $69 \%$ to $94 \%$ and $100 \%$, immediate tentative revascularization was still more effective as compared to the CTA strategy but with incremental cost-effectiveness ratios of $19623 / \mathrm{QALY}$ and $662400 / \mathrm{QALY}$, respectively. If the sensitivity of CTA was $95 \%$, immediate tentative revascularization was more effective with an incremental cost-effectiveness ratio of 
E24927/QALY. Thus the sensitivity of CTA must be at least $95 \%$ for the decision to switch from immediate tentative revascularization to the CTA strategy.

For the base case analysis it was assumed that patients were admitted for two nights for DSA. Since the duration of hospitalization varies across hospitals, the costs of DSA were assumed to be $€ 2063, € 1359$ and $€ 1242$ representing the scenario in which patients were admitted for three nights, for one night or could return home after a few hours of bed rest and observation, respectively. If patients could return home after a few hours of bed rest and observation after DSA or were admitted for only one night, immediate tentative revascularization was more effective than the DSA strategy but with incremental cost-effectiveness ratios of E28143/QALY and E22914/QALY, respectively, so exceeding the threshold of $€ 20000 /$ QALY suggesting that the DSA strategy is cost-effective in these situations. In case of an admission for three nights, immediate tentative revascularization dominated all other strategies. If the costs of DSA were $€ 1400$ and $€ 1425$, immediate tentative revascularization was more effective than the DSA strategy with incremental cost-effectiveness ratios of $121086 / \mathrm{QALY}$ and $€ 19943 / \mathrm{QALY}$, respectively. Thus the costs of DSA must be at least $€ 1425$ for the decision to switch from the DSA strategy to immediate tentative revascularization.

Varying other important variables did not alter the results. Immediate tentative revascularization remained the strategy of choice with incremental cost-effectiveness ratios ranging from $64409 / \mathrm{QALY}$ to $€ 9057 / \mathrm{QALY}$.

\section{Discussion}

This study addressed the costs, effects, and cost-effectiveness of various diagnostic strategies for detecting renal artery stenosis. The results, both for male and female patients, suggest that the optimal strategy is immediate tentative revascularization, i.e. scheduling every patient suspected of having renal artery stenosis for a revascularization procedure. The diagnostic DSA immediately preceding the revascularization procedure determines whether or not to proceed with the revascularization procedure.

Our findings may be explained by the poor sensitivity of CTA and MRA. The model included sensitivity data from the RADISH study, i.e. $69 \%$ for CTA and 57\% for MRA. Since these unfavourable sensitivity values were contrary to the results of nearly all other published studies on the validity of CTA and MRA [4], the model was recalculated assuming $98 \%$ sensitivity for CTA and MRA. In that case, for male patients, the CTA strategy was preferred, whereas for female patients, the MRA strategy was the preferred option. In case of $98 \%$ sensitivity for CTA and MRA, immediate 
rewascularization became the strategy of choice when the prior probability was $35 \%$ or higher, both for male and female patients.

In patients with a diagnosis of renal artery stenosis, the DSA strategy was more expensive as compared to immediate tentative revascularization since the diagnostic DS.A procedure and subsequent revascularization were performed during separate sessions. On the other hand, in patients without renal artery stenosis, the costs of a revascularization procedure that is terminated after the diagnostic DSA equal the costs of a DSA procedure ( $€ 1711)$ plus an additional amount of money for inefficient use of personnel, equipment, and room time (E206). Therefore, the optimal strategy will switch from DSA to immediate tentative revascularization as the prior probability increases.

Seven previously published studies analyzed the cost-effectiveness of the diagnostic work-up for renal artery stenosis [34-40]. The studies differed from our analysis with respect to the outcome measure (i.e. cost per successful treatment, cost per life-year gained), type of imaging techniques included in the evaluation, time span, sensitivity and specificity values, and the perspective of the analysis. Due to differences between the studies it was difficult to compare our results with the existing literature and to draw general conclusions about the optimal diagnostic work-up strategy for renal artery stenosis. To illustrate the diversity, we will discuss four papers $[34,35,39,40]$.

Helin et al. [34] compared captopril renography screening followed by angioplasty or surgery with lifetime drug treatment. The outcome measure of the screening strategy was the cost per successful treatment. Captopril renography was assumed to have a sensitivity of $100 \%$ and a specificity of $68 \%$. The authors concluded that, in a nonselected hypertensive population, general screening for renovascular hypertension appeared to be unjustified due to low prevalence $(4 \%)$. Screening with captopril renography became cost-effective when limited to patients with no obvious renal parenchymal disease and with hypertension that did not respond to two antihypertensive drugs or was detected in patients aged 30 years or younger.

Also, Nelemans et al. [35] assessed the cost-effectiveness of eight diagnostic strategies to diagnose renovasular hypertension. The analysis was conducted from the perspective of the health care system, the outcome measure was costs per life-year gained, and the time span was 10 years. The authors found that CTA before angiography maximized the number of additional life-years saved and was a costeffective alternative to captopril renography before angiography. Furthermore, strategies including MRA were only cost-effective if the costs of MRA could be halved. 
A more recent study by Lévesque et al. [39] analyzed the economic impact of contrast-enhanced duplex Doppler ultrasonography as compared to the usual diagnostic procedures, i.e. captopril-enlaanced renal scintigraphy or unenhanced ultrasonograpiny. The analysis was performed from the societal perspective and the costs per successful diagnosis were $\$ 422$ and $\$ 343$ for the usual diagnostic test and enhanced ultrasonography, respectively.

Finally, Carlos et al. [40] evaluated the cost-effectiveness of conventional angiography (sensitivity $99 \%$; specificity $99 \%$ ), CTA (sensitivity $96 \%$; specificity $96 \%$ ), and MRA (sensitivity $98 \%$; specificity $94 \%$ ). The imaging strategies were compared with the natural history of medication-resistant hypertension (i.e. two-drug therapy), and with enhanced medical therapy (i.e. a third antihypertensive medication was prescribed) without prior imaging. The analysis was carried out from the societal perspective and assessed lifetime costs and quality adjusted life years. The three imaging strategies and enhanced medical therapy dominated natural history. Conventional angiography dominated enhanced medical therapy, whereas CTA and MRA yielded cost-effectiveness ratios below $\$ 16000 / \mathrm{QALY}$ compared with enhanced medical therapy. Conventional angiography dominated CTA and MRA.

Various assumptions had to be made with respect to the data. For example, the clinical treatment results were derived from the RADISH study and DRASTIC study [8]. The clinical results after treatment and the results at one year were used to calculate the conditional probabilities for the first year of the follow-up. Since the follow-up period after treatment for renal artery stenosis was limited to twelve months, it was impossible to empirically determine the clinical results in the long-term. Furthermore, the decision model required conditional probabilities. Published studies commonly do not provide sufficient detail to derive this information and reported numbers are often not fully applicable to the problem under investigation. Therefore, data with respect to the clinical results beyond one year were based on literature data, adjusted and supplemented with expert opinion.

A conservative and arbitrary threshold incremental cost-effectiveness ratio of E20000/QALY was considered since this is a commonly quoted number for the Netherlands. Based on health policy decisions made in the Netherlands, the implied society's willingness-to-pay value probably lies between E33000/QALY and E54000/QALY [41,42]. Although these figures are substantially higher than the threshold we used, applying this range to the present analysis would lead to the same 
conclusion concerning the cost-effectiveness of diagnostic imaging strategres to detect renal artery stenosis.

The current analysis showed that diagnostic testing for renal artery stenosis appears to be justified even in a hypertensive population with a relatively low prevalence $2 \%$ for women and $3 \%$ for men) of renal artery stenosis. Furthermore, the deciston as $t o$ which diagnostic strategy to use in practice depends on the probability of renall artery stenosis. As the prior probability increases, the more invasive the optimal diagnostic imaging strategy becomes. For example, for male patients the strategy of choice switched from medical therapy (prior probability 1-2\%) to CTA (prior probability $3-9 \%$ ) and to immediate tentative revascularization (prior probability $\geq 10 \%$ ). Clinical practice varies considerably across hospitals and doctors, even if the patient population can be considered similar, and the clinical algorithm for the diagnostic imaging work-up of patients with suspected renovascular hypertension is not clearly defined. Our results suggest that clinical policy should be redefined and management decisions should be conditional on the prior probability. Therefore, for each individual patient a clinical prediction rule should be used to calculate the probability that renal artery stenosis is present [43].

In conclusion, our results suggest that immediate tentative revascularization is costeffective in patients with a high suspicion of renovascular hypertension, CTA is costeffective in those with a low suspicion, and medical therapy is cost-effective in those in whom renal artery stenosis is unlikely. 


\section{Appendix}

\section{Follow-up data}

\begin{tabular}{|c|c|c|}
\hline Variable: & Vallue & Referencesi \\
\hline \multicolumn{3}{|l|}{ Annual relative hazard ratios for mortality } \\
\hline Genteral population & 1 & Reference value: \\
\hline \multicolumn{3}{|l|}{ Essential hypertension } \\
\hline DEP $90-110 \mathrm{~mm} H \mathrm{~g}$ & 1.7 & 13 \\
\hline$D B P \geq 110 \mathrm{mmHg}$ & 2.7 & 13 \\
\hline \multicolumn{3}{|l|}{ After treatment for RAS"+ } \\
\hline group I & 24. & 13 \\
\hline group 2 & 4.0 & 13 \\
\hline group 3 & 6.4 & 13 \\
\hline \multicolumn{3}{|l|}{ Anntall mortality rate after major stroke } \\
\hline First year & $0.454 / \mathrm{yr}$ & 14 \\
\hline Second year and thereafter & $0.105 / \mathrm{yr}$ & 14 \\
\hline Annual mortality rate in dialysis patients & $0.265 / \mathrm{yr}$ & 15 \\
\hline \multicolumn{3}{|l|}{$\begin{array}{l}\text { Annual mortality rate in dialysis patients after having experienced } \\
\text { major stroke }\end{array}$} \\
\hline \multirow{2}{*}{\multicolumn{3}{|c|}{$\begin{array}{l}\text { Incidence of chronic renal failure } \\
\text { General population }\end{array}$}} \\
\hline & & \\
\hline $\mathrm{DBP}<90 \mathrm{mmH}$ & $0.00011 / y \mathrm{r}$ & 16 \\
\hline DBP $90-110 \mathrm{mmHg}$ & $0.00051 / \mathrm{yr}$ & 16 \\
\hline $\mathrm{DAP} \geq 110 \mathrm{mmF}$ & $0.00122 / \mathrm{yr}$ & 16 \\
\hline Afler revascularization & $0.0016 / y^{2}$ & $\llbracket 7$ \\
\hline Without revascularization & $0.027 / \mathrm{yr}$ & 18 \\
\hline After having experienced major stroke & $0.027 / y r$ & 18 \\
\hline \multicolumn{3}{|l|}{ Incidence of myocardial infarction } \\
\hline \multicolumn{3}{|l|}{ General population } \\
\hline $\mathrm{DBP}<90 \mathrm{~mm} \mathrm{Hg}$ & $0.0044 / \mathrm{yl}^{\mathrm{u}}$ & 19 \\
\hline DBP $90-110 \mathrm{mmHg}$ & $0.0095 / \mathrm{yr}$ & $\$ 9$ \\
\hline $\mathrm{DBP} \geq 110 \mathrm{mmHg}$ & $0.0136 / \mathrm{yr}$ & $\$ 9$ \\
\hline \multicolumn{3}{|l|}{ After treatment for RAS ${ }^{*}$} \\
\hline group 1 & $0,0346 / \mathrm{yr}$ & 19 \\
\hline group 2 & $0.0748 / \mathrm{yr}$ & 19 \\
\hline group 3 & $0.1071 / \mathrm{yr}$ & 19 \\
\hline After having experienced major stroke & $0.1071 / \mathrm{yr}$ & 19 \\
\hline In dialysis pritients & $0.1 / \mathrm{yr}$ & Expert opinton \\
\hline In clialysis patients after having experienced major stroke & $0.1 / y$ & Expert opinion \\
\hline \multicolumn{3}{|l|}{ Incidence of major stroke } \\
\hline \multicolumn{3}{|l|}{ General population } \\
\hline$D \mathrm{BP}^{\mathrm{S}}<90 \mathrm{~mm} H \mathrm{~g}$ & $0.0011 / y^{\circ}$ & 19 \\
\hline DBP $90-110 \mathrm{mmHg}$ & $0.0025 \mathrm{yz}$ & 19 \\
\hline $\mathrm{DB}\left\|^{3} \geq\right\| 10 \mathrm{mmHg}$ & $0.0101 / \mathrm{yr}^{\prime}$ & 19 \\
\hline \multicolumn{3}{|l|}{ Afler trisament for RAS ${ }^{4+}$} \\
\hline group I & $0.0059 / \mathrm{yr}$ & 19 \\
\hline group 2 & $0.0134 / \mathrm{yr}$ & 19 \\
\hline group 3 & $0.0543 / \mathrm{yr}$ & 19 \\
\hline Afler having experienced major stroke previously & $0.0543 / \mathrm{yr}$ & 19 \\
\hline In dialysis patients & $0.1 / y^{1}$ & Expert opinion \\
\hline $\begin{array}{l}\text { In dialysis patients after having experienced major stroke } \\
\text { previously }\end{array}$ & $0.1 / \mathrm{yr}$ & Expert opinion \\
\hline
\end{tabular}

DBP: diastolic blood pressure, RAS: renal artery stenosis.

"Thue clinical status levels were distinguished: (a) group 1: DBP $<90 \mathrm{mmHg}$ and creatinine $<1.8 \mathrm{mg} / \mathrm{dl}$ (nomal clinical status), (b) group 2: DBP $90-110 \mathrm{mmHg}$ and creatinine $<1.8 \mathrm{mg} / \mathrm{dl}$ (moderate clinical status), and (c) group 3: DBP $\geq 110 \mathrm{mmHg}$ and $/$ or creatinine $\geq 1.8 \mathrm{mg} / \mathrm{dl}$ (severe clinical status).

"Radiological revascularization or medical therapy. 


\section{References}

1. Kidney $\mathrm{DD}$, Deutsch $\mathrm{L}$. The indications and results of percutaneous transhuminal angioplasty and stenting in renal artery stenosis. Semin Vase Surg 1996; 9: 188-197.

2. Vasbinder GBC, Nelemans PJ, Kessels $\mathrm{AGH}_{\text {, }}$ et al, for the Renal Artery Diagnostio Imaging Study in Hypertension (RADISH) Study Group. Accuracy of computed tomographic angiography and magnetic resonance angiography for diagnosing renal artery stenosis. Ann Intern Med 2004; 141:674-682.

3. Working Group on Renovascular Hypertension. Detection, evaluation, and treatment of renovascular hypertension. Final report. Arch Intern Med 1987; 147:820-829.

4. Vasbinder GBC, Nelemans PJ, Kessels AGH, Kroon AA, Leeuw de PW, Engelshoven van JMA. Diagnostic tests for renal artery stenosis in patients suspected of having renovascular hypertension: A meta-analysis. Ann Intem Med 2001; 135: 401-411.

5. Lawrence V, Matthai $W$, Hartnaier $S$. Comparative safety of highosmolatity and lowosmolality radiographic contrast agents. Invest Radiol 1992; 27:2-28.

6. Waugh JR, Sacharias N. Arteriographic complications in the DSA era. Radiology 1992; 182: $243-246$.

7. Hessel SJ, Adams DF, Abrams HL. Complications of angiography, Radiology 1981; 138: 273-281.

8. Jaarsveld van $\mathrm{BC}$, Krijnen $\mathrm{P}$, Pieteman $\mathrm{H}_{3}$ et at, for the Dutch Renal Artery Stenosis Intervention Cooperative Study Group. The effect of balloon angioplasty on hypertension in atherosclerotic renal-artery stenosis. N Engl J Med 2000;342:1007-1014.

9. Weibull $\mathrm{H}$, Bergqvist D, Jonsson $\mathrm{K}$, Carlsson S, Takolander R. Analysis of complications after percutaneous transluminal angioplasty of renal artery stenoses. Eur I Vasc Surg 1987; $1: 77-84$.

10. Martin LG, Rees CR, O'Bryant. Percutaneous angioplasty of the renal arteries. In: Strandness DE, Breda van A, eds. Vascular diseases: surgical and interventional therapy, $3^{\text {tod }}$ edition. New York, Churchill Livingstone, 1994; 721-741.

11. Leertouwer TC, Gussenhowen EJ, Bosch JL, et al. Stent placement for renal arterial stenosis: where do we stand? A meta- analysis. Radiology 2000; $216: 78-85$.

12. Gold MR, Siegel JE, Russel LB, Weinstein MC. Cost-effectiveness in health and medicine. New York, Oxford University Press, 1996.

13. Isles $\mathrm{C}$, Main J, O'Connell J, et al. Survival associated with renovascular disease in Glasgow and Newcastle: a collaborative study. Scott Med J 1990; 35: 70-73. 
14. Hankey $G J$ Jamrozik K, Broadhurst RJ, et al. Five-year survival after first-ever stroke and related prognostic factors in the Perth Community Stroke Study. Stroke 2000, 31: 20802086 .

15. Byme C, Vernon $P$, Cohen JJ. Effect of age and diagnosis on survival of older patients beginning chronic dialysis. JAMA 1994; 271:34-36.

16. Iseki $K$, Kimura $Y$, Wakugami $K$, et al. Comparison of the effect of blood pressure on the development of stroke, acute myocardial infarction, and end-stage renal disease. Hypertens Res 2000; 23: 143-149.

17. Losinno $F$, Zuccall $A$, Busato $F$, Zucchelli $P$. Renal artery angioplasty for renovascular hypentension and preservation of renal function: Iong-term angiographic and clinical followup. AJR Am J Roentgenol 1994; 162: 853-857.

18. Chabova V, Schirger A, Stanson AW, McKusick MA, Textor SC. Outcomes of atherosclerotic renal artery stenosis managed without rewascularization. Mayo Clin Proc $2000 ; 75: 437-444$.

19. MacMahon S, Peto R, Cutller $J_{*}$ et al. Blood pressure, stroke, and coronary heart disease. Part 1. Prolonged differences in blood pressure: prospective observational studies corrected for the regression dilution bias. Lancet 1990; 335: 765-774.

20. Oostenbrink JB, Koopmanschap MA, Rutten FFH. Handleiding voor kostenonderzoek: Methoden en richtlijnprijzen voor economische evaluaties in de gezondheidszorg. Amstelveen, College voor zorgverzekeringen, 2000.

21. Wit de GA, Polder JJ, Jager KJ, Charro de ETh. De maatschappelijke kosten van nierziekten in Nederland. TSG 2001; 79: 49-54.

22. Bergen wan PFMM, Jonker JJC, Hout van BA, et al. Costs and effects of long-term oral anticoagulant treatment after myocardial infarction. JAMA 1995; 273: 925-928.

23. Bergman $L$, Meulen van der JHP, Limburg M, Habbema JDF, Costs of nedical care after first-ever stroke in the Netherlands. Stroke 1995; 26:1830-1836.

24. Kiiskinen $U_{*}$ Vartiainen $E_{*}$ Puska P, Aromaa A. Long-term cost and life-expectancy consequences of hypertension. J Hypertens 1998; 16:1103-1112.

25. Samsa GP, Matchar DB, Goldstein $L_{\text {, }}$ et al. Utilities for major stroke: results from a survey of preferences among persons at increased risk for stroke. Am Heart J 1998; 136: 703-713.

26. Postulart D, Adang EMM. Response shift and adaptation in chronically ill patients. Med Decis Making 2000;20:186-193.

27. Tsevat $J_{y}$ Goldman L, Lamas GA, et al. Functional status versus utilities in survivors of myocardial infarction. Med Care 1991; 29: 1153-1159. 
28. Lawrence WF, Fryback DG, Martin PA, Klein R, Klein BEK. Health status and hypertension: a population-based study. J Clin Epidemiol 1996; 49: 1239-1245.

29. Bosch JL, Tetteroo E, Mali WPTM, Hunink MGM, for the Dutch Miac Stent Trial Study Group. Iliac arterial occlusive disease: cost-effectiveness analysis of stent placement versus percutaneous transluminal angioplasty. Radiology 1998; 208: 641-648.

30. Koopmanschap MA, Ineveld van BM. Towards a new approach for estimating indirect costs of disease. Soc Sci Med 1992; 34: 1005-1010.

31. Koopmanschap MA, Rutten FF, Ineveld van BM, Roijen van $L$. The friction cost method for measuring indirect costs of disease. J Health Econ 1995; 14: 171-189.

32. Koopmanschap MA, Rutten FF. A practical guide for calculating indirect costs of disease. Pharmacoeconomics 1996; 10: 460-466.

33. College voor zorgverzekeringen. Farmacotherapeutisch Kompas $2000 / 2001$.

34. Helin KH, Tikkanen I, Von Knorring JE, et al. Screening for renovascular hypertension in a population with relatively low prevalence. J Hypertens 1998; 16: 1523-1529.

35. Nelemans PJ, Kessels AGH, Leeurw de P, Haan de M, Engelshoven wan J. The costeffectiveness of the diagnosis of renal artery stenosis. Eur J Radiol 1998; 27: 95-107.

36. Radermacher J, Brunkhorst R. Diagnosis and treatment of renovascular stenosis - a costbenefit analysis. Nephrol Dial Transplant 1998; 13:2761-2767.

37. Blaufox MD, Middleton ML, Bongiovanni J, Davis BR. Cost efficacy of the diagnosis and therapy of trenovascular hypertension. J Nucl Med 1996; 37: 171-177.

38. Lawrence WF, Grist TM, Brazy PC, Fryback DG. Magnetic resonance angiography in progressive renal failure: a technology assessment. Am J Kidney Dis 1995; 25: 701-709.

39. Lévesque J, Lacourcière $\mathrm{Y}$, Onrot $\mathrm{JM}$, et all. Economic impact of an ultrasonographic contrast agent on the diagnosis and initial management of patients with suspected renal artery stenosis. Can Assoc Radiol J 2002; $53: 228-236$.

40. Carlos RC, Axelrod DA, Ellis JH, Abraharmse PH, Fendrick AM. Incorporating patient centered outcomes in the analysis of cost-effectiveness: imaging strategies for renovascular hypertension. AJR Am J Roentgenol 2003; 181: 1653-1661.

41. Hout van $B, B$ onsel $G$, Habbema $D$, Maas van der $P$, Charro de $F$. Heart transplantation in the Netherlands; costs, effects and scenarios. I Health Econ 1993; 12:73-93.

42. Enckevort van PL, Ten Vergert EM, Bonsel GJ, et al. Technology assessment of the Dutch Lung Transplantation Program. Int I Technol Assess Health Care 1998; 14: 344-356.

43. Krijnen $P$, Jaarsveld van BC, Steyerberg EW, Man in "t Veld AJ, Schalekamp MADH, Habbema JDF. A clinical prediction rule for renal artery stenosis. Am Intern Med 1998; 129: 705-711. 


\section{Chapter 7}

\section{General discussion}


In this thesis on the economic evaluation of the diagnostic imaging work-up for renal artery stenosis in hypertensive patients two main subjects can be identified. The first is a clinical subject that involves the evaluation of DSA, CTA and MRA for the diagnostic work-up for hypertensive patients suspected of renal artery stenosis. The second is a methodological subject that focuses on the use of willingness-to-pay in health care.

\section{Clinical subject}

At the start of the studies described in this thesis, DSA was considered the reference standard for the diagnostic work-up for hypertensive patients suspected of having renal artery stenosis. However, due to disadvantages associated with the DSA procedure, less invasive diagnostic alternatives were widely used in clinical practice. In this respect, CTA and MRA seemed promising techniques for the detection of renal artery stenosis. However, at the time only a limited number of small well-designed studies had been published on the diagnostic accuracy of either CTA or MRA [1].

To define the optimal diagnostic work-up for the detection of renal artery stenosis in hypertensive patients, a large multi-centre prospective study was designed. The Renal Artery Diagnostic Imaging Study in Hypentension (RADISH) aimed (1) to assess the diagnostic accuracy of CTA and MRA and (2) to determine the costs and effects, including patient preferences, of applying DSA, CTA and MRA for the diagnosis of renal artery stenosis.

In the preceding chapters a number of studies related to the economic evaluation of the diagnosis of renal artery stenosis were reported. The results with respect to the diagnostic accuracy of CTA and MRA are reported elsewhere [2]. Aim of the cost analysis was to analyze the costs of the initial procedures and to make comparisons between perspectives. Thus, future costs were not considered. From the cost analysis it was concluded that CTA was the least costly diagnostic imaging procedure irrespective of the perspective used. From the societal perspective, the costs of DSA, CTA and MRA were $€ 1721,6424$, and 6966 , respectively. Overall the radiology department incurred the largest proportion of the costs. The analysis revealed that the costs varied among the various viowpoints from which the analysis was conducted. For example, the costs of CTA ranged from $€ 7$ from the patient perspective to 6424 from the societal perspective. However, the ordering of the procedures according to costs was the same, irrespective of the perspective of the analysis. So, performing the analysis from different 
perspectives led to the same conclusion concerning the least costly diagnostic imaging strategy.

Patient preferences were estimated using the willingness-to-pay method. Patients after having undergone DSA, CTA and MRA were asked to imagine the hypothetical scenario in which the patient had to return to the hospital with the same complaints two years later. Furthermore, they were asked to imagine that the health insurance company did not cover CTA and MRA, whereas on the other hand, DSA was covered. Patients were given a description of each imaging modality, which served as a reminder. They were not informed about the sensitivity and specificity of the tests, complication rates, and treatment benefit. Also the health effects in the long-term as a result of a missed diagnosis, and the possibility to undergo inappropriate treatment as a result of a falsepositive test, were not explicitly mentioned. Patients were asked how nuch they would be willing to pay for CTA and MRA in order to avoid DSA. The study revealed that patients preferred CTA. Thirty-eight patients (18\%) were not willing to pay for CTA, whereas 55 patients $(26 \%)$ were not willing to pay for MRA.

Although the costs of CTA were substantially lower than those of DSA, the latter procedure has the advantage of providing therapeutic options at the time of the diagnostic evaluation, thus leading to cost savings in patients with demonstrated renal artery stenosis. To take into account this potentially advantageous feature of DSA, and to include long-term costs and health benefits in the analysis, a cost-effectiveness analysis was conducted to compare various diagnostic strategies for detecting renal artery stenosis.

For the cost-effectiveness analysis, a Markov decision analytic model was developed. The results of the cost analysis were included in the model. As part of the cost-effectiveness analysis, patients were asked to indicate the experienced burden associated with each of the diagnostic imaging tests on a visual analogue scale ranging from 0 (not bothersome at all) to 10 (extremely bothersome). The scores on the visual analogue scales showed that patients experienced CTA as the least bothersome and DSA as the most bothersome test. These scores were used in the Markov model to reflect temporary disutility from the diagnostic imaging techniques. Disutility was incorporated in the model as a quality of life reduction. Alternatively, the willingnessto-pay values of the patient preference study could have been used in the costeffectiveness model to reflect temporary disutility. To avoid double counting, however, the willingness-to-pay data were not actually used. The cost-effectiveness analysis 
slowed that the optimal diagnostic work-up would be to schedule every hypertensive patient suspected of having renal artery stenosis for a revascularization procedure. The diagnostic DSA immediately preceding the revascularization procedure determines whether or not to proceed with the revascularization procedure. Thus, combining the results of the cost analysis and the cost-effectiveness analysis demonstrated that the relatively low costs associated with a CTA procedure did not counterbalance the unfavourable health effects and future costs as a result of missed diagnoses of renal artery stenosis.

Sensitivity analyses revealed that the higher the prior probability of renal artery stenosis the more invasive the optimal diagnostic strategy became, although even when the prior probability decreased to $10 \%$, immediate tentative revascularization remained the most attractive strategy. So, in spite of the lower costs, lower morbidity and mortality rates, a limited gain with revascularization, and lower disutility values of CTA as compared to DSA, immediate tentative revascularization was the diagnostic strategy of choice over a wide range of values for the prior probability of renal artery stenosis.

Since the diagnostic performance of CTA and MRA was poor and contrary to the results of nearly all other published studies on the validity of CTA and MRA [1,2] questions may rise about the applicability of the results of the cost-effectiveness study. On the other hand, so far the RADISH study has been the largest multi-centre prospective study comparing the diagnostic performance of CTA and MRA. The study was well designed with state-of-the art equipment and scan protocols, experienced observers, blinded image evaluations, and so on. The RADISH study has provided an important contribution to the knowledge and literature with respect to the diagnosis of renal artery stenosis. To optimize health care for hypertensive patients with suspected renal artery stenosis, results from the RADISH study should therefore be considered and used in clinical practice. Despite the favourable results in the literature, based on the results of the RADISH study it was concluded that CTA and MRA are not sensitive enough for the diagnoses of renal artery stenosis. From the cost-effectiveness point of view, it was concluded that the immediate tentative revascularization strategy, i.e. the diagnostic DSA determines whether or not to proceed with revascularization, was the preferred approach. Thus, DSA remains the method of choice for the diagnostic work-up of hypertensive patients suspected of having renal artery stenosis.

It is important to stress that the results of a decision analytic model are conditional on the input data and assumptions, and sensitivity analyses should be performed to 
explore the effects of alternative data and assumptions on the results. Thus, the major advantage of decision analytic modelling is that it provides a flexible tool to reapply the analysis process for similar decisions, for example when the analysis is applied to other patients or populations, or when up-to-date information becomes available.

A limitation of the cost-effectiveness analysis was that the model required input data that were not available from the literature, or published studies did not provide sufficient detail to derive the required information, or reported numbers, often based on a single study, were not fully applicable to the problem or population under investigation. Lack of data meant that literature data had to be adjusted and supplemented with expert opinion. In addition, several assumptions with respect to the data had to be made. Variable estimates were incorporated in the decision model as fixed, deterministic numbers. A first-order Monte Carlo simulation was performed, which aims to illustrate the stochastic uncertainty with respect to the outcomes of the cost-effectiveness analysis due to variability across patients. In reality, however, due to heterogeneity across study populations and due to finite sample sizes of every study, there is uncertainty about the probabilities, utility values and cost estimates used in the model. Currently, probabilistic sensitivity analysis, also referred to as second-order Monte Carlo simulation, is an upcoming technique for handling parameter uncertainty in cost-effectiveness modelis [3]. An advantage of probabilistic sensitivity analysis is that acceptability curves can be constructed, which plot the probability that a strategy is cost-effective compared to the alternative for varying threshold values of the costeffectiveness ratio. Whereas we used a threshold incremental cost-effectiveness ratio of $€ 20000 / Q A L Y$, the presentation of acceptability curves enables decision-makers to choose the threshold value of interest, and to assess the cost-effectiveness of interventions given an array of values of the ceiling cost-effectiveness ratio. Moreover, given that the differences across diagnostic imaging strategies were small, the question may rise whether these are true differences. Cost-effectiveness acceptability curves capture this uncertainty, and provide decision-makers with information about the expected cost-effectiveness of an intervention, or the probability of making the correct decision. It is reasonable to presume that probabilistic sensitivity analysis will become common practice, and it would be a challenge to re-examine the input data used in the cost-effectiveness analysis and to perform up-to-date analyses. 


\section{Conclusions}

Combining the results of the aforementioned studies, we conclude that at present MRA should not be used for the diagnosis of renal artery stenosis in hypertensive patients. From a short-term point of view CTA appeared to be the least costly and least bothersome imaging test. Also patients were willing to pay more for CTA as compared to MRA to avoid DSA. However, from a long-term efficiency point of view, the optimal diagnostic strategy would be to schedule every hypertensive patient suspected of having renal artery stenosis for a revascularization procedure. The diagnostic DSA immediately preceding revascularization determines whether or not to proceed with the revascularization procedure.

\section{Implications and future directions}

The evidence emanating from the cost analysis, cost-effectiveness analysis, and patient preference study does not provide decision-makers with conclusive arguments with respect to the optimal diagnostic imaging work-up for renal artery stenosis in hypertensive patients. On the other hand, to decide on the efficient use of health care technology the cost-effectiveness analysis provided the most revealing information. Therefore we emphasize the implications of the cost-effectiveness study for decisionmaking on the meso and micro level. It should be noted that on the macro level costeffectiveness data are used to inform policy decision-makers about the desirability of the introduction of new medical technologies in health care. Efficiency data are also used to decide on the inclusion of health care services into and the exclusion of services from the basic health insurance package [4]. However, the RADISH study was not set up with that goal in view.

On the meso level the Dutch Institute for Healthcare Improvement (CBO) is concerned with the development of evidence-based clinical guidelines. The aim of guideline development is to contribute to the quality improvement, effectiveness and efficiency of clinical care for patients by changing practice based on high quality information. This is realized by developing evidence based national guidelines, which can be used for protocols for local practice. According to the hypertension guideline of the CBO [5], DSA is recommended as a decisive test provided that there is high clinical suspicion of renal artery stenosis. The suspicion is based on the absence or presence of clinical clues, such as sudden onset of hypertension, malignant or drug-resistant hypertension, abdominal bruit, and smoking history. In addition, the guideline states that also MRA might be an appropriate technique to produce images of the renal 
arteries. However, based on the poor validity of MRA [2] together with the finding that the application of MRA did not prove to be cost-effective, this clain should be reconsidered. CTA is not mentioned in the hypertension guideline. This does not imply, however, that MRA should be abandoned for the diagnostic work-up of renal artery stenosis. For example, in the University Hospital Maastricht, The Netherlands, MRA is still performed in patients with iodine allergy [personal communication]. Furthermore, developments in CTA and MRA technology may increase the diagnostic performance of both techniques for the detection of renal artery stenosis.

On the micro level cost-effectiveness information that focuses on clinical decisionmaking should be translated into clinical practice. The dissemination of new research knowledge into healthcare has largely depended on publication of research in peerreviewed journals and on continuing medical education programs. However, studies in the United States and the Netherlands suggest that $30 \%-40 \%$ of patients do not receive care complying with current scientific evidence and $20 \%-25 \%$ of the care provided is not needed or potentially harmful $[6,7]$. The recognition that traditional approaches fail to transfer research findings into practice, and hence do not result in optimal health care has led to increased efforts to identify more effective implementation strategies $[8,9]$. Implementation research is the scientific study of methods to promote the uptake of research findings, and hence to reduce inappropriate care. It includes the study of influences on healthcare professionals" behaviour and interventions to enable them to use research findings more effectively $[10]$. Although the area of implementation research is beyond the scope of this thesis, the first step would be to map current practice, since there is considerable variety across hospitals and doctors with respect to the diagnostic work-up for renal artery stenosis.

\section{Recommendations}

- MRA should not be used for the diagnosis of renal artery stenosis in hypertensive patients.

- Inmediate tentative revascularization is the optimal diagnostic imaging strategy for detecting renal artery stenosis in hypertensive patients from a cost-effectiveness point of view.

- The optimal diagnostic work-up should be conditional on the prior probability. For each individual patient a clinical prediction rule should be used to calculate the probability that renal artery stenosis is present. 
- Results from the RADISH study should be used to revise the hypertension guideline of the CBO.

- The dissemination of research findings could benefit from implementation research, the first step being to map current clinical routines.

\section{Methodological subject}

In this thesis three methodological studies were performed. The first study was conducted as part of the RADISH study, and compared willingness-to-pay with willingness to give up time. This study will be denoted as the WTP-WTGT study. The second methodological study is the WTP-CA study, and compared direct willingnessto-pay with conjoint analysis. At the start of these studies, the contingent valuation method to estimate willingness-to-pay suffered from a number of unresolved methodological flaws that restrain the application of direct willingness-to-pay in the framework of cost-benefit analysis. Some of these problems are listed in the first chapter of this thesis. These problems were also the main reason to investigate alternative approaches to obtain stated preferences. However, convergent validity is in itself not a useful criterion to decide upon which approach is the best. Therefore, the performance of willingness-to-pay is compared to that of the alternative approaches investigated in this thesis as far as possible. The third methodological study was performed as part of the WTP-CA study, and explored a method to determine the range and levels for the cost-attribute in conjoint analysis.

The WTP-WTGT study was performed from the patient perspective. Respondents were patients who had lately undergone DSA, CTA and MRA. No explicit information was provided with respect to features of the diagnostic tests that are generally considered objective and unambiguous such as the sensitivity of the tests, complication rates and contraindications. Instead, it is to be expected that patients mainly have taken into account their subjective experience as the basis for their valuations. The WTP-WTGT study used once-only payments and the elicitation method was a combination of the take-it-or-leave-it technique followed by a payment card.

Both willingness-to-pay and willingness to give up time identified CTA as the most preferred test, providing evidence for the convergent validity. Furthermore, the agreement between willingness-to-pay and willingness to give up time responses was high. The performance of willingness-to-pay and willingness to give up time was compared by assessing the number of protest answers and the discriminative ability. 
The willingness to give up time method yielded a lower percentage of protest answers than the willingness-to-pay method. Two percent of the patients gave protest answers on the willingness to give up time questions, whereas $12 \%$ gave protest answers on the willingness-to-pay questions. A probable explanation is that using time instead of money is less value-laden, which increases the acceptability of the willingness to give up time approach as compared to money valuations. With respect to the discriminative ability, both techniques performed equally poor. Seventy-eight percent of the respondents stated the same time value and $77 \%$ of the respondents stated the same money value for CTA as for MRA.

The possibility to use time to value health care was first mentioned by Johannesson and Jönsson [11]. Nevertheless, the willingness to give up time method is rarely discussed in the literature. This may be dictated by the recommendation in the early 1990 s to concentrate on the willingness-to-pay approach, due to the inherent strength of directly arriving at a monetary measure well founded in economic theory. A major disadvantage of the willingness to give up time method is that, for use in cost-benefit analysis, the method requires conversion to monetary units, which is not straightforward. So, the measurement part of the willingness to give up time method may be slightly more convenient than measuring willingness-to-pay. However, the willingness to give up time method requires an additional valuation part, i.e. converting time to monetary units, which poses a huge difficulty on the method. Although the willingness to give up time method performed better than willingness-to-pay with respect to the number of protest answers, we conclude that the willingness to give up time method seems not to be more advantageous for use in the framework of costbenefit analysis than direct willingness-to-pay.

The WTP-CA study was conducted from the societal perspective using a representative sample of the general population. Hence, a majority of the respondents had no affinity with the diagnostic tests under evaluation. Consequently, to ensure informed choices the respondents were supplied with comprehensive information. The WTP-CA study used the ex-ante insurance-based approach. Persons at risk for a disease, and therefore at risk of consuming the health care program, were asked to state a willingness-to-pay value as a monthly insurance premium to have the program available. The elicitation process involved a payment card. Main finding was that direct willingness-to-pay and conjoint analysis yielded opposite findings, which was striking since both contingent valuation and conjoint analysis intend to measure the same willingness-to-pay concept. Direct 
willingness-to-pay indicated DSA as the most preferred diagnostic imaging test, whereas according to the indirect willingness-to-pay method, CTA was the most preferred test. In the discussion section of the conceming chapter, the following possible explanations were mentioned: incomparable data from discrete choice experiments and payment cards, presentation of direct willingness-to-pay questions, ordering effects, and preference reversals. In addition, the use of the ex-ante insurance-based approach mighit have contributed to the opposite findings. According to the literature $[12,1,3]$, we adopted the ex-ante insurance-based approach since in the Netherlands the payment mechanism for health care is predominantly an insurance system. Nevertheless, we believe that the insurance approach is more cognitively demanding than out-of-pocket payments at the point of consumption, which is called the ex-post user-based approach. Insurance questions require that respondents are aware of the monthly, quarterly or yearly recurring payments, as opposed to once-only payments. Furthermore, health (care) involves uncertainty with respect to an individual"s demand for health care, and uncertainty with respect to the impact of an intervention on an individual's health. These uncertainties are reflected in the insurance mechanism, which means that we had to provide respondents, who were currently non-users, with information about the risk of needing the program under evaluation in the future; in addition to information about the outcome of that program, which was described in terms of probabilities. It is possible that respondents had difficulty understanding the risk information presented to them [14]. Unfortunately, it is unclear from our data whether these difficulties have actually occurred, what the impact is on the results, and most important, whether our decision to use the insurance-based payment vehicle has affected the direct willingnessto-pay and indirect willingness-to-pay results differently. At the start of the WTP-CA study no health care research was published that involved a comparison between contingent valuation and conjoint analysis. Yet, a recent paper by Ryan [15] found comparable willingness-to-pay estimates for dichotomous choice direct willingness-topay and discrete choice conjoint analysis. Ryan made use of two existing data sets, and the studies were conducted consecutively with the same subjects, whereas our study was set up with the intension of comparing monetary values. A secondary study finding was that incremental willingmess-to-pay obtained with contingent valuation was substantially lower than incremental willingness-to-pay obtained with conjoint analysis. In the discussion section of the concerning chapter, the following possible explanations were mentioned: more than half of the respondents stated the same willingness-to-pay value 
for each diagnostic test, use of the payment card format, omission of an opt-out option, and the chosen range for the cost-attribute in the conjoint analysis study.

The performance of direct willingness-to-pay and conjoint analysis was compared by assessing the discriminative ability and the theoretical validity. In the direct willingness-to-pay study, 54\% of the respondents stated the same willingness-to-pay value for DSA, CTA and MRA. The discriminative ability of conjoint analysis cannot be assessed the same way as direct willingness-to-pay. In conjoint analysis the researcher computes the willingness-to-pay values after the respondents hawe completed the discrete choice tasks, whereas in direct willingness-to-pay the respondents provide their willingness-to-pay values directly. So, we were not able to assess on the individual level whether respondents expressed different incremental willingness-to-pay values for CTA and MRA. Alternatively, we might investigate to what extent respondents discriminate between the scenarios. The conjoint analysis study revealed that in $13 \%$ of the choices neither scenario was identified as superior, indicating that the respondents viewed the scenarios in the choice set as equally attractive. This means that the discriminative ability of conjoint analysis was satisfactory. The theoretical validity of direct willingness-to-pay was disappointing. The study could not provide evidence for the positive influence of income on willingness-to-pay, which is a general assumption from economic theory. Also the other a priori expectations could not be confirmed. Respondents with cardiovascular disease were even less likely to take a supplementary private insurance for MRA, which is contradictory to the point of view that respondents should show risk-averse behaviour. The conjoint analysis technique performed slightly better on the theoretical validity tests than direct willingness-to-pay. Respondents with cardiovascular disease had a higher willingness-to-pay than respondents without cardiovascular disease. Also, in the conjoint analysis study respondents with claustrophobia attached a higher value to the space surrounding the patient compared to respondents without claustrophobia. Consequently, respondents with claustrophobia had a higher willingness-to-pay for an open space as opposed to a tunnel than respondents without claustrophobia. As in the direct willingness-to-pay study, the assumed positive influence of income on willingness-to-pay could not be confirmed.

Although not hypothesized a priori the direct willingness-to-pay study showed a relationship between the level of education and willingness-to-pay responses. A probable explanation is that the direct willingness-to-pay tasks were too difficult for lower educated persons. However, in order to establish public preferences for health care programs, the willingness-to-pay concept should be understandable for all 
members of society. In contrast to the direct willingness-to-pay study, the level of education was not associated with willingness-to-pay in the conjoint analysis study.

In conclusion, no evidence could be provided for the convergent validity between direct willingness-to-pay and conjoint analysis. Nevertheless we were able to compare the discriminative ability and the theoretical validity. In both cases conjoint analysis performed better than direct willingness-to-pay.

As part of the WTP-CA study, a method was explored to determine the range and levels for the cost-attribute. A potential problem in the design phase of a conjoint analysis discrete choice experiment is to set the appropriate levels for the cost-attribute. The use of discrete choice experiments assumes that behaviour is consistent with consumer theory. One of the axioms of consumer theory is that preferences are continuous. The continuity axiom implies compensatory decision-making, indicating that individuals are willing and able to trade between attributes when making choices. In the context of cost-benefit analysis choices that are consistent with the compensatory decision-making model imply that individuals will accept more of one attribute (e.g. higher survival rate) in compensation for a reduction in income. However, studies have shown that it is not uncommon that subjects violate the continuity axiom and adopt non-compensatory decision-making strategies, which may affect the resulting willingness-to-pay estimates. Non-trading behaviour may be related to the chosen range and interval between the levels of the attributes included in the analysis. Therefore the levels must be constructed so that respondents are willing to trade between the cost-attribute and other attributes of interest. We proposed a method to determine the levels for the cost-attribute to be implemented in an actual discrete choice experiment. Main finding was that most respondents would not trade. Recently, Cains and Van der Pol [16] conducted an experiment with repeated follow-up questions with the aim to reduce non-trading behaviour in discrete choice experiments. The authors suggest that subjects may not trade because they are not presented with the "right" trade-offs. Therefore, the repeated follow-up procedure presented individuals with trade-offs that were systematically varied in response to their previous answer. The results pointed out that non-trading behaviour could be nearly eliminated by asking the "right" questions. It can be argued that the repeated follow-up approach makes our proposed method redundant. However, a disadvantage of repeated follow-up questions, which is an adaptive approach, is that it requires computer-based interviews. Another disadvantage of adaptive conjoint analysis is that the importance of the price attribute is underestimated [17]. This is obviously of 
great concern, in particular when conducting a conjoint study that intends to derive willingness-to-pay estimates. Hence, our proposed method is especilally suitable to determine the levels for the cost-attribute to be implemented in paper-and-pencil conjoint studies. Our study is a first attempt to establish a technique to set the levels for the cost-attribute. In our opinion, the proposed method is intuitively suitable (face validity), yet the results are disappointing. This means that further research must indicate whether the method, possibly adapted, has any value in the future. The first step would be to verify the correctness of the underlying assumptions, which is accomplished by using the individual willingness-to-pay responses resulting from the first stage of the procedure as levels for the cost-attribute in a discrete choice experiment. Respondents trading levels would support the validity of the assumptions. Further research should also focus on how to deal with conflicting requirements. The trading criterion, for example, may result in considerably more levels than is reasonable given the requirement that each attribute in a discrete choice experiment should have a comparable number of levels [18]. We explored the proposed method with the aim to use the resulting levels in a conjoint analysis study. However, the method can also be useful in the design phase of a contingent valuation study, for example to establish the range of willingness-to-pay values to be included in the payment card, or to identify the relevant range from which to sample bids to be used in a dichotomous choice format.

\section{Implications and future directions}

As stated in the first chapter of this thesis, the direct willingness-to-pay method suffers from a number of problems, including framing effects, which was recently confirmed again [19-21]. Obviously, from a policy perspective this is of major concem. Costbenefit analysis is still the preferred method of economic evaluation from a theoretical point of view. However, willingness-to-pay as a measure of benefit has proved to be of limited practical value. Despite a bulk of literature with respect to the contingent valuation method, up till now direct willingness-to-pay has failed to guide actual decision-making. From a policy decision-making perspective, the final goal is to establish a willingness-to-pay measuring instrument that can be confidently used for valuing program benefits in the framework of cost-benefit analysis. However, we strongly feel that the direct willingness-to-pay approach does not fulfil this need, and should not be used in cost-benefit studies that aim to inform health care resource allocation decisions. One might argue that the approach may nonetheless be useful to 
provide ranking information. However, the occurrence of preference reversals [22] impedes even this mode of using contingent valuation data.

At the start of the studies described in this thesis, the conjoint analysis method to estimate willingness-to-pay indirectly was considered a promising alternative to direct willingness-to-pay. Also our conclusion is that conjoint analysis appears to be a more credible technique as compared to direct willingness-to-pay. However, this statement should be interpreted with caution. First, this conclusion is based on a limited number of performance checks. Second, there appears to be more critical appraisal to the use of direct willingness-to-pay in the context of policy decisions as compared to conjoint analysis. Up till now, little attention has been paid to the usefulness of the willingnessto-pay estimates obtained with conjoint analysis, and consequently to the feasibility of conjoint analysis in a cost-benefit perspective. For example, how does noncompensatory decision-making affect the implicit willingness-to-pay estimates, should we analyze non-traders, and how? Also, when analyzing data from discrete-choice experiments assumptions have to be made about the functional form of the utility function. The most commonly used model is the linear additive model which assumes that the overall utility derived from any combination of attributes is given by the sum of the separate part-worth utilities of the attributes. It would be valuable to extend discrete choice experiments to allow for non-linearity in the utility function, and to investigate the impact of different functional forms on willingness-to-pay estimates.

At present it is unclear to what extent discrete choice experiments can actually overcome the limitations associated with the contingent valuation method to estimate willingness-to-pay. An important issue concerns the question whether conjoint analysis is less susceptible to framing effects than direct willingness-to-pay. For example, an unresolved issue concerns the impact of the cost range on the parameter weights, and consequently on the resulting willingness-to-pay estimates. Two studies have investigated this topic, with inconclusive results $[23,24]$. Also, the impact of the number of levels on willingness-to-pay must be further investigated. If future research provides evidence that parameter weights are sensitive to manipulations of the cost range and levels, this would stress the importance of establishing a rigorous method for determining the appropriate levels for the cost-attribute. Also, future studies should investigate the sensitivity of conjoint analysis results to the ordering of the scenarios. To our knowledge only one health care study, which used the conjoint analysis rating. approach, has addressed this issue, and found no evidence that the ordering of scenarios 
was important [25]. To date, it is unclear whether conjoint analysis will present researchers with new (framing) problems.

An advantage of conjoint analysis is that scope tests are superfluous since the impact of each of the attributes on overall utility can be derived directly from the estimated model. In direct willingness-to-pay studies, the sensitivity of the responses to the magnitude of benefit, which is determined using scope tests, is an indication that the method is theoretically valid. However, performing scope tests involves additional research efforts. Furthermore, several studies have assessed the sensitivity of contingent valuation to changes in scope or scale with mixed results [26-30]. A recent study by Smith [31] found that income is a key factor in determining sensitivity to scale. The author found that the higher the proportion of income the expressed willingness-to-pay represents, the greater the insensitivity of that willingness-to-pay to changes in the scale of the good, irrespective of changes in underlying marginal utility.

A major limitation of conjoint analysis is that it camot handle a large number of attributes. A common belief among researchers is that scenarios with more than ten attributes are too difficult to handle for respondents [e.g. 32]. People cannot oversee so many attributes and they become tired and thus will ignore and attend attributes in random and uncontrolled ways, or they will tend to use heuristics that lead to biased preference measures. An alternative approach is hierarchical information integration proposed by Louviere [33] and Oppewal et al. [34]. Hierarchical information integration allows researchers to handle large number of attributes in conjoint analysis. The approach categorizes the relevant attributes into subsets (constructs; dimensions), and separate experiments are designed for each of the dimensions. This allows estimating preference functions "as if" one full profile design had been administered without the information load of such a large full profile task [35]. Up till now, the hierarchical information integration method has not been applied in the health care sector. Since the evaluation of health care commodities often may involve large number of attributes, analysts could benefit from experiences gained in other sectors [e.g. 36,37].

In conclusion, conjoint analysis is a promising technique, which was confirmed in this thesis. Nevertheless, before the technique can be confidentially used as an instrument guiding healthcare decision-making, a number of methodological issues should first be resolved. 


\section{Recommendations}

- Direct willingness-to-pay should not be used in cost-benefit studies that aim to inform actual decision-making.

- The willingness to give up time approach should not be used in the framework of cost-benefit analysis.

- Future work should examine the extent to which conjoint analysis actually overcomes the limitations associated with contingent valluation. Particularly, conjoint studies should focus on possible framing effects.

- Further research should prove whether the proposed method to set the levels for the cost-attribute in conjoint analysis is walid and has practical value in the design phase of a conjoint analysis experiment, the first step being to investigate the assumptions underlying the method.

- In establishing the appropriate levels for the cost-attribute in conjoint analysis different requirements play a role. Research must indicate how to deal with possibly conflicting requirements.

- It is not uncommon that people adopt non-compensatory decision-making strategies. Research must indicate what the impact is of non-trading behaviour on the resulting willingness-to-pay estimates, and how researchers should deal with non-traders.

- Research must provide evidence about the functional form of the utility function that best fits the data. 


\section{References}

1. Vasbinder GBC, Nelemans PJ, Kessels AGH, Kroon AA, Leeuw de $\mathbb{P} W$, Engelshoven van IMA. Diagnostic tests for renal artery stenosis in patients suspected of having renovascular hypertension: A meta-analysis. Ann Intern Med 2001; $135 ; 401-411$.

2. Vasbinder GBC, Nelemans PJ, Kessels AGH, et al., for the Renal Artery Diagnostic Imaging Study in Hypertension (RADISH) Study Group. Accuracy of computed tomographic angiography and magnetic resonance angiography for diagnosing renal artery stenosis. Ann lintern Med 2004; 141 : 674-682.

3. Briggs AH. Handling uncertainty in cost-effectiveness models. Pharmacoeconomics 2000 ; 17: 479-500.

4. Sande van der S, Lamberts SWJ, Rooijmans HGM. Kennis op de plank? Het nuttig effect van onderzoeken uit het programma van het fonds Ontwikkelingsgeneeskunde. Ned Tijdschr Geneeskd 2003; 147: 2390-2393.

5. Kwaliteitsinstituut voor de gezondheidszorg CBO. Herziening richtlijn hoge bloeddruk 2000. http:/Www.cbo.nl.

6. Schuster M, McGlynn E, Brook RH. How good is the quality of health care in the United States? Milbank Q 1998; 76: 517-563.

7. Grol R. Successes and failures in the implementation of evidence-based guidelines for clinical practice. Med Care 2001; 39 (Suppl): I146-I154.

8. Bero L, Grilli R, Grimshaw JM, Harvey E, Oxman AD, Thomson MA. Closing the gap between research and practice: an overview of systematic reviews of interventions to promote the implementation of research findings. BMJ 1998, 317: 465-468.

9. Grimshaw JM, Eccles MP. Is evidence-based implementation of evidence-based care possible? Med J Aust 2004; 180 (Suppl): S50-S51.

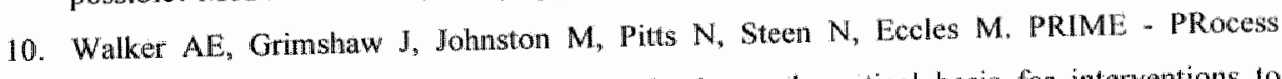
modelling in ImpleMEntation research: selecting a theoretical basis for interwentions to change clinical practice. BMC Health Serv Res 2003; 3: 22 .

11. Johannesson $M$, Jönsson B. Economic evaluation in health care: Is there a role for costbenefit analysis? Health Policy 1991; 17: 1-23.

12. Gafni $A$. Willingness-to-pay as a measure of benefits. Relevant questions in the context of public decisionmaking about health care programs. Med Care 1991; 29: 1246-1252.

13. O'Brien B, Gafni A. When do the "dollars" make sense? Toward a conceptual framework for contingent valuation studies in health care. Med Decis Making 1996; 16: 288-299.

14. Slovic P. Perception of risk. Science $1987 ; 236: 280-285$. 
15. Ryan $M$. A comparison of stated preference methods for estimating monetary values. Health Ecoin $2004: 13: 291-296$.

16. Cairns 3 , Pol van der M. Repeated follow-up as a method for reducing non-trading behaviour in discrete choice experiments. Soc Sci Med 2004; $58: 2211-2218$ :

17. Williams $P$, Kuroy $D$. Calibrating price in $A C A$ : The ACA price effect and how to manage it. Sawtooth Software. Research paper series, 2000.

18. American Marketing Association. Conjoint analysis: a guide for designing and interpreting conjoint studies. Market Research Division, Marketing Research Techniques Series, 1992.

19. Ridder de $A$, Graeve de D, Order bias in estimates of willingness to pay for drugs to treat attention-deficit/hyperactivity disorder. Eur J Heallh Econom 2005; 6: 146-151.

20. Smith RD. It's not just what you do, it's the way that you do it: the effect of different payment card formats and survey administration on willingness to pay for health gain. Health Econ (in press).

21. Whynes DK, Wolstenholme JL, Frew E. Evidence of range bias in contingent valuation payment scales. Health Econ 2004: 13: 183-190.

22. Olsen JA, Donaldson C, Shackley P. Implicit versus explicit ranking: on inferring ordinal preferences for health care programmes based on differences in willingness-to-pay. J Health Econ $2005 ; 24: 990-996$.

23. Verlegh PWJ, Schifferstein HNJ, Wittink DR. Range and number-of-levels effects in derived and stated measures of attribute importance. Market Lett 2002; 13:41-52.

24. Slothuus Skjoldborg U, Gyrd-Hansen D. Conjoint analysis. The cost-variable: an Achilles' heel? Health Econ 2003; 12: 479-491.

25. Ryan M, McIntosh E, Shackley P. Methodological issues in the application of conjoint analysis in health care. Health Econ 1998; 7:373-378.

26. Kartman $B$, Andersson $F$, Johannesson $M$. Willingness to pay for reductions in angina pectoris attacks. Med Decis Making 1996; 16:248-253.

27. Kartman B, Stalhammar NO, Johamnesson M. Valuation of health changes with the contingent valuation method: a test of scope and question order effects. Health Econ 1996; 5 : $531-541$.

28. Kartman $B$, Stalhammar NO, Johannesson $M$. Contingent valuation with an open-ended follow-up question: a test of scope effects. Health Econ 1997; 6: 637-639.

29. O'Brien $B J$, Goeree $R$, Gafini $A$, et al. Assessing the value of a new pharmaceutical. $A$. feasibility study of contingent valuation in managed care. Med Care 1998; 36: 370-384.

30. Norinder $A$, Hjalte $K$, Persson U. Scope and scale insensitivities in a contingent valuation study of risk reductions. Health Policy $2001 ; 57: 141-153$. 
31. Smith RD. Sensitivity to scale in contingent valuation: the importance of the budget constraint. J Health Econ 2005; 24: 515-529.

32. Green PE, Srinivasan V. Conjoint analysis in marketing: new developments with implications for research and practice. J Marketing 1990; 54:3-19.

33. Louviere JJ. Hierarchical information integration: a new method for the design and analysis of complex multiattribute judgment problems. Advances in Consumer Research 1984: 11: 148-155.

34. Oppewal H, Louviere JJ, Timmermans HJP. Modeling hierarchical conjoint processes with integrated choice experiments. J Marketing Res 1994; 31: 92-105.

35. Oppewal H. Compromising between information completeness and task simplicity: a comparison of self-explicated, hierarchical information integration, and full-profile conjoint methods. Advances in Consumer Research 2003; 30: 298-304.

36. Ulengin B. Using hierarchical information integration to examine customer preferences in banking. International Journal of Bank Marketing 1998; 16: 202-210.

37. Oppewal $\mathrm{H}$, Vriens $\mathrm{M}$. Measuring perceived service quality using integrated conjoint experiments. International Journal of Bank Marketing 2000; 18: 154-169. 
Summary 
This thesis describes studies on the evaluation of the diagnosis of renal artery stenosis in patients with hypertension. Renal artery stenosis is a potential cause of hypertension. The studies are based on the data of the Renal Artery Diagnostic Imaging Study in Hypertension (the RADISH study) and a population based willingness-to-pay survey. The general objective of this thesis is twofold. The first aim is to estimate the costs, benefits and cost-effectiveness of the use of diagnostic imaging techniques to detect renal artery stenosis. The second aim is to address some methodological issues with respect to the use of willingness-to-pay in health care.

Chapter 2 describes a cost analysis from various perspectives. Costs are assessed of computed tomography angiography (CTA), magnetic resonance angiography (MRA), digital subtraction angiography (DSA), and percutaneous revascularization. From the societal perspective, DSA is the most costly ( 1721$)$ and CTA the least costly diagnostic technique (E424). CTA is the least costly imaging procedure irrespective of the perspective. The societal costs associated with percutaneous renal artery revascularization range from $€ 2680$ to 66172 . Overall the radiology department incurs the largest proportion of the costs. For the management of renal artery stenosis, performing the analysis from different perspectives leads to the same conclusion concerning the least costly diagnostic imaging test and revascularization procedure.

Chapter 3 describes a comparison between willingness-to-pay and willingness to give up time. Both methods are used to measure preferences. Aim of the study is to analyze the convergence validity, i.e. the comparability, of willingness-to-pay and willingness to give up time, and the agreement between the answers to willingness-to-pay and willingness to give up time questions. Telephone interviews were used to gather information about respondents" preferences for diagnostic tests. Respondents are patients participating in the RADISH study. The willingness-to-pay method and the willingness to give up time method both reveal that patients prefer CTA to MRA in order to avoid DSA. The agreement between willingness-to-pay and willingness to give up time responses is high (Kappa $0.65-0.85$ ). The willingness-to-pay technique yields relatively more protest answers $(12 \%)$ as compared to the willingness to give up time technique $(2 \%)$, which raises questions with respect to the application of the willingness-to-pay method in a broad policy decision-making context. On the other hand, the strength of willingness-to-pay is that the method directly arrives at a monetary 
measure well founded in economic theory, whereas the willingness to give up time method requires conversion to monetary units.

Conjoint analysis is a method to measure preferences for products and services. It is based on the assumption that decisions are not based on a single criterion, but on several factors considered jointly. With conjoint analysis it is possible to estimate respondents' willingness to pay indirectly. Therefore, conjoint analysis will be referred to as indirect willingness-to-pay. In order to estimate willingness-to-pay, a cost-attribute should be included in the analysis. The levels for the cost-attribute should be chosen in such a way that they be subject to trading decisions. Chapter 4 describes a method for deciding on the levels for the cost-attribute in conjoint analysis. The proposed method was applied to the field of diagnostic imaging tests. A random sample of members of the general population is presented with a number of attributes of diagnostic tests and the levels for these attributes. For example, the "sensitivity" attribute has three levels: $50 \%, 85 \%$ and $100 \%$. Then the respondents are asked to use the attributes and levels to compose the most and least attractive diagnostic test. Finally, the respondents are asked to report the maximum willingness-to-pay for the most and least altractive alternative. The proposed method reveals for each respondent the consideration set (for example ranging from $€ 6.8$ to $€ 11.3$ ), which includes values that are relevant for that particular respondent. The proposed method also reveals for each respondent the maximum individual interval (in the example the maximum individual interval is 4.5). Using this information, three rules (called MAXIMUM, MEAN and MINIMUM) are subsequently applied both to determine the range for the cost-attribute and to determine the interval between the levels. Based on the ranges and intervals, the specific levels are derived. The rules are assessed against the criterion of levels being subject to trading decisions. Combining the MEAN rule for the range with the MEAN rule for the interval yields the optimal solution with respect to levels being subject to trading decisions. The proposed method contributes to the discussion about how to determine the range and levels for the costattribute in conjoint analysis. However, the current study shows that even the optimal solution will provoke only a small proportion of respondents to make trade-offs. Further research should indicate whether the method is valid and practically applicable.

Chapter 5 describes a comparison between contingent valuation and conjoint analysis. Both methods are used to estimate willingness-to-pay. Contingent valuation is a method to express preferences in terms of money. Contingent valuation studies use surveys to 
present respondents with hypothetical scenarios and to reveal their willingness to pay for health care interventions. Contingent valuation is referred to as direct willingness-topay. Respondents are randomly selected members of the general population. Preferences are elicited for three diagnostic imaging techniques to detect renal artery stenosis, i.e. DSA, MRA, and CTA. Main finding is that direct willingness-to-pay and conjoint analysis yield opposite findings. According to conjoint analysis, the incremental willingness-to-pay is 69.88 for MRA and 613.67 for CTA. Using the direct willingness-to-pay method, incremental willingness-to-pay is - $E 0.78$ for MRA, and -60.69 for CTA. A secondary finding is that incremental direct willingness-to-pay walues are lower than incremental indirect; i.e. conjoint analysis, willingness-to-pay values. The theoretical validity is the extent to which results are consistent with a priori expectations. The conjoint analysis method performs slightly better on the theoretical validity tests than direct willingness-to-pay. The finding that the level of education influenees the direct willingness-to-pay responses raises questions with respect to the use of direct willingness-to-pay in a broad policy decision-making context. Altogether conjoint analysis seems a more credible technique although this statement should be interpreted with caution.

Chapter 6 aims to determine the cost-effectiveness of performing DSA, CTA, MRA, or proceeding immediately to tentative revascularization in patients suspected of having renovascular hypertension. Treatment with antihypertensive medication is considered the reference strategy. Using a Monte Carlo Markov decision model, cost-effectiveness analysis is performed from the societal perspective. The outcome measure is: costs per quality adjusted life year gained (QALY). Data are derived from the RADISH study and from published literature. For a 50-year old male patient with a diastolic blood pressure greater than $95 \mathrm{mmHg}$ and one or more clinical clues suggestive of renovascular hypertension, proceeding immediately to tentative revascularization is the least costly and most effective strategy, i.e. it dominates all other strategies. For a 50 -year old female patient immediate tentative revascularization is cheaper and more effective than CTA and MRA. Immediate tentative revascularization is also more effective than the DSA strategy but also more costly. The incremental cost-effectiveness ratio is 67143/QALY. The results are sensitive to the prior probability of stenosis. As the prior probability increases, the more invasive the optimal diagnostic imaging strategy becomes. The results are also sensitive to the sensitivity of CTA and MRA, and the costs associated with DSA. The results suggest that immediate tentative 
revascularization is cost-effective in patients with a high suspicion of renovascular hypertension, CTA is cost-effective in those with a low suspicion, and medical therapy is cost-effective in those in whom renal artery stenosis is unlikely.

Chapter 7 summarizes and discusses the main findings of the studies described in this thesis. Also, implications, future directions and recommendations are presented. 


\section{Samenvatting}


Dit proefschrift beschrijft studies naar beeldwormende diagnostiek bij patiẻnten met hoge bloeddruk die mogelijk veroorzaakt wordt door een nierarteriestenose. De data zijn ontleend aan de Renal Artery Diagnostic Imaging Study in Hypertension (RADISH studie) en een willingnesss-to-pay onderzoek onder de algemene bevolking. Op de eerste plaats richt het proefschrift zich op de kosten, baten en kosteneffectiviteit van het gebruik van beeldvormende diagnostiek om nierarteriestenose op te sporen. Ten tweede behandelt het proefschrift enkele methodologische aspecten van het toepassen van willingness-to-pay in de gezondheidszorg.

Hoofdstuk 2 beschrijft een kostenanalyse vanuit verschillende perspectieven. De kosten zijn berekend van computer tomografische angiografie (CTA), magnetische resonantie angiografie (MRA), intra-arteriële digitale subtractie angiografie (DSA), en percutane revascularisatie. Bezien vanuit het maatschappelijk perspectief is DSA de duurste (€1721) en CTA de goedkoopste ( $€ 424)$ diagnostische test. CTA is de goedkoopste beeldvormende techniek ongeacht welk perspectief wordt gehanteerd. De maatschappelijke kosten van percutane revascularisatie van de nierarteriën variëren van $€ 2680$ tot $€ 6172$. Voor alle procedures geldt dat het grootste deel van de kosten gemaakt wordt door de afdeling radiologie. Het uitvoeren van de kostenanalyse vanuit verschillende perspectieven resulteert in dezelfde conclusie met betrekking tot de goedkoopste diagnostische test en revascularisatie procedure.

Hoofdstuk 3 beschrijft een vergelijking tussen twee methoden om voorkeuren te meten: willingness-to-pay (betalingsbereidheid) en willingness to give up time (bereidheid om tijd op te offeren). Het doel van de studie is om de convergentie validiteit, oftewel de vergelijkbaarheid, van beide methoden te bepalen, alsmede de overeenstemming tussen de antwoorden op de willingness-to-pay en willingness to give up time vragen. Door middel van een enquête die telefonisch is afgenomen, is bepaald aan welke diagnostische test respondenten de voorkeur geven. Respondenten zijn patiënten die participeren in de RADISH studie. De willingness-to-pay en willingness to give up time methode wijzen allebei uit dat patiënten de voorkeur geven aan CTA boven MRA ten einde DSA te vermijden. De overeenstemming tussen de willingness-to-pay and willingness to give up time antwoorden is hoog (Kappa 0.65-0.85). De willingness-topay methode produceert relatief meer protest antwoorden (12\%) vergeleken met de willingness to give up time methode (2\%). Dit roept vragen op omtrent de bruikbaarheid van de willingness-to-pay methode voor beleidsbeslissingen. Echter, de kracht van de 
willingness-to-pay benadering is dat de methode direct een waardering in temen van geld oplevert, terwijl de willingness to give up time methode een omzetting naar geld vereist.

Conjunct meten is een methode om de betalingsbereidheid (willingness-to-pay) te bepalen. Het is een methode waarmee afwegingen die respondenten maken bij het kiezen tussen producten en diensten in beeld kunnen worden gebracht. Met de conjunct meten methode kan op een indirecte manier de betalingsbereidheid worden bepaald, vandaar dat dit de indirecte willingness-to-pay methode wordt genoemd. Om de betalingsbereidheid te kunnen bepalen noet er een kenmerk "kosten" in de analyse worden meegenomen. De niveaus van dit kenmerk moeten zodanig gekozen worden dat respondenten de verschillende kenmerken tegen elkar afwegen. Hoofdstuk 4 beschrijft een methode om de niveaus van het kenmerk "kosten" in een conjunct meten studie te bepalen. De voorgestelde methode is toegepast op het gebied van diagnostische beeldvormende technieken. Een aselecte steekproef uit de algemene bevolking krijgt een aantal kenmerken van diagnostische testen voorgelegd met de niveaus van deze kenmerken. Het kenmerk "sensitiviteit" bijvoorbeeld heeft drie niveaus: $50 \%, 85 \%$ en $100 \%$. Vervolgens is aan de respondenten gevraagd om met behulp van de kenmerken en bijbehorende niveaus zowel de meest als de minst aantrekkelijke diagnostische test samen te stellen. Tot slot is aan iedere respondent gevraagd om zijn of haar maximale betalingsbereidheid voor zowel de meest als de minst aantrekkelijke diagnostische test op te geven. De voorgestelde methode levert voor iedere respondent een reeks op (bijvoorbeeld van $\in 6.8$ tot en met $€ 11.3$ ) die voor de betreffende respondent relevante waarden bevat. Daarnaast levert de voorgestelde methode voor iedere respondent hat maximale individuele interval tussen de niveaus op (het maximale individuele interval in het voorbeeld is 4.5). Gebruik makend van de verkegen informatie, worden vervolgens drie regels (genaand MAXIMUM, GEMIDDELDE en MINIMUM) toegepast on zowel het bereik van het kenmerk "kosten" te bepalen als het interval tussen de niveaus. De niveaus worden afgeleid van het bereik en interval. De regels worden beoordeeld aan de hand van het criterium dat respondenten de verschillende kenmerken tegen elkaar moeten afwegen. De resultaten laten zien dat toepassing van de regel GEMIDDELDE, voor zowel het bereik als voor thet interval, leidt tot de beste oplossing als het gaat on het vaststellen van de niveaus van het kenmerk "kosten". De voorgestelde methode draagt bij aan de discussie omtrent het vaststellen van het bereik en de niveaus van het kenmerk "kosten" in een conjunct meten studie. Echter, de 
onderhavige studie wijst uit dat zelfs de beste oplossing ertoe zal leiden dat slechts een klein deel van de respondenten afwegingen maakt tussen de kenmerken. Vervolgonderzoek zal moeten aantonen of de methode valide is en toepasbaar in de praktijk.

Hoofdstuk 5 beschrijft een vergelijking tussen contingent waardering en conjunct meten. Beide methoden worden gebruikt om de betalingsbereidheid te bepalen. Contingent waardering is een methode om preferenties in geld uit te drukken. De methode maakt gebruik van enquêtes. Aan de hand van hypothetische situaties wordt gevraagd naar de betalingsbereidheid van mensen voor gezondheidszorg programma's. Dit wordt de directe willingness-to-pay methode genoemd. Het betreft een onderzoek dat is uitgevoerd onder een aselecte steekproef uit de algemene bevolking. Door middel van een enquête die telefonisch is afgenomen, is bepaald welke diagnostische test om nierarteriestenose op te sporen de voorkeur heeft. De belangrijkste bevinding is dat de directe willingness-to-pay en conjunct meten tegengestelde resultaten opleveren. Volgens de conjunct meten methode is de incrementele betalingsbereidheid $€ 13.67$ voor CTA en $€ 9.88$ voor MRA. De directe willingness-to-pay methode resulteert in een incrementele betalingsbereidheid van - 60.69 voor CTA en -60.78 voor MRA. Een tweede bevinding is dat de incrementele waarden verkregen met de directe willingnessto-pay methode lager zijn dan de incrementele waarden verkregen met de conjunct meten methode. De theoretische validiteit is de mate waarin de onderzoeksdata in overeenstemming zijn met a priori verwachtingen. De theoretische validiteit van de conjunct meten methode is wat beter dan die van de directe willingness-to-pay methode. De directe willingness-to-pay methode laat zien dat het opleidingsniveau van inwloed is op de betalingsbereidheid. Dit roept vragen op omtrent de bruikbaarheid van de directe willingness-to-pay methode voor beleidsbeslissingen. Alles bij elkaar beschouwd lijkt conjunct meten een overtuigender methode alhoewel deze bewering voorzichtig geinterpreteerd moet worden.

Hoofdstuk 6 beschrijft de kosteneffectiviteit van het toepassen van DSA, CTA, MRA, of percutaan revasculariseren bij patiënten die verdacht worden van het hebben van nierarteriestenose. Behandeling met antilhypertensiva is de referentie strategie. De kosteneffectiviteitanalyse is uitgevoerd vanuit het maatschappelijke perspectief. $\mathrm{Er}$ is gebruik gemaakt van een Markov Monte Carlo besliskundig model. De uitkomstmaat is: kosten per gewonnen levensjaar gecorrigeerd voor de kwaliteit van leven (QALY). De 
input voor het model is ontleend aan de RADISH studie en gepubliceerde literatum. Voor een 50-jarige mannelijke patiënt met een diastolische bloeddruk hoger dan 95 $\mathrm{mmHg}$ en éen of meer klinische aanwijzingen suggestief voor renovasculaire hypertensie, is meteen percutaan revasculariseren de goedkoopste en de meest effectieve strategie, waarmee het alle andere strategieën domineert. Voor een 50-jarige vrouwelijke patiênt is meteen percutaan revasculariseren goedkoper en effectiever dan CTA en MRA. Meteen percutaan revasculariseren is ook effectiever dan DSA maar wel duurder. De incrementele kosteneffectiviteitratio is $67143 / \mathrm{QALY}$. De uitkomsten zijn gevoelig voor de a priori kans op nierarteriestenose. Hoe hoger namelijk deze a priori kans, des te invasiever wordt de optimale diagnostische strategie. Daarnaast zijn de uitkomsten gevoelig voor de sensitiviteit van CTA en MRA en de kosten van DSA. De resultaten suggereren dat meteen percutaan revasculariseren kosteneffectief is bij patiënten met een hoge verdenking op renovasculaire hypertensie, CTA is kosteneffectief in geval van een lage verdenking, en behandeling met antihypertensiva is kosteneffectief wanneer nierarteriestenose onwaarschijnlijk is.

In hoofdstuk 7 worden de belangrijkste resultaten van het proefschrift samengevat en bediscussieerd. Daarnaast worden implicaties beschreven en suggesties gedaan voor verder onderzoek. 


\section{Dankwoord}

Bij het tot stand komen van dit proefschrift zijn vele mensen betrokken geweest. Hiervoor dank ik hen allemaal van harte. Een aantal personen wil ik graag met name noemen.

Professor van Engelshoven, promotor, Professor Hunink, promotor, en Carmen Dirksen, copromotor. Bedankt voor jullie geduld, ik besef dat ik dat behoorlijk op de proef heb gesteld. Professor van Engelshoven, ik wil U bedanken voor de nogelijkheid om dit proefschrift te schrijven. Daarnaast heb ik veel waardering voor de vriendelijkheid en humor die $\mathrm{U}$ in de begeleiding weet te leggen. Uw klinische invalshoek was bijzonder waardevol. Professor Hunink, ik dank U voor de inhoudelijke begeleiding. UW enthousiasme, duidelijkheid en kennis hebben me enorm geholpen. Carmen, het verschijnen van mijn proefschrift is ook voor jou een mijlpaal. Gefeliciteerd, je eerste copromotorschap zit er op. Bedankt voor de ontelbare uren die je erin gestopt hebt, de vele waardevolle inhoudelijke discussies en - niet te vergeten - de lachpartijen.

Manuela, we zijn vijf jaar kamergenoten geweest en dat was erg gezellig. Ik ben blij dat je mijn paranimf bent. Margriet, je hebt me veel werk uit handen genomen, bedankt. Verder dank ik mijn collega's van de afdeling Klinische Epidemiologie en Medical Technology Assessment, de RADISH projectgroep, Hans Ouwersloot en Professor Kasper.

Familie en vrienden, in het bijzonder Thea, Ben, Eeg, Jet en Bas, will ik danken voor de belangstelling, ondersteuning en de vele gezellige momenten gedurende de afgelopen jaren. Jullie support is van onschatbare waarde.

Lieve papa en mama, jarenlang voorzichtig informeren naar de stand van zaken leverde nooit al te veel op. Het antwoord is nu gegeven, mijn boekje is klaar.

Lieve Pim, Tom en Bram, jullie zijn geweldige kereltjes.

Lieve Mark, wat ik ook schrijf om je te bedanken, ik schiet hoe dan ook schromelijk tekort. Ik zal iets anders moeten bedenken. 


\section{About the author}

Debby van Helvoort-Postulart was born on August 11,1970 in Nijmegen. She graduated from the Canisius College in Nijmegen in 1990 (HAVO). She studied Nursing at the Hogeschool Nijmegen (currently Hogeschool van Arnhem en Nijnegen) and got her Bachelor of Nursing degree in March 1996. In the same year she started to study Health Sciences at the University of Maastricht. In October 1998, she received her Master of Science degree in Health Policy and Administration cum laude. From December 1998 to December 2003 she worked as a researcher at the department of Clinical Epidemiology and Medical Technology Assessment (KEMTA) of the university hospital Maastricht, where she performed research on the economic evaluation of diagnostic imaging tests for detecting renal artery stenosis. Since November 2005 she works at the department of KEMTA as a post-doc researcher. 